\title{
A reassessment of the basal dinosaur Guaibasaurus candelariensis, from the Late Triassic Caturrita Formation of south Brazil
}

\author{
Max C. Langer ${ }^{1 *}$, Jonathas S. Bittencourt ${ }^{1}$ and Cesar L. Schultz ${ }^{2}$ \\ ${ }^{1}$ Departamento de Biologia, FFCLRP-USP, Av. Bandeirantes 3900, Ribeirão Preto, Brazil \\ Email: mclanger@ffclrp.usp.br; jonathas@pg.ffclrp.usp.br \\ ${ }^{2}$ Instituto de Geociências, UFRGS, Av. Bento Gonçalves 9500, Porto Alegre, Brazil \\ Email: cesar.schultz@ufrgs.br \\ * Corresponding author
}

\begin{abstract}
The dinosaur record of the Santa Maria beds of Rio Grande do Sul (Mid-Late Triassic; south Brazil) includes the herrerasaur Staurikosaurus pricei, and two basal members of the sauropodomorph lineage: Saturnalia tupiniquim and Unaysaurus tolentinoi. The most enigmatic of the saurischian taxa is, however, Guaibasaurus candelariensis, previously regarded as either a basal theropod or a basal sauropodomorph. This study provides a detailed anatomical revision of all specimens originally referred to $G$. candelariensis by Bonaparte and co-authors, including its type-series and a more recently excavated partial postcranium. Although coming from different sites, these specimens share a unique combination of traits, and at least one possible autapomorphic feature of the pelvis, which support the inclusivity and uniqueness of the species. G. candelariensis was a medium-sized (nearly $2 \mathrm{~m}$ long) biped with an intriguing mix of plesiomorphic and derived (eusaurischian/theropod) features. Phylogenetic studies reveal weak support for the nesting of $G$. candelariensis within Theropoda, but this affinity is bolstered by various traits it shares with neotheropods. The Norian age of $G$. candelariensis corroborates previous studies that suggest the continuous radiation of more basal dinosauromorphs until the end of the Triassic, after the appearance of the three main dinosaur clades.
\end{abstract}

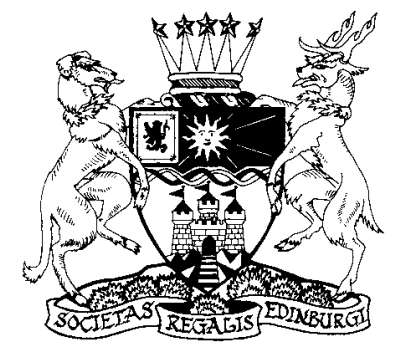

KEY WORDS: Dinosauria, Eusaurischia, Norian, Rio Grande do Sul, Saurischia

The basal dinosaur Guaibasaurus candelariensis Bonaparte, Ferigolo \& Ribeiro, 1999 from the Late Triassic of south Brazil (Fig. 1), has a short but confusing taxonomic history. In the original description, Bonaparte et al. (1999) regarded the taxon as a basal saurischian, more primitive than herrerasaurids, possibly theropod, and ancestral to sauropodomorphs. Furthermore, they promoted Guaibasaurus to the type-genus of a new family, Guaibasauridae, emphasising its distinctiveness from other known basal saurischians. Based mostly on the study of its type-series, subsequent cladistic studies have supported a theropod affinity for $G$. candelariensis (Langer 2004; Yates 2007a, b; Langer et al. 2007a), but after the description of a new partial skeleton of $G$. candelariensis, Bonaparte et al. (2007) proposed the nesting of Saturnalia tupiniquim, another Late Triassic dinosaur from south Brazil (Langer et al. 1999, 2007a; Langer 2003), in Guaibasauridae. This view was endorsed by Ezcurra (2008) and Ezcurra \& Novas (2009), who included the guaibasaurid clade within Sauropodomorpha. In contrast, a more basal position in the saurischian evolutionary tree, below the Theropoda/ Sauropodomorpha split, has never been proposed based on numerical phylogenies.

This paper redescribes the osteology of G. candelariensis, supplementing and emending the original studies (Bonaparte et al. 1999, 2007) as necessary. The first photographic record of the referred specimens is also provided. Yet, the production of good photographs of the most complete specimen, UFRGS PV0725T, is hampered by the poor preservation of its bone surfaces and because the skeleton is still partially embedded in matrix. In fact, the specimen appears to have been overprepared in parts, while others portions still lack some preparation work. Nonetheless, bearing in mind that there are no plans to conduct supplementary preparation in the near future, a detailed approach to the available osteological information was considered timely. Indeed, a renewed understanding of the anatomy of $G$. candelariensis, a Late Triassic dinosauromorph with still dubious affinities (Langer et al. 2010), is important for a broader understanding of the early evolution of dinosaurs.

Institutional abbreviations: AMNH, American Museum of Natural History, New York-NY, USA; FFCLRP-USP, Faculdade de Filosofia, Ciências e Letras de Ribeirão Preto, Universidade de São Paolo, Brazil; GPIT, Institut für Geologie und Paläontologie, Tübingen, Germany; HMN, Humboldt Museum für Naturkunde, Berlin, Germany; MCN, Museu de Ciências Naturais, Fundação Zoobotânica do Rio Grande do Sul, Porto Alegre, Brazil; MCP, Museu de Ciências e Tecnologia, PUCRS, Porto Alegre, Brazil; MCZ, Museum of Comparative Zoology, Cambridge-MA, USA; MNA, Museum of Northern Arizona, Flagstaff-AZ, USA; NHMUK, Natural History Museum, London; NMMNH, New Mexico Museum of Natural History, Albuquerque-NM, USA; PEFO, Petrified Forest National Park, Holbrook-AZ, USA; PULR, Museo de Ciencias Naturales, Universidad Nacional de La Rioja, La Rioja, Argentina; PVL, Fundación "Miguel Lillo", Tucumán, Argentina; PVSJ, Museo de Ciencias Naturales, San Juan, Argentina; QVM, National Museum of Natural 


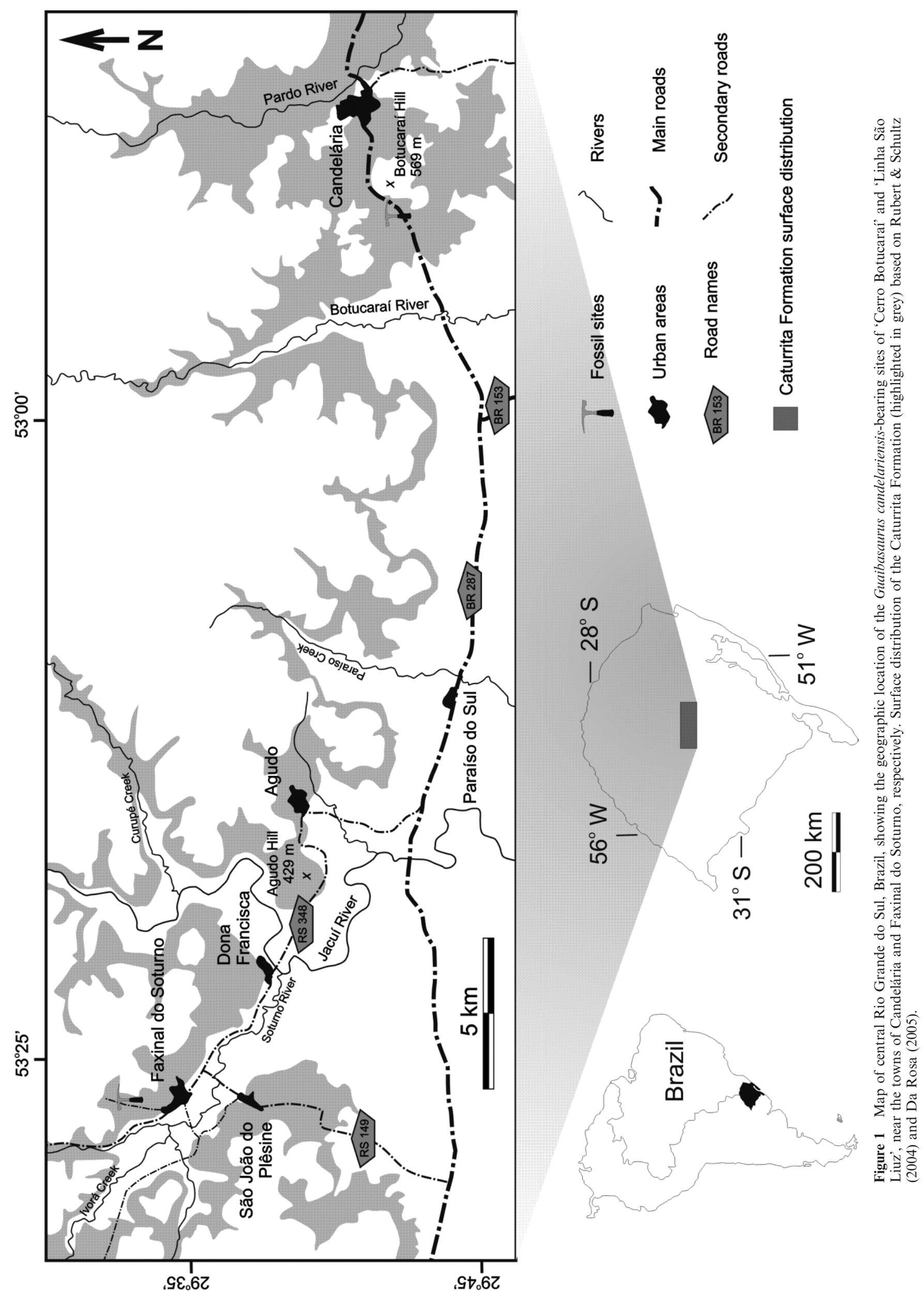


History, Harare, Zimbabwe; SAM, Iziko South African Museum, Cape Town, South Africa; SMNS, Staatliches Museum für Naturkunde, Stuttgart, Germany; TTU-P, Texas Tech University, Lubbock-TX, USA; UCMP, University of California Museum of Paleontology, Berkeley-CA, USA; UFRGS, Instituto de Geociências, Universidade Federal do Rio Grande do Sul, Porto Alegre, Brazil; UNSJ, Universidad Nacional de San Juan, San Juan, Argentina; ZPAL, Institute of Paleobiology of the Polish Academy of Science, Warsaw, Poland.

\section{Systematic palaeontology}

Dinosauria Owen, 1842

Saurischia Seeley, 1888

Eusaurischia Padian, Hutchinson \& Holtz, 1999

cf. Theropoda Marsh, 1881

Guaibasaurus Bonaparte, Ferigolo \& Ribeiro, 1999

Guaibasaurus candelariensis Bonaparte, Ferigolo \& Ribeiro, 1999

Figs 2-17, Tables S1-S9

1998 Guaibasaurus dandelariai Bonaparte \& Ferigolo, p. 11 (nomina nuda)

Holotype. MCN PV2355, partial skeleton including: six incomplete trunk vertebrae; trunk ribs fragments; the centrum of the second sacral vertebra; 16 caudal vertebrae, including a series of then articulated proximal elements with haemal arches; partial left scapulocoracoid; right ilium lacking the pubic peduncle and preacetabular ala; left ilium including the acetabular area and caudal portion of the postacetabular ala; paired pubes lacking parts of the medial lamina and distal margin, and most of the obturator plate (the proximal and distal portions are better preserved in the right and left bones respectively); right ischium lacking the distal third and proximal margin; left ischium lacking the pubic articulation, most of the obturator plate, and parts of the distal edge; right femur lacking the proximal articulation; left femur lacking both extremities; right tibia and fibula lacking the proximal margin; left tibia and fibula lacking both extremities; fragmentary right tarsus; and partial feet, lacking most of the phalanges (Bonaparte et al. 1999).

Paratype. MCN PV2356, articulated left hind limb including the distal half of the tibia and fibula, astragalus, calcaneum, the pair of distal tarsals, and nearly complete foot (Bonaparte et al. 1999). Although lacking a perfect fit to the articulated part of the bone, the proximal end of a left tibia may also belong to that specimen. That piece was collected $a$ posteriori by José Bonaparte from the same spot that yielded the rest of the material (C. N. Rodrigues, pers. comm. 2010), and later assembled to MCN PV2356 (J. Ferigolo, pers. comm. 2007).

Referred material. UFRGS PV0725T (Fig. 2), articulated partial skeleton including: trunk, sacral, and most of the caudal vertebrae; partial left forelimb; right humerus; nearly complete pelvic girdles and limbs, although the pubes and ischia are partially covered by matrix and parts of the tarsi and feet are fragmentary (Bonaparte et al. 2007). MCN PV 10112: unprepared block containing articulated parts, some isolated elements of which, including a left metacarpal I, were freed from the matrix.

Localities. The type-series comes from one of the sites $\left(29^{\circ} 41^{\prime} 19^{\prime \prime} \mathrm{S}\right.$; $52^{\circ} 50^{\prime} 55^{\prime \prime} \mathrm{W}$; SAD-69) around the Botucaraí Hill, at the southern banks of BR-287 road, about $8 \mathrm{~km}$ west of the town of Candelária. The referred specimens were both collected from the same spot (J. Cisneros, pers. comm. 2010), at the site known as 'Linha São Luiz' $\left(29^{\circ} 33^{\prime} 28^{\prime \prime}\right.$; $53^{\circ} 26^{\prime} 56^{\prime \prime} \mathrm{W}$; SAD-69), about $2 \mathrm{~km}$ north from the town of Faxinal do Soturno ( $30 \mathrm{~km}$ west of the Botucaraí Hill). See Langer et al. (2007b) for the faunal content of these sites, which are both located in central Rio Grande do Sul, Brazil (Fig. 1).

Horizon. Middle portion of the Caturrita Formation, Rosário do Sul Group, Paraná Basin (Andreis et al. 1980; Rubert \& Schultz 2004); highstand systems tract of Santa Maria 2 Sequence (Zerfass et al. 2003) and/or upper part of Sequence II of Faccini (1989); Ictidosaur Assemblage Zone (Rubert \& Schultz 2004; Langer et al. 2007b).

Diagnosis. Saurischian dinosaur distinguished from all other well-known Triassic members of the group by a unique combination of anatomical features. It differs from typical herrerasaurs (Herrerasaurus, Staurikosaurus) by possessing axially elongated caudal trunk vertebrae, a long postacetabular ala with a well developed brevis fossa, and an unexpanded distal end of the pubis; from neotheropods by the retention of two sacral vertebrae, an unexpanded preacetabular ala, and an uncompressed calcaneum; from members of the sauropodomorph lineage by a narrow distal end of the humerus, and particularly from Saturnalia and Panphagia by a transversally elongated distal end of the tibia. It also differs from Saturnalia, Chindesaurus (PEFO 10395), and Eoraptor, by the absence of a trochanteric shelf, and from the latter by a narrow metacarpal III. In addition, G. candelariensis bears a peculiar proximal expansion at the mid-length of the caudoproximal corner of its astragalus, otherwise recognised only in Silesaurus (ZPAL AbIII 361/20), Chindesaurus (PEFO 10395), and a basal theropod from the Dockum Group of Texas (Nesbitt \& Chatterjee 2008). The specimens referred to $G$. candelariensis match one another in almost every anatomical detail, but autapomorphic traits are hard to establish. Nevertheless, a groove extending dorsoventrally along the cranial part of the iliac antitrochanter and a reduced distal surface of the astragalus (which has cranial and caudal surfaces facing somewhat distally) are seen in both partial skeletons, probably representing unique features of $G$. candelariensis. In addition, the caudal process of the pubis in UFRGS PV0725T (not preserved in the holotype) has a unusual transverse groove on the caudal margin.

\section{Description}

The overall preservation of the type-series of $G$. candelariensis is good; taphonomic class I of Holz \& Schultz (1998). Yet, because of its fragility, the preservation of the bone surface can be poor in parts, and it was often damaged during preparation, e.g. distal margin of the right femur. In UFRGS PV0725T, skeletal parts with small fractures in the external layers of bone, and the modification in shape of a few elements, suggest some degree of early calcite cementation (classes II-III of Holz \& Schultz 1998). The partial skeleton UFRGS PV0725T (Fig. 2 ) is preserved in various contiguous blocks. The two larger parts include: (1) the cranial portion of the trunk (vertebrae 1-8) and most of the ribcage, and (2) the caudal part of the trunk, the sacrum, the pelvic girdles and limbs, and two caudal vertebrae. Two smaller blocks contain (1) the left pectoral epipodium and hand, and (2) a few rib fragments from the left side. The tail is preserved in two medium sized blocks, the distal of which is fractured in smaller pieces.

The following anatomical accounts reflect a general agreement, or minimal lack of discrepancy, among the different specimens attributed to $G$. candelariensis. When variation occurs, it is quoted accordingly. Directional and positional 


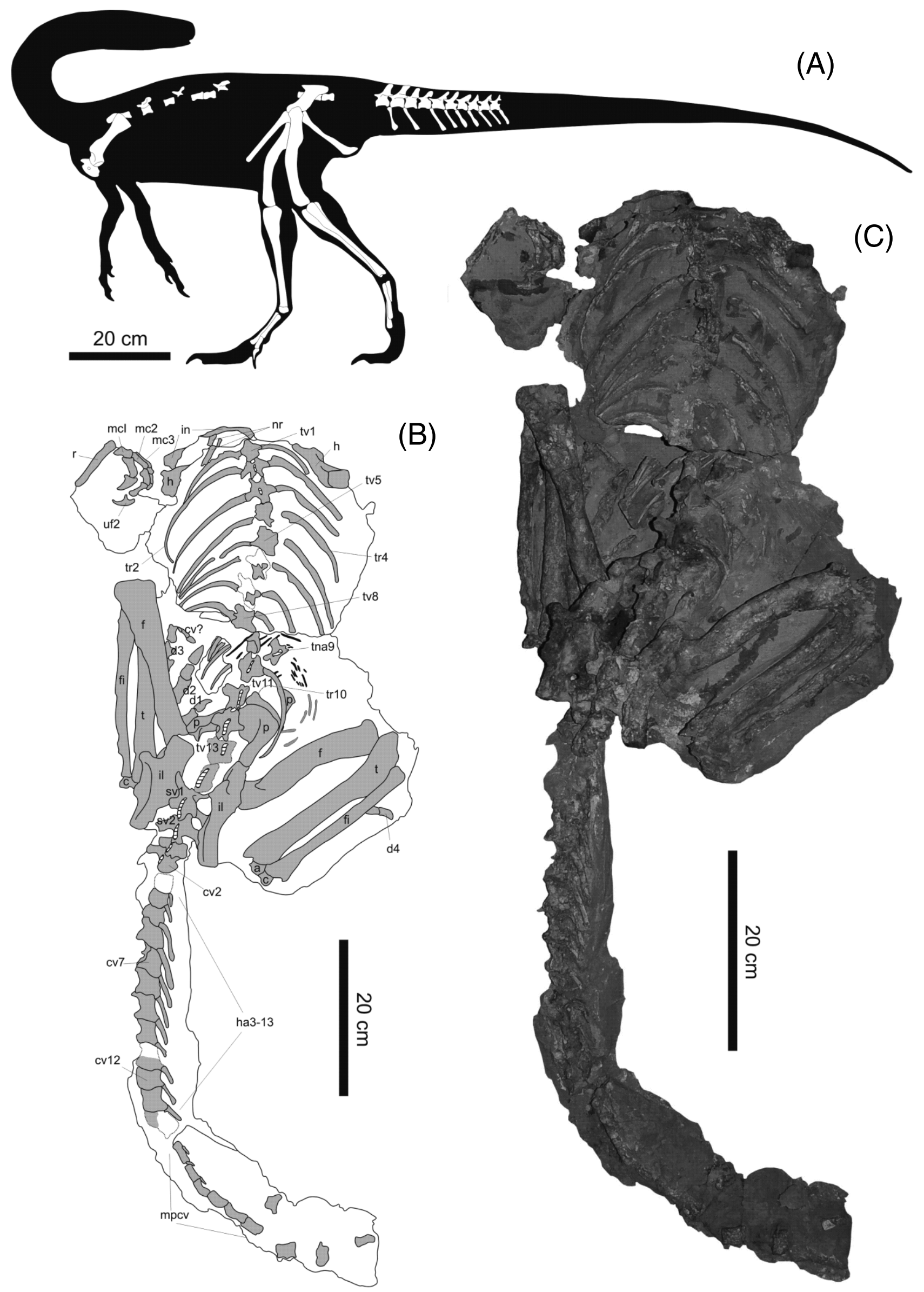


terms follow the conventions of the compendium 'The Dinosauria' (Weishampel et al. 2004) and the 'Nomina Anatomica Avium' (Baumel 1993), e.g. dorsal/plantar are applied to the foot, except for the proximal part of the metatarsals, where cranial/caudal are used instead. The pectoral girdle is vertically oriented (Nicholls \& Russell 1985; Langer et al. 2007c), while the forelimb is described with its long axis as vertical, and the rotational axis of the elbow joint orthogonal to the sagittal plane (Sereno 1993; Langer et al. 2007c). As a result, the deltopectoral crest expands cranially from the lateral margin of the humerus, and the radius is positioned lateral to the ulna. The manus, on the other hand, is rotated $180^{\circ}$ for descriptive purposes, so that the 'inner' digits are medially displaced. The nomenclature of vertebral laminae was simplified from that of Wilson (1999). Because its caudal counterpart is lacking in G. candelariensis, the 'anterior centroparapophyseal lamina' is simply termed centroparapophyseal lamina. Likewise, because always intersected by the paraphophysis (see Wilson, 1999; p. 642), an 'anterior centrodiapophyseal lamina' is also lacking in the recovered vertebral remains of $G$. candelariensis, and its caudal counterpart is simply termed centrodiapophyseal lamina. Measurements of all available skeletal elements are presented in Tables S1-S9.

\subsection{Axial skeleton}

As preserved, the holotype of $G$. candelariensis includes only a portion of the trunk series, namely two isolated neural arches, three semi-articulated vertebrae, as well as a badly preserved centrum supporting an associated rib (Table S1). A larger block includes ten articulated caudal vertebrae, plus four non-articulated centra: one sacral and three tail elements (Table S2). In addition, three isolated caudal centra and fragments of trunk ribs have also been recovered. The axial skeleton of UFRGS PV0725T includes 14 pre-sacral, two sacral, and 24 caudal vertebrae (Table S3). The articulation and relative positions of the pre-sacral elements suggest that they include the entire trunk series, with a vertebrae number matching that estimated for other basal saurischians (Bittencourt \& Kellner 2009). Yet, the first vertebra is very fragmentary and may include a portion of the preceding element (last cervical vertebra). Because of the better preservation of bone surfaces, the holotype provides more detailed information of the vertebral anatomy than the more complete axial skeleton of UFRGS PV0725T.

2.1.1. Trunk vertebrae. One of the isolated neural arches of MCN PV2355 is fragmentary, preserving only the prezygapophyses and the partial left side of the arch. Medial to the prezygapophyses, it is not possible to recognise ventrally extensive articulation facets (hypantra). The other isolated neural arch (Fig. 3A-B), on the other hand, preserves the base of the neural spine (especially caudally), the postzygapophyses, the right transverse process (with incomplete margins), and the ventral lamina associated with this process. As preserved, the transverse process is caudally inclined and tapers laterally. It is ventrally buttressed by a pillar, extending caudoventrally along the neural arch, to reach its caudoventral corner. This corre- sponds to the centrodiapophyseal lamina ('pcdl' of Wilson 1999), which is broader $(2.5 \mathrm{~mm})$ that the other laminae of the neural arch. A much thinner $(1.5 \mathrm{~mm})$ lamina extends from the transverse process to the cranioventral corner of the arch ('crl', Fig. 3B), forming a well defined ventral chonos (Welles 1984). Depending on the position of the parapophysis, indicated by a badly preserved prezygoparapophyseal lamina, this lamina may correspond to both the paradiapophyseal and 'anterior centroparapophyseal' laminae (sensu Wilson 1999) or only to the former. The craniodorsal corner of the neural arch is deformed, but inconspicuous cranial chonos and prezygodiapophyseal lamina are seen. Caudal to the centrodiapophyseal lamina, a dorsoventrally elongated excavation is present. This is bound caudally by a faint crest ('alcc', Fig. 3A; see also Yates 2007a) extending caudoventrally from the postzygodiapophyseal lamina, caudal to where another concavity is present. All of these elements represent a modification of the caudal chonos (Langer \& Benton 2006), occupying an area covered by the postzygodiapophyseal lamina. At the caudal margin of the neural arch, a small pillar of bone extends ventrally from between the postzygapophyses. The ventral portion of this pillar is incompletely preserved, with flat sub-parallel lateral margins, and appears to represent the hyposphene. A deep excavation is present below the transverse process (Fig. 3B; see also Bonaparte et al. 1999, fig. 2A), but it is uncertain if this perforates the neural arch.

The semi-articulated trunk vertebrae of the holotype are preserved in a small block of sediments (Fig. 3C). The cranial elements have well preserved centra, not transversely compressed (contra Bonaparte et al. 1999), with deep collateral excavations, but no ventral keel. The neural arch of the more cranial vertebra is badly fragmented, whereas the bases of the neural spine and transverse processes, along with the right prezygapophysis and adjacent parts of the neural arch, are preserved in the following element (Fig. 3D). The transverse processes is laterally expanded and buttressed by well developed laminae, which extend both cranially (prezygodiapophyseal) and cranioventrally to form deeply excavated cranial and ventral chonoe. The latter lamina bears a dorsal thickening that possibly matches the position of the parapophysis (not clearly identified as such), just ventral to the cranial part of the transverse process, suggesting its centroparapophyseal correspondence. The third vertebra of the series lacks its centrum, but preserves incomplete neural spine ('ns' in Fig. 3C), mostly covered by sediments on its right side, and left transverse process. The former has an oblique cranial margin, and the latter a fan-shaped (craniocaudally expanded) base.

Based on the shape of the transverse processes and the inferred position of the parapophyses, and on the comparison to UFRGS PV0725T and other basal dinosaurs (e.g. Huene 1926; Santa Luca 1980; Welles 1984), the most complete isolated neural arch of the holotype of $G$. candelariensis seems to correspond to the cranial part of the trunk, while the semiarticulated elements appears to come from the caudal part of that series. In UFRGS PV0725T, trunk vertebrae 1-8 and the respective ribs are preserved, along with the humeri and other

Figure 2 Guaibasaurus candelariensis, partial skeletons: (A) skeletal reconstruction depicting the preserved parts of the holotype, MCN PV2355 (modified from Jaime Headden). (B-C) blocks and skeletal remains of UFRGS PV0725T in dorsal view: (B) outline drawing; (C) photograph. The small block containing the left arm is figured upside down and rotated $90^{\circ}$ counterclockwise; see original position in Bonaparte et al. (2006, fig. 1). Fragments of the gastralia highlighted in black, and other bones in grey. Abbreviations: $\mathrm{a}=$ right astragalus; $\mathrm{c}=\mathrm{calcanea}$; $\mathrm{cv}=$ caudal vertebrae; $\mathrm{d}=$ pedal digits; $\mathrm{f}=$ femora; $\mathrm{f}=$ fibulae; $\mathrm{h}=$ humeri; $\mathrm{ha}=$ haemal arches; $\mathrm{il}=\mathrm{iliae}$; in =indeterminate bone (possible left clavicle); $\mathrm{mc}=$ metacarpals; $\mathrm{mpcv}=$ mid-proximal caudal vertebrae; $\mathrm{nr}=\mathrm{possible}$ cervical ribs; $\mathrm{p}=$ pubes; $\mathrm{r}=$ left radius; $\mathrm{sv}=$ sacral vertebrae; $\mathrm{t}=$ tibiae; tna9=neural arch of the ninth trunk vertebra; $\operatorname{tr}=$ trunk ribs; $t v=$ trunk vertebrae; uf $2=$ ungual phalanx of the second manual digit. Trunk, sacral and caudal vertebrae, trunk ribs, metacarpals and pedal digits are numbered accordingly. 

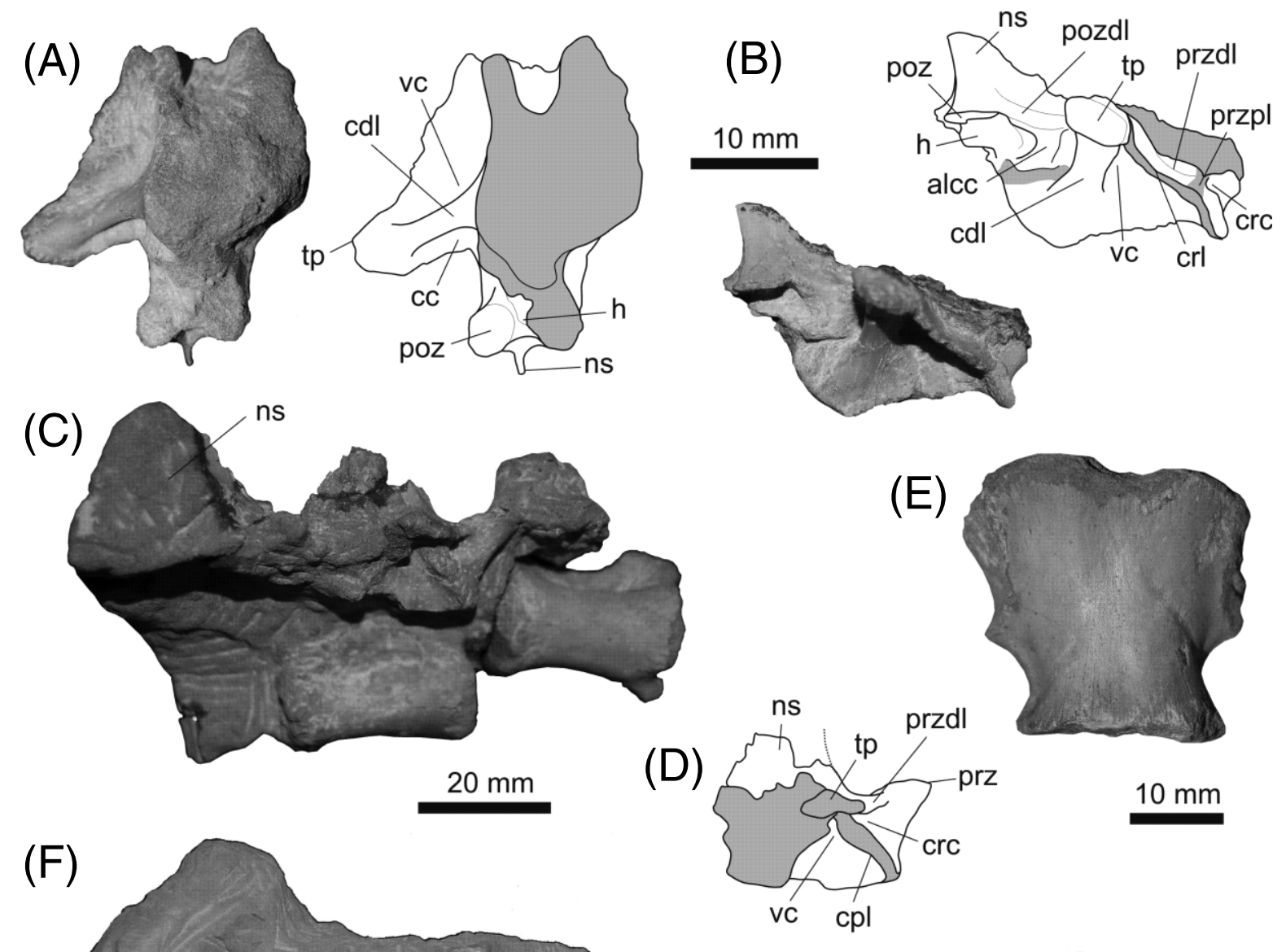

(E)

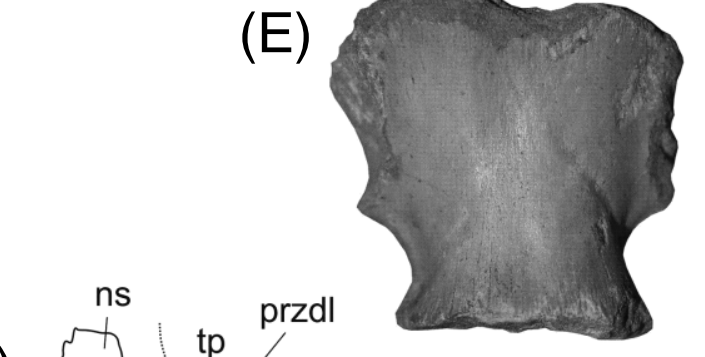

$10 \mathrm{~mm}$

$(F)$
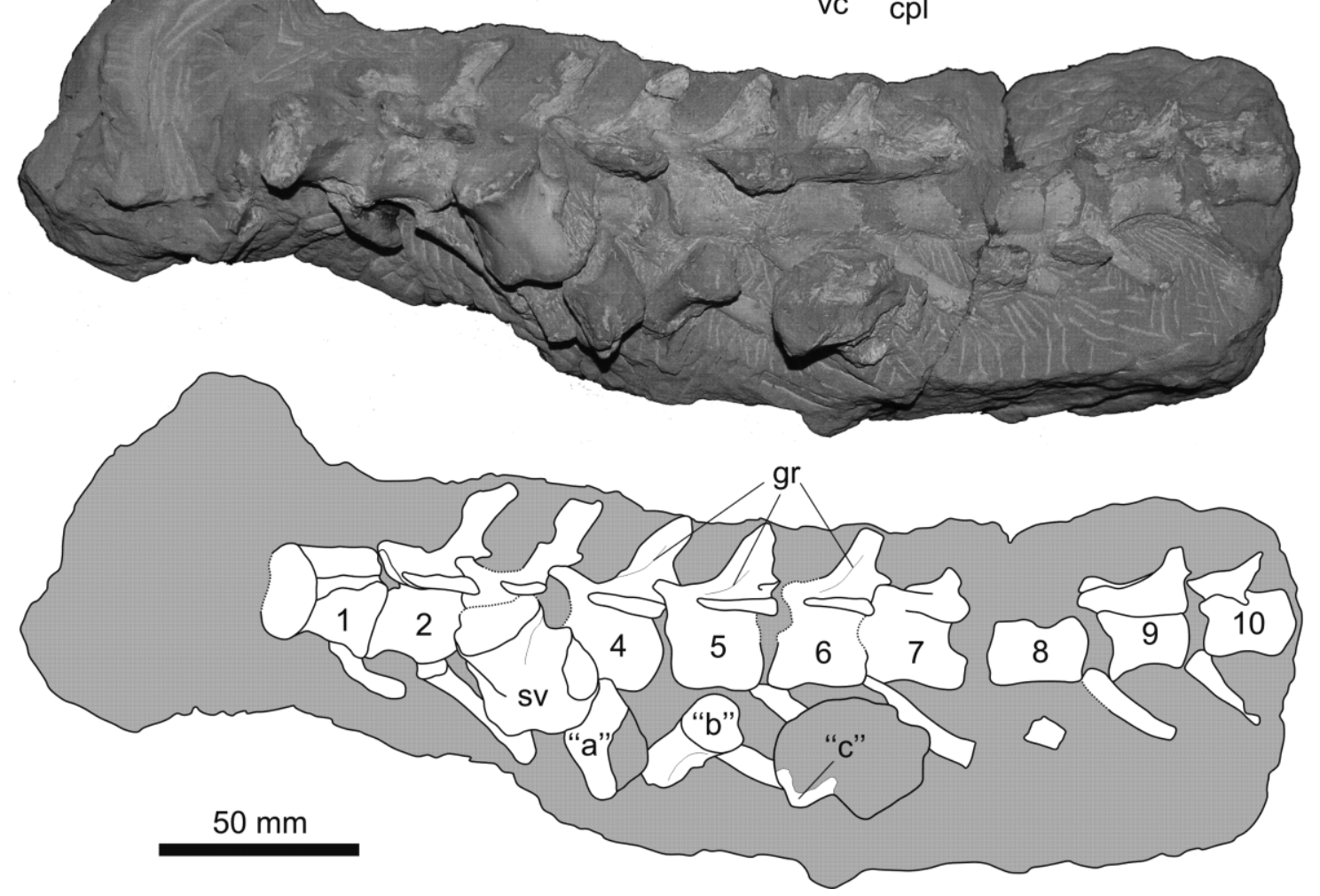

Figure 3 Guaibasaurus candelariensis (MCN PV2355), vertebrae: (A-B) isolated trunk neural arch, photographs and outline drawings: (A) ventral view; (B) right lateral view; (C-D) block of sediments containing two trunk vertebrae in right lateral view: (C) photograph of the entire block; (D) outline drawing of the neural arch of the second vertebra; (E) second sacral vertebra in ventral view; (F) photograph and outline drawing of a block of sediments containing one isolated 2nd sacral vertebra, ten articulated vertebrae from the proximal part of the tail (numbered according to their relative position in the preserved segment), and three isolated caudal vertebrae. Abbreviations: ' $a-c$ ' $=$ isolated caudal centra; alcc='auxiliary lamina on caudal chonos'; $c c=$ caudal chonos; $\mathrm{cdl}=$ centrodiapophyseal lamina; $\mathrm{cpl}=$ centroparapophyseal lamina; $\mathrm{crc}=$ cranial chonos; $\mathrm{crl}=$ 'cranial lamina'; $\mathrm{gr}=$ neural spine groove; $\mathrm{h}=$ hyposphene; $\mathrm{ns}=$ neural spine; $\mathrm{poz}=$ postzygapophysis; pozdl=postzygodiapophyseal lamina; prz=prezygapophysis; przdl=prezygodiapophyseal lamina; przpl=prezygoparapophyseal lamina; $\mathrm{sv}=2 \mathrm{nd}$ sacral vertebra; $\mathrm{t} \mathrm{p}=$ transverse process; $\mathrm{vc}=\mathrm{ventral}$ chonos. Matrix and broken areas highlighted in grey; dotted lines represent reconstructed parts. 
bones, in a single large block of sediments. The rest of the pre-sacral series is articulated to the sacrum in another block, which also contains some tail vertebrae and the pelvic girdles and limbs. The blocks are nearly continuous, and there is no evidence for missing vertebrae between them. Yet, the two cranialmost vertebrae of the caudal block (trunk elements 9-10) are slightly displaced, and disarticulated along the neurocentral joint.

The first trunk vertebra of UFRGS PV0725T is badly preserved, exposed only in dorsal view, lacking its cranial margin and most of the neural arch. On the contrary, trunk vertebrae 2-3 (Fig. 4A) have relatively complete transverse processes, which taper laterally and are caudolaterally oriented. Trunk vertebrae 4-5 lack most of their dorsal surfaces, but their right lateral sides are exposed. The centra bear typically concave ventral margins and no perforating cavities (as in all other available trunk vertebrae), and recognisable neurocentral joints (also seen in trunk vertebrae 11-13). Trunk vertebrae 6-7 are very fragmentary and concealed by matrix. Their positions are mostly inferred utilising the proximal end of the respective ribs as guidelines. The dorsal surface of 8th trunk vertebra is slightly better preserved. It has a partial right transverse process that is sub-rectangular in dorsal outline.

The 9th trunk vertebra of UFRGS PV0725T includes the disarticulated centrum and neural arch. The former is exposed in left lateral and ventral views; there is no ventral keel, and the transverse process is similar to those of trunk vertebrae 2-3. The only recognised lamina of the vertebra connects the transverse process to the caudoventral corner of the neural arch (centrodiapophyseal lamina), but the material is not well preserved enough to positively assume the absence of other laminae extending over the neural arch. The centrum of the 10th trunk vertebra is also displaced from its original position, and preserved among an intricate mesh of bone fragments. Its neural arch is, however, preserved in articulation with those of trunk vertebrae 11-12. Its incomplete sub-rectangular transverse processes are dissimilar to those of more cranial trunk vertebrae, as they seem to expand strictly laterally.

Although partially incomplete, vertebrae 11-12 (Fig. 4B-D) are the best preserved of the trunk series of UFRGS PV0725T, and accessible from various views. The former bears the most complete trunk neural spine, which is incomplete at its dorsal margin, but longer (dorsally and axially) than half the length of the centrum. The transverse process is expanded at its lateral margin and slightly cranially directed. It is bounded by well preserved centroparapophyseal, centrodiapophyseal and postzygodiapophyseal laminae, which define deep ventral and caudal chonoe. The centrodiapophyseal lamina is almost twice the breadth of the centroparapophyseal lamina. The deformed cranial margin of the neural arch prevents the identification of the prezygapophyses and associated laminae in the 11th trunk vertebra. The next trunk vertebra is roughly similar to the preceding element, but its centroparapophyseal and centrodiapophyseal laminae are sub-equal in width. The former is better seen on the left side of the vertebra (Fig. 4D), and corresponds to a vertically elongated bump, extending from the cranioventral corner of the neural arch to intercept the mid-length of the prezygodiapophyseal lamina. This cranial displacement of the dorsal end of the lamina restricts the lateral expression of the cranial chonos. Likewise, on the right side of the vertebra, the centrodiapophyseal lamina does not reach the caudoventral corner of the neural arch. Instead, it terminates more dorsally, on the caudal margin of the pedicel, reducing the ventral expression of the caudal chonos. Ventral to the postzygapophyses, a vertically oriented sheet of bone (also seen in the preceding vertebra) appears to represent a remnant of the hyposphene. Trunk vertebrae 13-14 are badly preserved, but the centrodiapophyseal lamina of the former is broader than its centroparapophyseal lamina, although significantly thinner than the centrodiapophyseal laminae of the two preceding vertebrae.

2.1.2. Sacral vertebrae and ribs. A two-vertebrae sacrum is inferred for UFRGS PV0725T (Fig. 4E). In fact, the transverse processes/ribs of the cranially adjacent trunk vertebra are not preserved, and it could be argued that they reached the medial surface of the ilium, which is not well preserved enough for the identification of articular facets. Yet, a line extending between the tips of the preacetabular alae barely surpasses the midlength of that last trunk vertebra. The alae are also well set apart the lateral margins of the vertebra, both dorsally and laterally. Therefore, there is no evidence for the addition of a trunk vertebra to the sacrum of $G$. candelariensis. Furthermore, its two obvious sacral vertebrae cover almost the whole length of the dorsal iliac lamina, in a fashion reminiscent of that seen in various archosaurs with a two-vertebrae sacrum (Walker 1961; Ewer 1965; Bonaparte 1984; Sereno \& Arcucci 1993, 1994).

The elongated and narrow neural spine of the first sacral vertebra is incomplete dorsally, lacking evidence for spine tables. Its articulation to the ilium is composed of conjoined ribs and transverse processes. The latter are dorsoventrally flattened, extending laterocaudally, and slightly dorsally. Each process is sub-triangular, getting craniocaudally narrower at the lateral margin. The cranial margin of each rib is composed of a well developed vertical platform, which sets the cranial limit of a space between the sacral vertebrae and the ilium. It extends laterally from the cranial part of the centrum, and has a curved cranial expansion at its lateral half, forming a cranially concave wall as seen from above. The rib attachment in the medial surface of the ilium starts at mid-depth of the preacetabular ala, extending ventrally and then slightly cranially along the pubic peduncle. Other parts of the ribs are concealed by sediments and other bones. Yet, the exposed medial surface of the left ilium suggests that a horizontal platform extended caudally from the ventral margin of the cranial wall.

The transverse processes of the second sacral vertebra are also caudolaterally directed, extending horizontally to the caudal end of the iliac postacetabular alae. This leaves almost no space in the ilium for the articulation of an extra sacral vertebra incorporated from the caudal series. Each rib is firmly attached, but not fused, in a large articulation area that occupies the dorsocranial corner of the lateral surface of the centrum, possibly entering the lateral surface of the preceding element. It expands laterally as a fan-shaped, moderately deep element. Its caudoventral margin forms an oblique (caudodorsal to cranioventral) platform, the caudal margin of which joins that of the transverse process. Cranial to that, the space between the sacral vertebrae and the ilium is floored by the rib and roofed by the transverse process. The rib articulates to the ilium on the medial surface of the crest that forms the medial margin of the brevis fossa.

In the holotype, contra Bonaparte et al. (1999), the medial iliac surface bears no sign of a three-vertebra sacrum. Of the two centra described by Bonaparte et al. (1999, fig. 3) only the larger can be identified as a sacral centrum. The reduced size of its caudal part, as well as the craniodorsal position of the rib articulation, allows its correspondence to the second sacral vertebra of UFRGS PV0725T. A pair of collateral blunt horizontal crests extends from the rib articulation to the caudal margin of the vertebra. The caudal articulation is slightly concave, as is the ventral margin in lateral view. The latter also bears a cranial midline groove, which is continuous to an excavation on the ventral margin of the cranial articulation. 

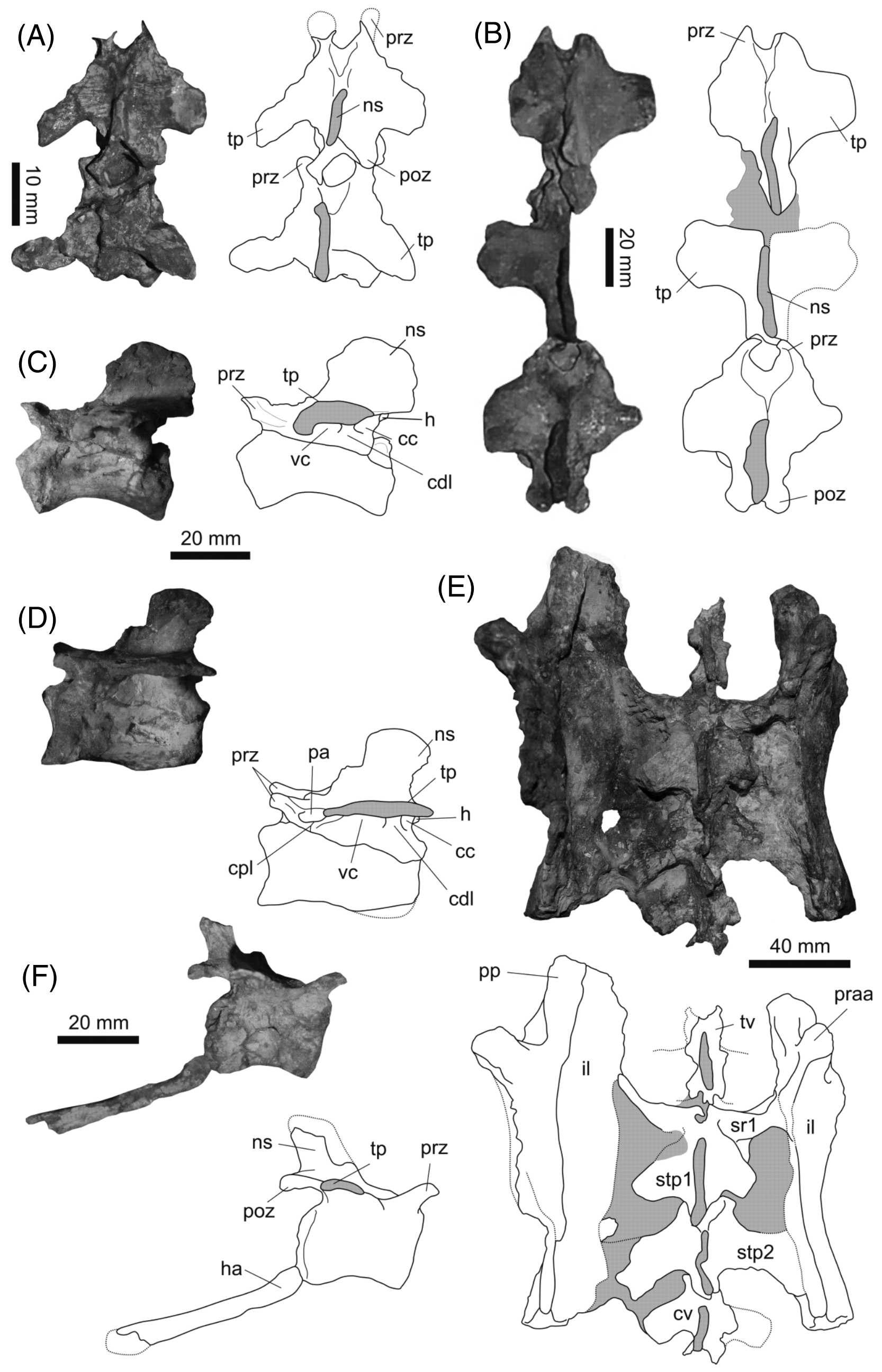

(C)
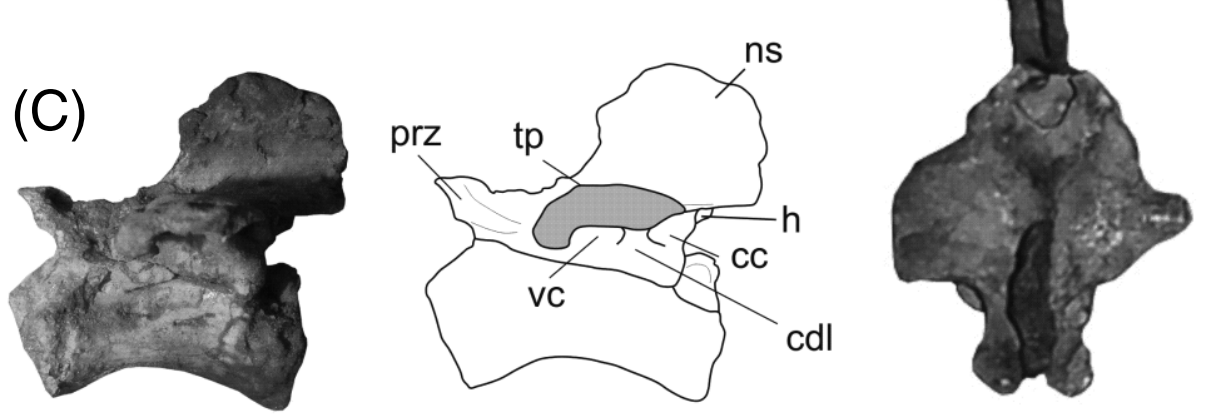
2.1.3. Caudal vertebrae. Considering that basal dinosaurs have a tail composed of 40-50 vertebrae (Huene 1926; Santa Luca 1980; Colbert 1989; Novas 1993), it is likely that the 24 preserved caudal vertebrae of UFRGS PV0725T correspond to about half the total tail length of $G$. candelariensis. Caudal vertebrae 1-2 were preserved in articulation to the sacrum. The following element (caudal vertebra 3 ) is lacking, but its position can be inferred by that of its haemal arch. It is followed by tail vertebrae $4-14$, preserved in articulation. The following ten vertebrae are preserved in another block, including a series of six articulated elements and four isolated vertebrae. These have an ambiguous position, but likely correspond to the midproximal part of the tail.

The cranial half of the first caudal vertebra fits within the inner limits of the iliac postacetabular alae. Yet, although incomplete, its laterocaudally directed transverse processes do not appear to reach the pelvic girdle or the ribs/transverse processes of the second sacral vertebra. Tail vertebrae $2-4$ are very incomplete, but the series composed of vertebrae 5-14 allows a better evaluation of their anatomy. Tail vertebrae 7-9 have tapering transverse processes, which are slightly inclined both dorsally and caudally. The eighth tail vertebra bears caudally inclined neural spines, at the base of which the postzygapophyses are elevated. The following two vertebrae have shorter and more vertically oriented neural spines. In some elements of this series, a longitudinal crest on the ventral margin of the centrum and a depression below the cranial portion of the transverse processes are present. The following mid-proximal series of six caudal vertebrae are preserved with less detail. The neural arches are mostly obliterated, and it is not clear if there is any elongation of the prezygapophyses.

The holotype of $G$. candelariensis includes three isolated caudal centra, and a block containing 13 tail vertebrae (Fig. $3 F)$, ten of which are in articulation. Their centra are laterally concave, but the apophyses are mostly incomplete. Vertebrae 2-6 have distally inclined neural spines and transverse processes. The neural spine occupies the distal half of the neural arch, and the cranial half of its lateral surface is excavated by an oblique groove ('gr' in Fig. $3 \mathrm{~F}$ ) in all elements distal to vertebra 3. The neural spines of the last two elements are represented by a distally displaced elevation, which extends as a faint midline ridge along the proximal half of the neural arch. Reduced transverse processes are preserved in vertebra 9, and are strictly laterally directed. In all preserved elements the postzygapophyses are elevated on the base of the neural spine, ventral to which the neural arch is markedly excavated. The transverse processes are dorsoventrally flattened, and no infradiapophyseal fossae are seen. The neurocentral joints are concealed in most elements, but appear not to be fused in vertebrae 5 and 9 . Two of the centra preserved below the articulated series may represent more proximal vertebrae, while the slenderer middle element (' $b$ ' in Fig. 3F) and the three isolated centra may come from a more distal portion of the tail. The former two elements ('a' and ' $c$ ' in Fig. 3F) may well represent caudal vertebrae $1-2$, so that the articulated series may correspond to elements 3-12. In fact, between vertebrae 6 and 9 of the articulated series, the neural spine changes from a long distally inclined element to an apparently much shorter and distally displaced spine. In UFRGS PV0725T, the last long and distally inclined neural spine is that of the 8th tail vertebrae. In other dinosaurs, similar transition points are around the same position (Santa Luca 1980), more proximal (Welles 1984), or more distal (Huene 1926) in the tail.

2.1.4. Non-sacral ribs, gastralia and hemal arches. Only fragmented ribs are preserved in the holotype of G. candelariensis. This includes the proximal portions of two-headed trunk ribs, as well as partial shafts, all of which are caudally excavated by a longitudinal groove. The proximal shafts also bear a longitudinal ridge on the cranial surface. This leads to the short tuberculum, which is connected by an extensive sheet of bone to the longer capitulum. Most of the ribcage of UFRGS PV0725T is preserved (Fig. 2), along with fragments tentatively referred to one or two ribs laying cranial to that series on the left side (supposedly from the last neck vertebrae). These are nearly straight bones, whereas trunk ribs are arched and bear a longitudinal groove along the caudal surface. Some of them are nearly complete (e.g. right rib 2; left rib 10), indicating that cranial trunk ribs are about 30\% longer than more caudal elements. Ribs are preserved until the 11th trunk vertebra, the robustness of which suggests that the next (12th) vertebra originally supported free, well developed ribs; a condition also indicated by the craniocaudal expansion of its transverse processes. This may also have been the case of the 13th trunk vertebra, while the last element (14th) most likely possessed reduced ribs concealed within the pelvic area. The badly preserved rib articulations of UFRGS PV0725T are generally similar to those of the holotype.

In UFRGS PV0725T, below and displaced towards the right side of trunk vertebrae and ribs 9-10, a set of slender rod-like elements surely represent parts of the gastralia. Their craniomedial to caudolateral orientation is reminiscent of the 'V' shaped arrangement of archosaur gastralia (Claessens 2004). Both left and right medial gastralia are represented, but their midline imbrication is not clearly seen. Caudal vertebrae of both the holotype and UFRGS PV0725T have preserved, but mostly incomplete haemal arches. These are slightly expanded at the distal portion, but not caudally projected in lateral view. The most complete of these correspond to twice the length of the neighbouring centra, and bear dorsally closed haemal canals.

\subsection{Pectoral girdle and limb}

The only preserved scapulocoracoid of $G$. candelariensis is the left element of the holotype (Table S4). In contrast, UFRGS PV0725T lacks any evidence of these elements, but partially preserves both humeri, as well as most of the rest of the left forelimb (Table S5). In addition, right in front of the left humerus, a transversely elongated $(14 \mathrm{~cm})$ bone is present (Fig. 5D). It is mainly exposed cranially, at the frontal margin of the front-block ('in' in Fig. 2), whereas its caudal margin is concealed by matrix. This may be one of the elements recognised as scapulae by Bonaparte et al. (2007), but it lacks any typical traits of that bone, differing substantially from that of the holotype. As preserved, the element is flattened, caudally

Figure 4 Guaibasaurus candelariensis (UFRGS PV0725T); vertebrae and ilia, photographs and outline drawings: (A) trunk vertebrae 2-3 in dorsal view; (B) trunk vertebrae 10-12 in dorsal view; (C) trunk vertebra 11 in left lateral view; (D) trunk vertebra 12 in left lateral view; (E) ilia, last trunk vertebra, both sacral vertebrae, and first tail vertebra in dorsal view; $(\mathrm{F})$ tail vertebra 8 in right lateral view. Abbreviations: cc $=$ caudal chonos; $\mathrm{cdl}=$ centrodiapophyseal lamina; $\mathrm{cpl}=$ centroparapophyseal lamina; $\mathrm{cv}=$ caudal vertebra; $\mathrm{h}=\mathrm{hyposphene}$; ha= haemal arch; il=ilium; ns=neural spine; pa=parapophysis; poz=postzygapophysis; $p p=i l i a c$ pubic peduncle; praa=iliac preacetabular ala; prz=prezygapophysis; sr1=rib of first sacral vertebra; stp $1-2=$ transverse process of first/second sacral vertebra; $t p=$ transverse process; $t v=$ trunk vertebra; $v c=v e n t r a l$ chonos. Matrix and broken areas highlighted in grey; dotted lines represent reconstructed parts. 

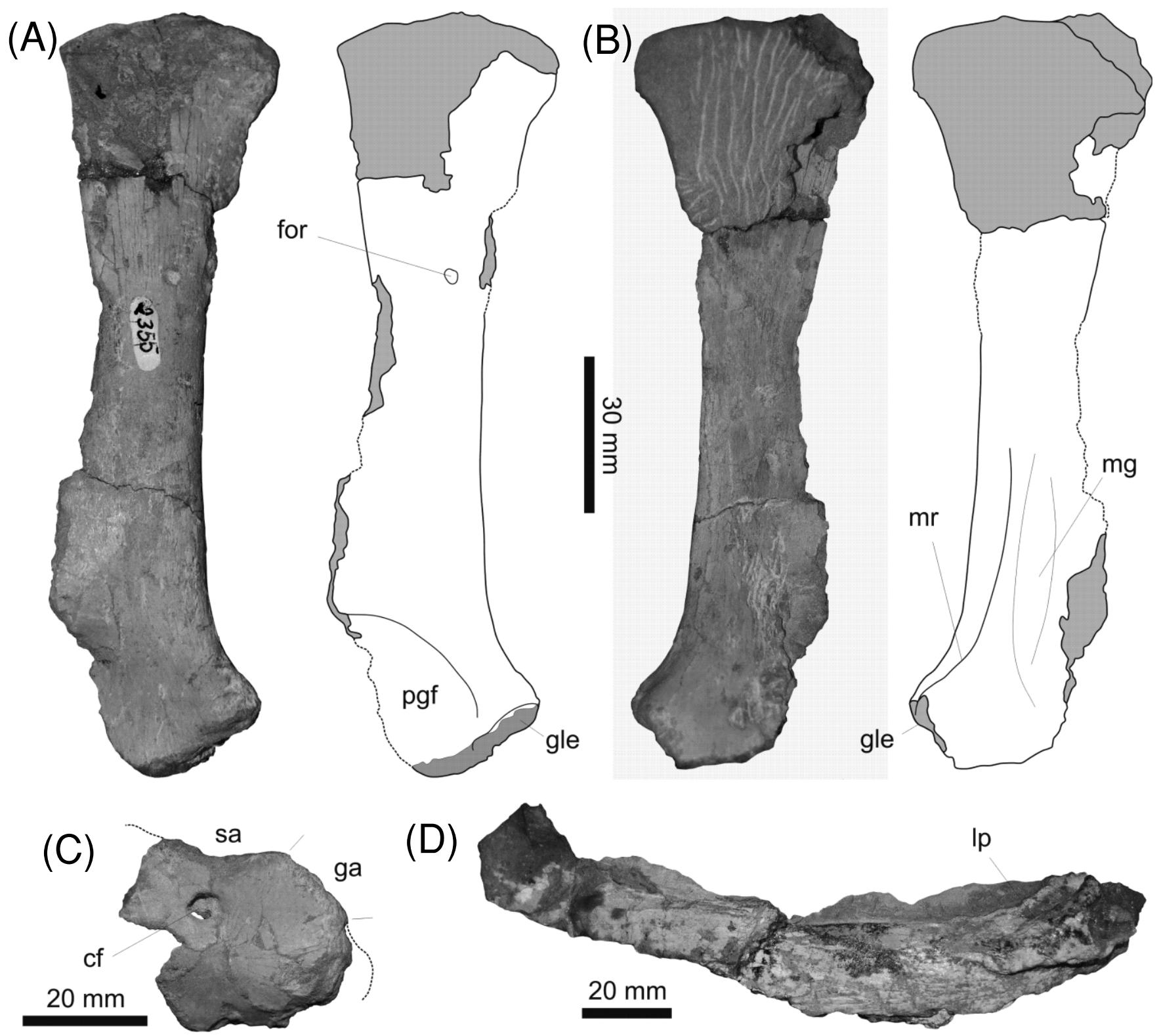

(D)

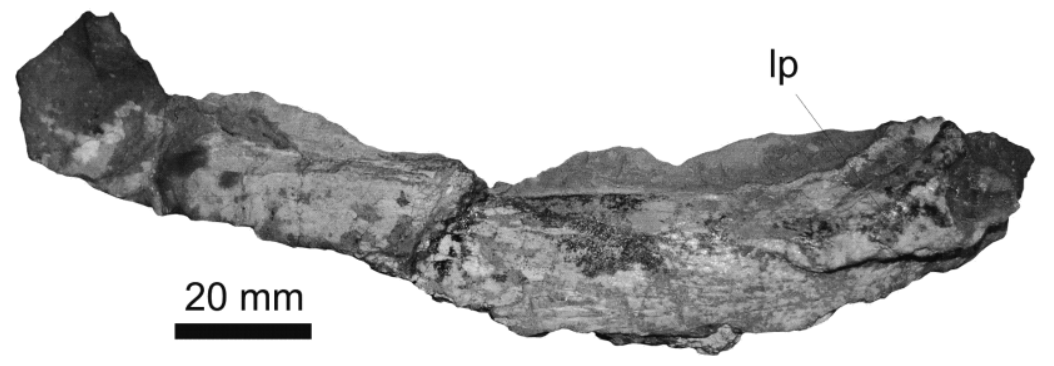

Figure 5 Guaibasaurus candelariensis: (A-C) left scapulocoracoid of MCN PV2355: scapula in lateral (A) and (B) medial views, photographs and outline drawings; (C) coracoid in lateral view, photograph; (D) UFRGS PV0725T, indeterminate bone in ventral view. Abbreviations: $\mathrm{cf}=$ coracoid foramen; for $=$ foramen; ga $=$ glenoid area; gle=glenoid; $\mathrm{lp}=$ lateral protuberance; $\mathrm{mg}=$ medial groove; $\mathrm{mr}=$ medial ridge; $\mathrm{pgf}=$ preglenoid fossa; $\mathrm{sa}=$ scapular articulation. Matrix and broken areas highlighted in grey; dotted lines represent reconstructed parts.

concave and cranially convex, and tapers medially, although the medial tip is missing. A longitudinal protuberance ('lp' in Fig. 5D) extends along the lateral fifth of the bone, expanding towards its broad lateral surface. Ventromedial to this, the bone surface has a rugose texture, with longitudinally oriented sub-parallel wrinkles. Alternatively, this curved element could be interpreted as a rib from the cranial part of the trunk, but all of these elements have been identified in their respective positions above the left humerus (Fig. 2). Instead, the bone is at least twice as broad as any preserved rib (at their lateral half), and is overlapped dorsally by the humerus. It is also curved, unlike typical neck ribs. Instead, it may represent a (left) clavicle, otherwise identified (forming a furcula) only in Coelophysis among Triassic dinosaurs (Nesbitt et al. 2009a). If considered as such, the clavicle of $G$. candelariensis would be unlike that of any other known dinosaur. As in sauropodomorphs, the bones would not be fused together to form a furcula (Yates \& Vasconcelos 2005; Martínez 2009), but their size relative to other pectoral bones is at least twice that seen in these and other dinosaurs, approaching the pseudosuchian condition (Huene 1942; Krebs 1965; Long \& Murry 1995; Gower \& Schoch 2009). Further preparation, perhaps revealing its caudal margin, may clarify the identity of this bone.

2.2.1. Scapulocoracoid. The articulated scapulocoracoid is medially concave and laterally convex, following the contour of the ribcage. The scapula is composed of a robust body and an elongated blade (Fig. 5A-B). The latter gradually expands craniocaudally towards its dorsal end, becoming mediolaterally thinner. Yet, the exact shape of the blade is difficult to determine, given the incomplete preservation of its outer edges, especially on the cranial and dorsal margins. As preserved, the dorsal portion of the blade is particularly expanded caudally. The lateral surface of the blade is pierced by a large foramen, while the ventral part of the medial surface is crossed by a longitudinal ridge ('mr' in Fig. 5B), following the contour of the caudal margin of the bone. This forms the caudal margin of a subtle longitudinal groove ('mg' in Fig. 5B), which excavates the medial surface of the blade. More ventrally, the 

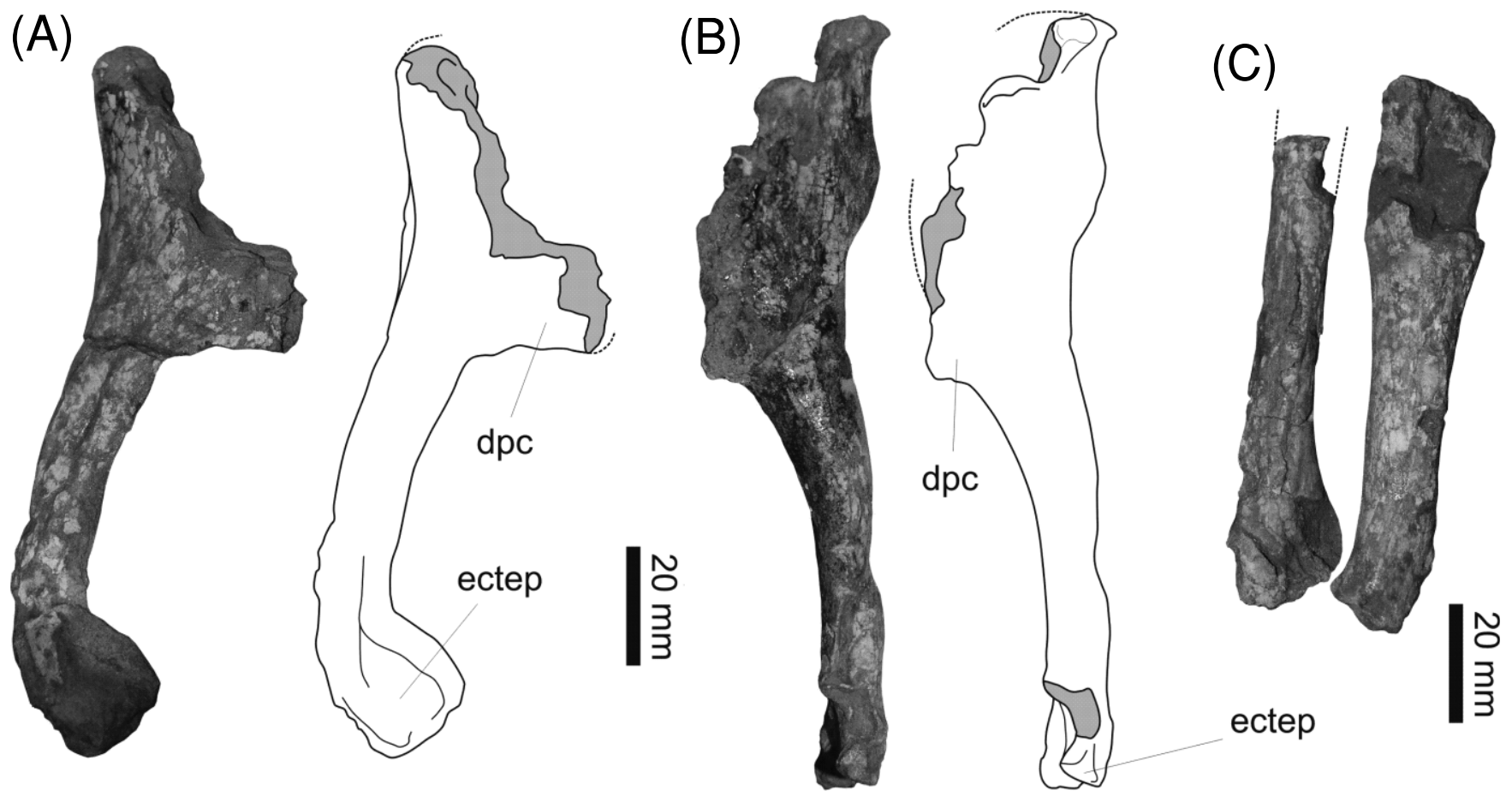

Figure 6 Guaibasaurus candelariensis (UFRGS PV0725T), humeri and pectoral epipodium: (A-B) photographs and outline drawings of the humeri in lateral view: (A) right element; (B) left element; (C) left radius and ulna in caudal view, photograph. Abbreviations: $\mathrm{dpc}=$ deltopectoral crest; ectep=ectepicondyle. Matrix and broken areas highlighted in grey; dotted lines represent reconstructed parts.

ridge marks the medial margin of a flat surface that extends laterally until the caudal edge of the blade and forms the dorsocaudal margin of the glenoid. As a whole, but especially more ventrally, the caudal margin of the blade is lateromedially broader than the cranial margin. The scapular body is incomplete cranially, and the acromial process is not preserved. A subtle lateral excavation (slightly more marked cranially) corresponds to the preglenoid fossa, ventral to which the lower margin of the scapula is more projected at its mid-length. The ventrocaudally and slightly laterally directed glenoid is ovoid, with a flattened margin for the coracoid articulation, but its bone surface is mostly missing.

As preserved, the coracoid of G. candelariensis (Fig. 5C) has a rounded outline, but most of the cranial portion, ventral margin and subglenoid area is missing. The strictly dorsocaudally facing glenoid has a sub-triangular outline, with an oblique lateral margin, a caudoventral apex and a straight craniodorsal base, where it meets the scapular part of the articulation. The coracoid foramen is restricted to that bone, and perforates the coracoid in a medioventral to laterodorsal direction.

2.2.2. Humerus. The proximal margins of both humeri of UFRGS PV0725T are fragmentary, which also lack the proximal portions of the deltopectoral crests (Fig. 6A-B). Although mostly complete, both distal ends are also badly preserved. In addition, neither of the bones is freed from the bearing rock, and their medial surfaces are covered by matrix. Furthermore, the right element is more robust than the left, suggesting some degree of calcite cementation (Holz \& Schultz 1998), while the distal end of the left bone appears craniocaudally flattened. The apex of the deltopectoral crest is placed at the level of a plane that orthogonally intersects the long axis of the humerus at a distance from the proximal margin that corresponds to about $45 \%$ of the preserved length of the bone. Considering that neither of the humeri has a completely preserved proximal margin, these figures could be underestimated. As better seen in the right humerus, the distal margin of the deltopectoral crest expands abruptly from the shaft. The crest also forms a nearly right angle to the distal intercondylar line, but is slight more laterally inclined in the left bone. Distal to the deltopectoral crest, the humeral shaft is strongly bowed caudally. The cranial surface is exposed in the left bone, revealing a broad longitudinal groove medial to the deltopectoral crest, for the origin of the pectoralis and/or coracobrachialis muscles, and a more distal brachial fossa.

2.2.3. Pectoral epipodium. The radius and ulna of UFRGS PV0725T are preserved, but partially covered by matrix, and only the caudal surface of both elements (Fig. 6C), plus the medial surface of the radius, is exposed. This reveals few anatomical details, apart from a shallow longitudinal groove on the distal half of the ulna, which bears no evidence of an enlarged olecranon process. The radius lacks its proximal portion, and is nearly featureless, except for its distal expansion.

2.2.4. Manus. Contra Bonaparte et al. (2007), no evidence of the right manus was found in UFRGS PV0725T. This element may have been identified during preparation, but it is not currently exposed in the specimen. In contrast, the left hand is preserved (Fig. 7A-C), along with the epipodium, in a small isolated block of sediment, which fits craniolaterally to the main front-block (Fig. 2). No carpal elements could be safely identified, but most metacarpi and phalanges are exposed. Four digits were recognised, and it is uncertain if a fifth element was present in life, as in other basal dinosaurs (Galton 1976; Santa Luca 1980; Sereno 1993; but see Nesbitt et al. 2009b). Digits II and III are sub-equal in length, while digit I, and most probably also digit IV, are significantly shorter. Metacarpal I is much shorter and broader at its mid-length than metacarpals II and III. Its proximal margin is incomplete, but has a sub-triangular outline, with flattened flexor and lateroextensor surfaces. The flexor surface and distal portion of the lateral surface are concealed by matrix, and the distal articulation shows a more distally projected lateral condyle. This condyle seems also deeper in the flexor/extensor axis, but not transversally broader. The medial condyle bears a deep 


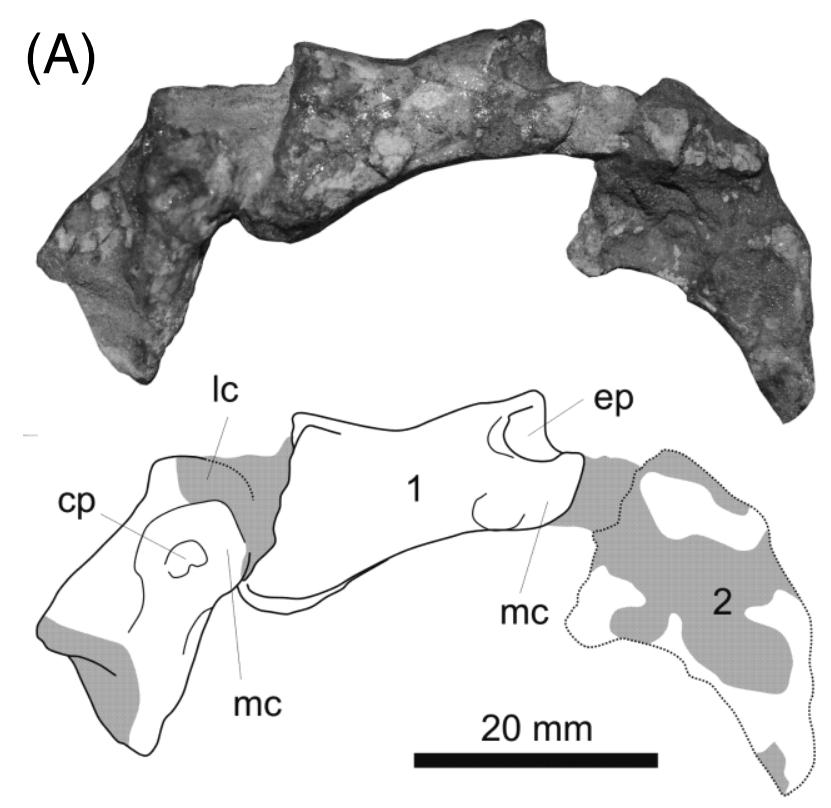

(B)

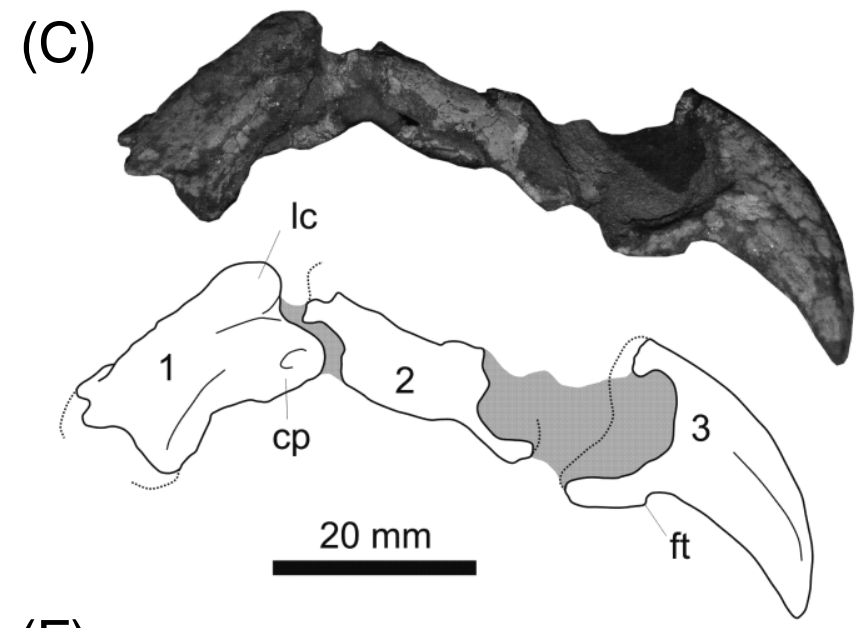

(D)

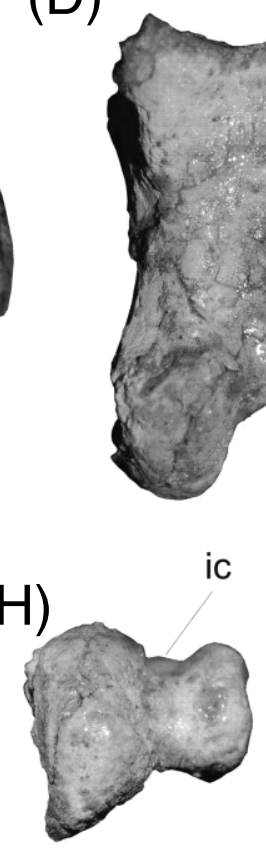

(H)
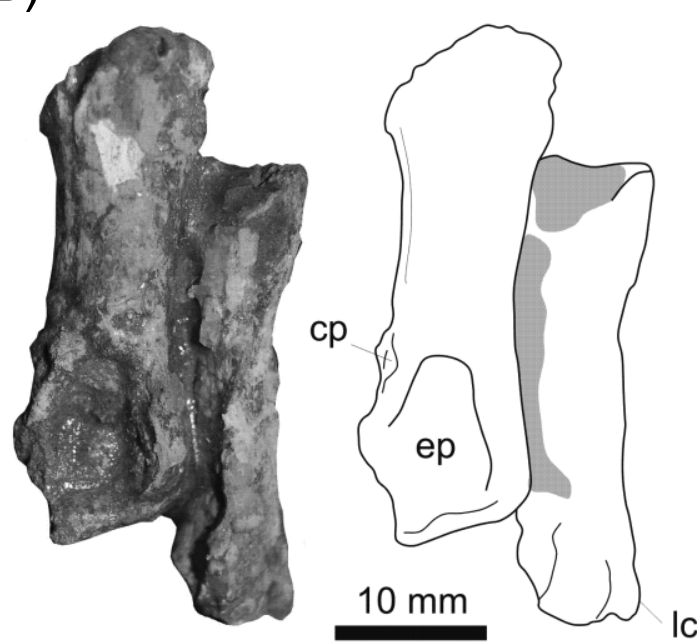

IC
(F)

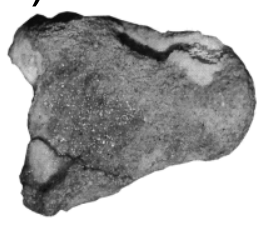

(G)

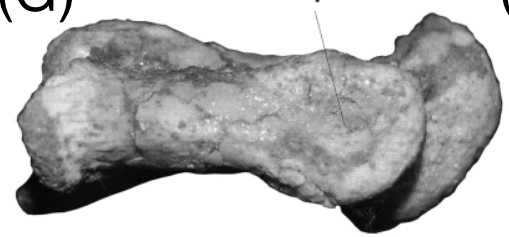

$\mathrm{mc}$

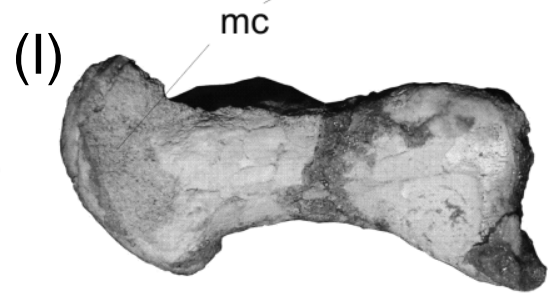

Figure 7 Guaibasaurus candelariensis, manus: (A-C) photographs and outline drawings of the left hand of UFRGS PV0725T (phalanges numbered accordingly): (A) digit I in medial view; (B) metacarpi II and III in extensor view; (C) phalanges of digit II in medial view; (D-I) photographs of the left metacarpal I of MCN PV 10112: (D) extensor; (E) flexor; (F) proximal; (G) medial; (H) distal; (I) lateral views. Abbreviations: $\mathrm{cp}=$ collateral pit; e $\mathrm{p}=$ extensor pit; $\mathrm{ft}=$ flexor tubercle; $\mathrm{ic}=$ intercondylar groove; $\mathrm{lc}=$ lateral condyle; $\mathrm{mc}=\mathrm{medial}$ condyle. Matrix and broken areas highlighted in grey; dotted lines represent reconstructed parts.

collateral pit, but the extensor depression is restricted to a transversally narrow groove between the condyles. It is unclear if the distal part of the bone is rotated relative to the proximal articulation.

An isolated left metacarpal I (Fig. 7D-I) was collected from the same site as UFRGS PV0725T. It matches the metacarpal I of that specimen in all apparent characteristics, and is tentatively referred to $G$. candelariensis. Its proximal articulation is sub-triangular, with a rounded medial apex and a flattened lateral surface for articulation with metacarpal II. The distal condyles are not rotated relative to the proximal articulation. The collateral pits are well developed, but the extensor depression is represented by an inconspicuous concavity. The lateral condyle is more distally projected, larger in all dimensions, and more expanded towards the extensor surface. The intercondylar groove excavates the flexor more deeply than the extensor surface.

Metacarpals II-IV of UFRGS PV0725T were distally displaced from their original positions. Their proximal articulations are flat, and that of metacarpal II is transversally broader at the extensor margin. This suggests that the proximal articulation joints of the metacarpals are arched towards that same direction. The proximal portion of Metacarpal II bears flattened medial and lateral margins for articulation with the neighbouring elements. The shaft is not laterally or medially arched. The distal part of the bone shows a slight clockwise rotation as seen from the carpal area. The lateral condyle is more craniocaudally deep, but slightly less projected distally. 
The extensor surface of the distal portion of the metacarpal is excavated by a well developed depression, the lateral rim of which is more conspicuous. Reduced collateral pits are present in both sides. Metacarpal III is significantly narrower than more medial metapodials, and the poor preservation of its bone surface prevents the observation of various anatomical details. The element is incomplete proximally, but the distal portion includes a slightly more distally projected lateral condyle, although the medial condyle may be somewhat damaged. Metacarpal IV is preserved as a proximally incomplete, elongated, and nearly featureless element. The bone expands continuously towards its distal end, and could well bear a phalanx, but no sign of that element was preserved.

The manual phalangeal formula of $G$. candelariensis is 2-3-4-?. Most phalanges are badly preserved, with little of the bone surface remaining. Phalanx 1 of digit I is longer than, and sub-equal to, the respective metacarpal and ungual. Although incompletely preserved, its distal part is rotated clockwise in relation to the proximal part of the bone. In addition, its extensor pit is deeply excavated, there are shallow collateral pits, and the medial condyle is farther projected distally. Only the general shape of the ungual of digit I is preserved. It is curved but non-raptorial, and a flexor tubercle may be present. Phalanges 1 and 2 of digit II are badly preserved, the latter lacking most of its extensor portion. Nonetheless, phalanx 2 is the longer of them, and sub-equal to the ungual. As preserved, phalanx 1 is lateromedially compressed, with the condyles equally projected distally. It possesses a groove-like extensor pit, and shallow collateral pits. The ungual of that digit is the largest of the hand; it is curved and preserves an evident flexor tubercle. Few details are preserved in the phalanges of digit III, which are significantly narrower that the more medial elements. The distal part of phalanx 3 and the proximal part of the ungual are missing. Yet, their estimated lengths reveal that phalanx 3 is the longest of the digit.

\subsection{Pelvic girdle and limb}

The pelvic skeleton of $G$. candelariensis is known based on girdle and limb elements of the holotype and UFRGS PV0725T, as well as on the partial left limb of the paratype (Tables S6-S9), which allow the comparison of their relative dimensions. The length relations of these bones indicate that the holotype is roughly $15-20 \%$ smaller than both UFRGS PV0725T and the paratype.

2.3.1. Ilium. As seen in UFRGS PV0725T, the dorsal iliac lamina of $G$. candelariensis is mediolaterally broader at its cranial and caudal portions (pre- and postacetabular alae). This condition, along with the inward arching of the lamina, forms a laterally concave surface dorsal to the acetabulum, which corresponds to the origin area of $\mathrm{m}$. iliofemoralis cranialis (Langer 2003). In the holotype, as well as in the left side of UFRGS PV0725T, this area is dorsoventrally deep, allowing the reconstruction of a convex dorsal margin of the lamina, at least on its caudal portion. As preserved, the very short preacetabular ala resembles the horn of a western saddle, laterally buttressed by a broad iliac preacetabular ridge (see Langer 2003, fig. 1C). This expands dorsocranially from the dorsocranial margin of the acetabulum, bending cranially and laterally towards the tip of the ala. Cranioventral to that, the laterocranial surface of the ala bears a dorsoventrally elongated excavation ('praf', in Fig. 8F), possibly equivalent to the preacetabular fossa (Hutchinson 2001a). The long postacetabular ala of $G$. candelariensis corresponds to nearly half the length of the ilium (UFRGS PV0725T). Its obliquely (dorsomedially to ventrolaterally) oriented ventral margin separates the origin of $\mathrm{m}$. iliofemoralis cranialis from the well developed brevis fossa (see Langer \& Benton 2006). The latter is medially buttressed by a vertically oriented sheet of bone, on the medial surface of which the rib of the second sacral vertebra is articulated. The fossa is laterally limited by the 'brevis shelf', which starts as a faint ridge near the acetabulum, but expands caudally to form a lateroventrally projected spine. Its caudal half overlaps the ventral margin of the postacetabular ala, forming the caudal-most part of the ilium. As especially seen in the right side of UFRGS PV0725T, the outer surface of the postacetabular ala bears a craniocaudally elongated rugose area ('ra' in Fig. 8) at its caudal portion, which superficially resembles the inferred attachment area for the iliotibialis and flexor tibialis muscles in Saturnalia tupiniquim (Langer 2003). The caudal margin of the postacetabular ala connects this rugose area to the medial iliac lamina, and has a concave caudal profile in dorsolateral view.

As seen in UFRGS PV0725T, the long pubic peduncle of G. candelariensis bears a mediolaterally expanded and cranioventrally facing pubic articulation. The acetabulum is craniocaudally elongated (about twice longer than deep), and bears a strong supra-acetabular crest, which is especially protruding at the dorsocranial margin of the acetabulum. In the holotype, the lateral expansion of the crest is sub-equal to the acetabular depth. The cranial portion of the crest, which extends along the pubic peduncle, is incomplete in all available specimens. Indeed, it is indistinct from the sharp cranial margin of the acetabulum, both of which reach the pubic articulation (Fig. $8 \mathrm{E}$ ). Caudal to that, the crest is somewhat truncated by a small caudodorsal expansion of the acetabulum ('acde' in Fig. 8). Accordingly, it does not follow the contour of that structure; neither extends caudally towards the postacetabular ala. The iliac portion of the acetabular medial wall is not extensively perforated, but a small gap may be present above the puboischial junction. The ventral margin of the wall is not complete in any specimen of $G$. candelariensis, but appears to have had a sigmoid outline, i.e., slightly concave at the caudal portion and straight to convex cranially. The ischiadic peduncle is primarily composed of a tapering column that extends caudoventrally from a smooth surface that separates the supraacetabular crest from the 'brevis shelf', forming the cranial margin of a surface somewhat continuous to the brevis fossa. Cranial to that, the antitrochanter enters the acetabulum, occupying about one fourth of its craniocaudal length. In UFRGS PV0725T, it is formed by an ovoid protruding area, caudoventrally bounded by the oblique ischiadic articulation. The outer surface of the antitrochanter can be distinguished from the rest of the acetabulum for its distinctive texture (smoother in the holotype) and more cranial, rather than strictly lateral, orientation. The right ilium of the holotype has a deep elongated groove ('ag' in Fig. 8A) that extends dorsally from the ventral margin of the wall, excavating the cranial part of the antitrochanter. Although this is enhanced by overpreparation, the presence of an equivalent (although much shallower and less dorsally extensive) groove in the left ilium, as well as in UFRGS PV0725T (cranial to the protruding part of the antitrochanter) suggests that it corresponds to a genuine anatomical element. Such a groove is unknown in other basal dinosaurs and might represent an autapomorphy of G. candelariensis.

2.3.2. Pubis. Data from the paired pubes of UFRGS PV0725T do not support a more vertical arrangement of the bones as reconstructed by Langer (2004, fig. 2.6H) based on the holotype of $G$. candelariensis. In fact, the ventral part of the proximal articulation of the more complete (right) pubis of the holotype is missing (Fig. 9B), hampering the definition of its orientation. Besides, the caudal kink of its shaft is absent both in the left pubis and in UFRGS PV0725T. In both specimens, the robust pubic body supports a short laminar obturator plate 
(A)
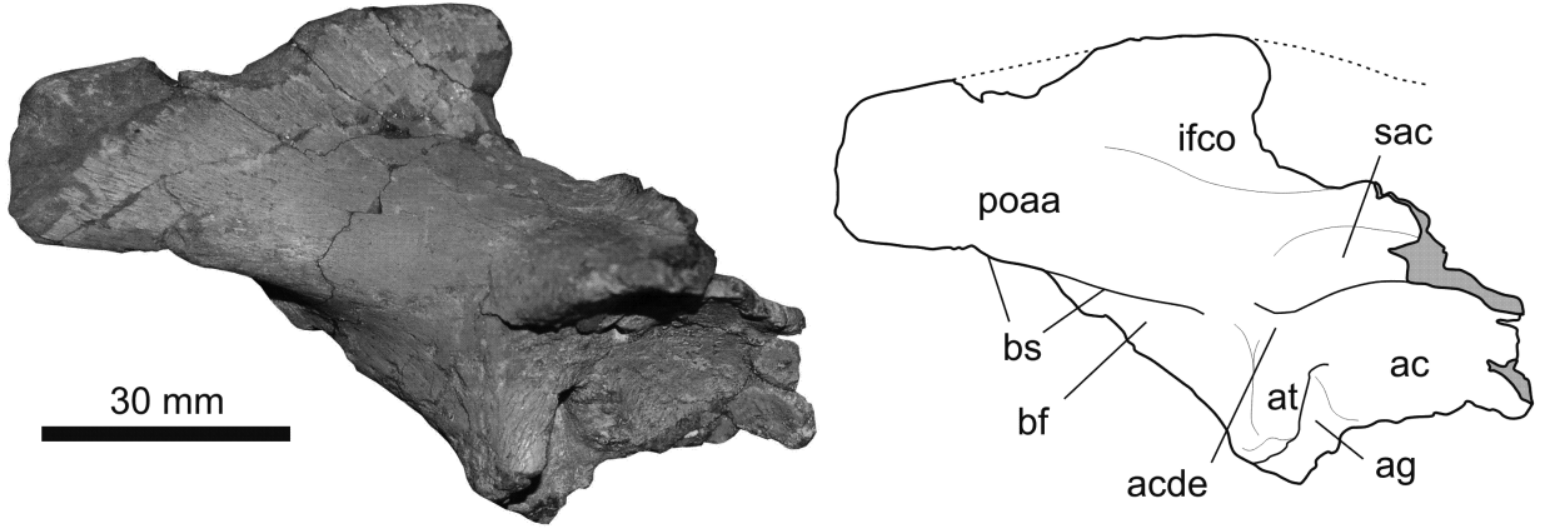

(B)

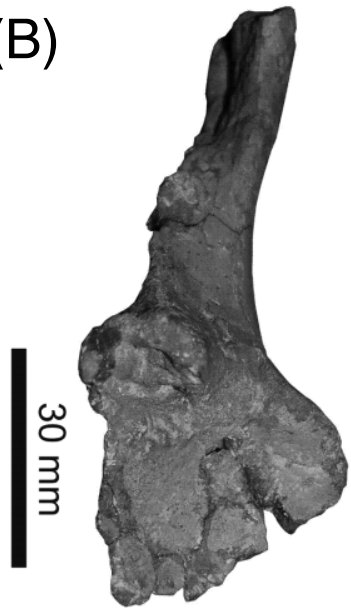

(D)

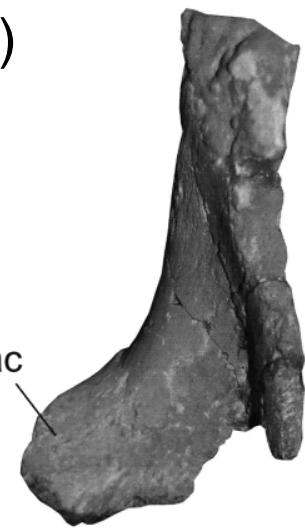

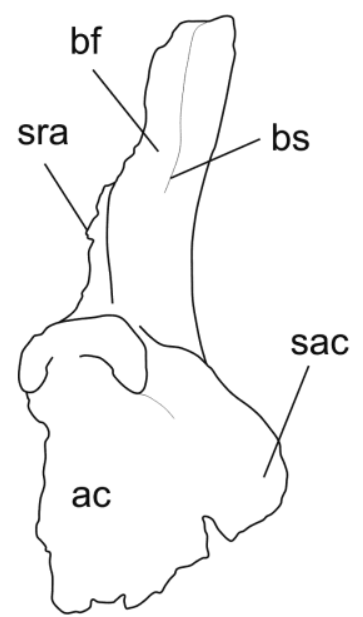

(C)
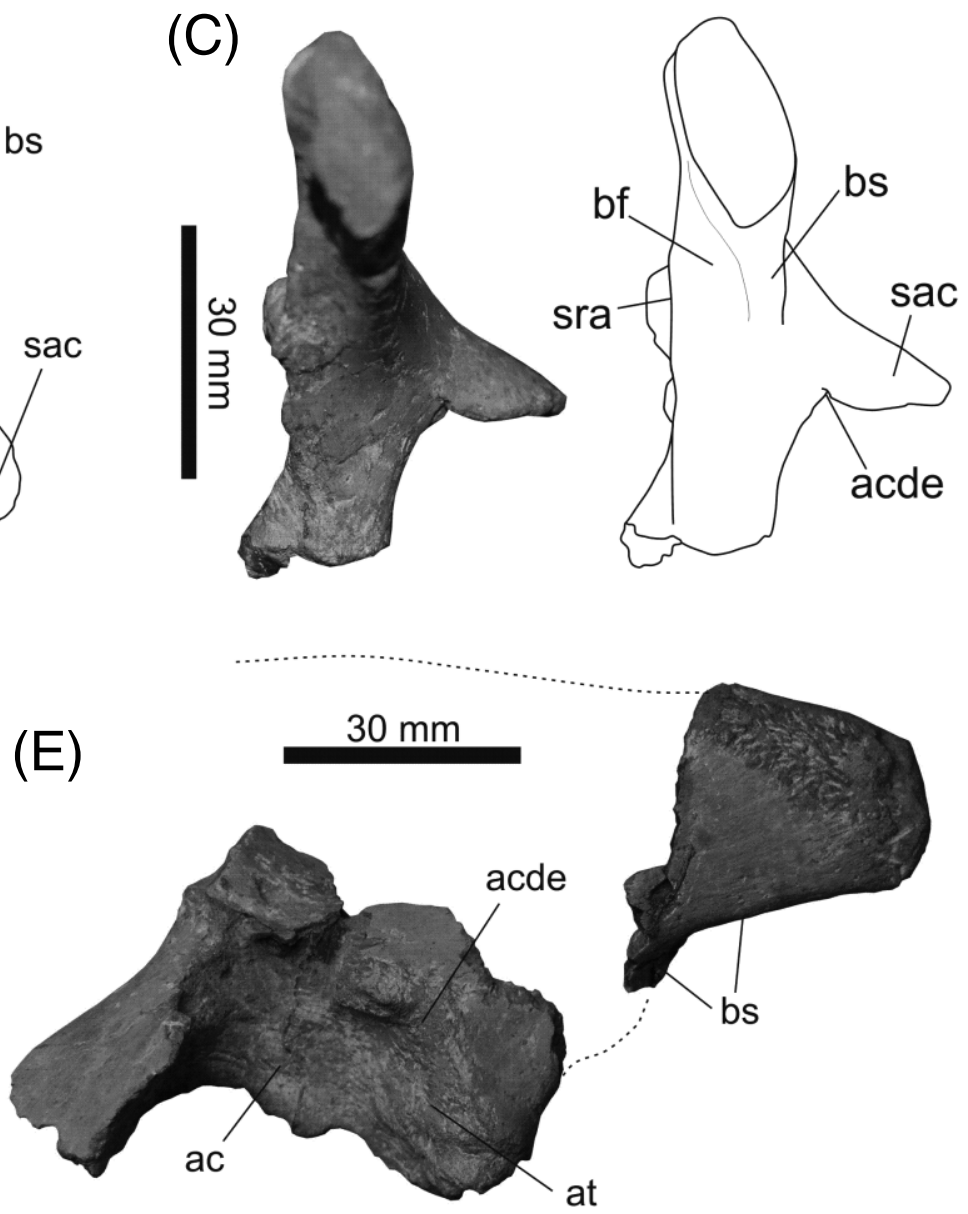

(F)

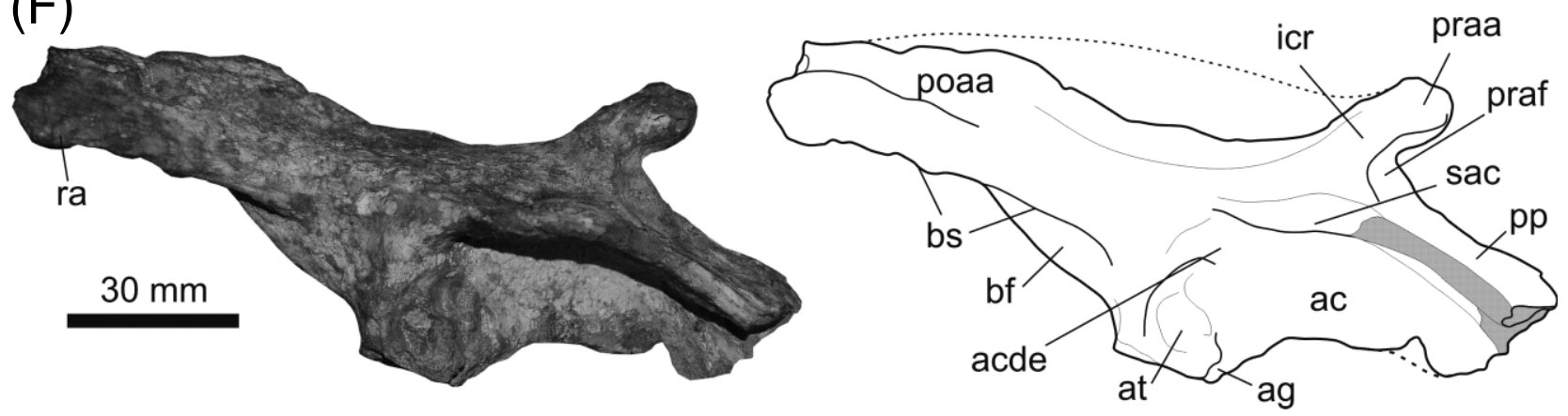

Figure 8 Guaibasaurus candelariensis, photographs and outline drawings of the ilia: (A-D) right ilium of MCN PV2355: (A) lateral view; (B) ventral view; (C) caudal view; (D) dorsal view; (E) left ilium of MCN PV2355 (holotype) in lateral view; (F) right ilium of UFRGS PV0725T in lateral view. Abbreviations: ac=acetabulum; acde=caudodorsal expansion of the acetabulum; $\mathrm{ag}=$ antitrochanteric groove; at=antitrochanter; $\mathrm{bf}=$ brevis fossa; $b$ s = brevis shelf; $i c r=i l i a c$ preacetabular ridge; ifco=iliofemoralis cranialis origin; poaa $=i l i a c$ postacetabular ala; $p p=i l i a c$ pubic peduncle; praa=iliac preacetabular ala; $p r a f=i l i a c$ preacetabular fossa; $r a=$ rugose area; $\mathrm{sac}=$ supracetabular crest; $\mathrm{sra}=$ articulation of second sacral rib. Broken areas highlighted in grey; dotted lines represent reconstructed parts. 

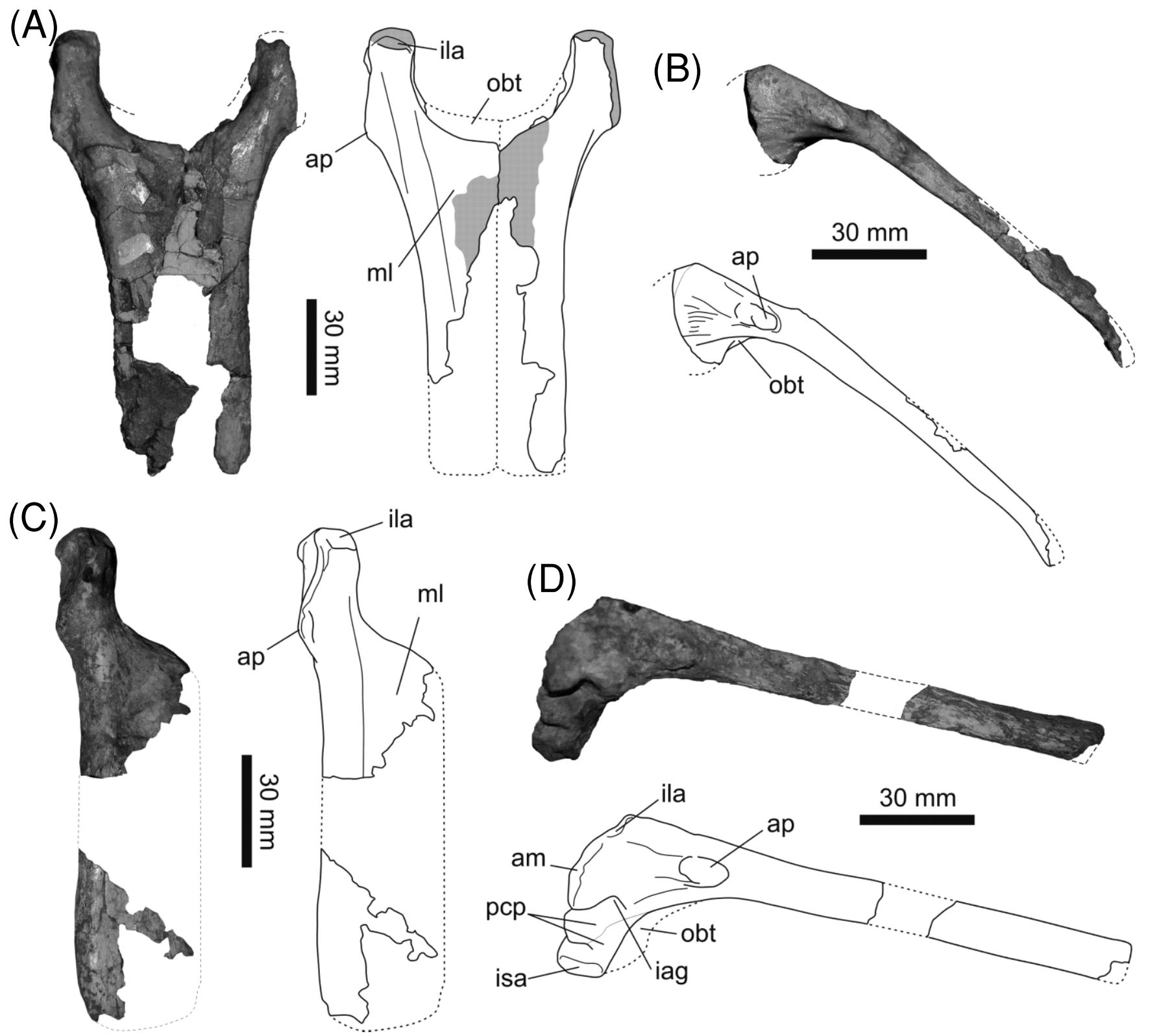

Figure 9 Guaibasaurus candelariensis, photographs and outline drawings of the pubes: (A-B) MCN PV2355: (A) paired pubes in cranial view; (B) right pubis in lateral view; (C-D) right pubis of UFRGS PV0725T: (C) cranial view; (D) lateral view. Abbreviations: am=acetabular margin; ap=ambiens process; iag=ischio-acetabular groove; ila=iliac articulation; isa=ischiadic articulation; $\mathrm{ml}=$ medial lamina; $\mathrm{obt}=$ obturator plate; $\mathrm{pcp}=$ caudal process of the pubis. Broken areas highlighted in grey; dotted lines represent reconstructed parts.

that occupies less than $30 \%$ of the pubic length. This is not completely preserved in any specimen, lacking evidence for any 'apertures', e.g., pubic/obturator foramens. The proximal pubis bears a well developed ischio-acetabular groove that excavates the lateral surface of the bone, but does not pierce its medial surface (see also Nesbitt et al. 2007). It separates the main part of the pubic body from its caudal process (Fig. 9D; see Langer 2003), which is not preserved in the holotype. The lateral surface of the latter bears a marked ridge, continuous to the lateroventral corner of the pubic shaft, which separates the floor of the ischio-acetabular groove from a ventral surface leading to the obturator plate. Caudal to that, a transverse groove crosses the caudal margin of the process, which articulates to the ischium. Dorsocranial to the ischio-acetabular groove, the blunt proximal margin of the pubis forms both the cranioventral corner of the acetabulum, which lacks a medial wall, and the iliac articulation. The latter is connected to the well developed 'ambiens process', i.e. 'pubic tubercle' (sensu Hutchinson 2001a), by a broad, but faint ridge that might be also related to the origin of M. ambiens (Langer 2003). Additionally, in the holotype, a series of longitudinal striations occupies the lateral surface of the pubic body.

The elongated pubic shaft of G. candelariensis is composed of a robust 'rod-like' lateral margin, with a thin medial lamina that expands from its dorsal margin. The latter is a distal continuation of the obturator plate, mediodorsally twisted and aligned orthogonal to the sagittal plane. Although the distal end of the pubis is not completely preserved in any specimen, the lamina seems to approach the distal tip of the bone, since no well developed bevel (Novas 1993) is seen. In UFRGS PV0725T, the length and shape of the right pubic shaft was reconstructed (Fig. 9C) based on the impression it left in the bearing rock. In the holotype, the pair of pubic shafts is markedly constricted distal to its proximal third, in a slightly theropod fashion (Sereno 1999; Carpenter et al. 2005), but retain sub-parallel lateral margins (Fig. 9). On the contrary, in UFRGS PV0725T, the pubes are only slightly constricted distal to the 'pubic tubercle'. As a consequence, the distal ends 

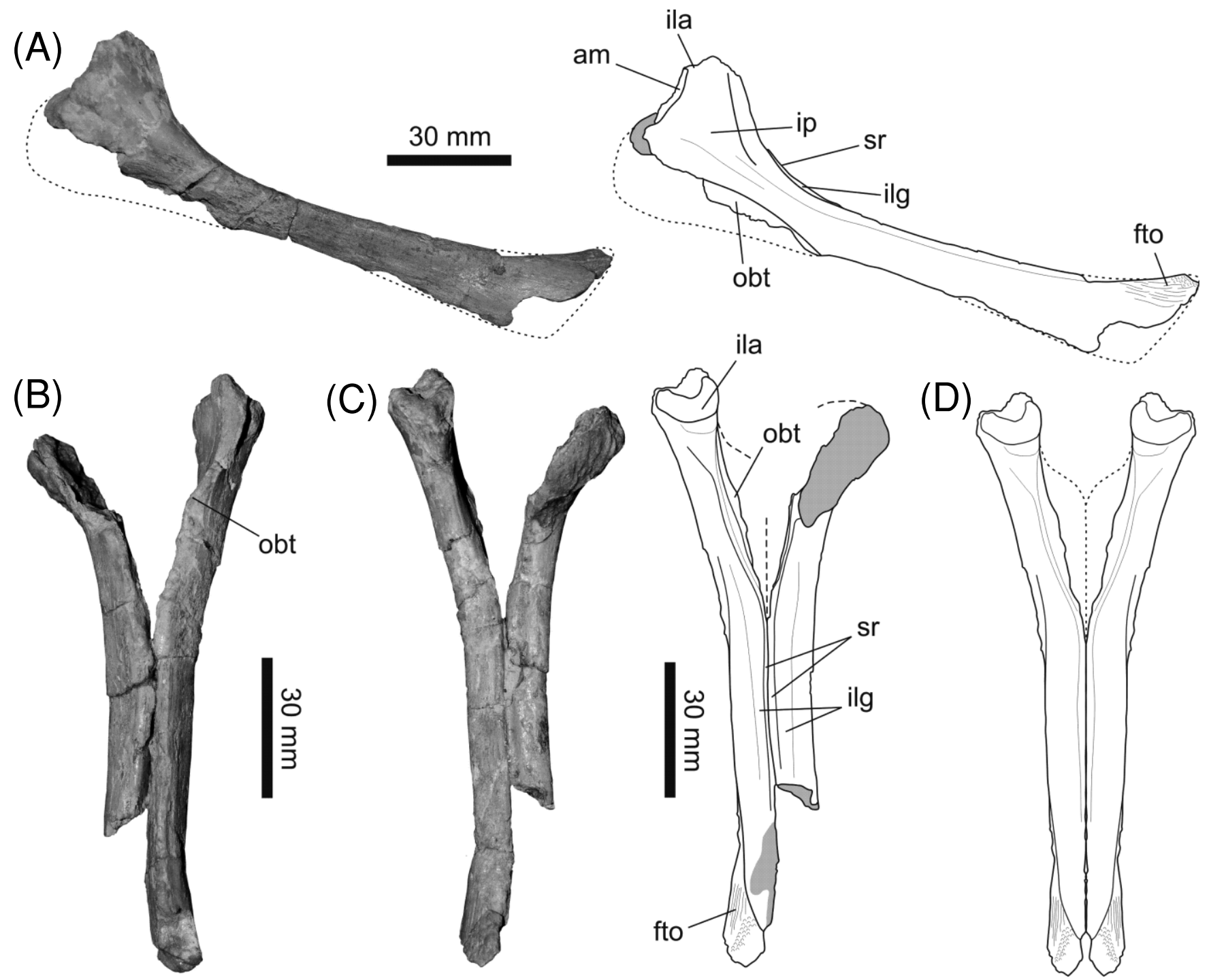

Figure 10 Guaibasaurus candelariensis (MCN PV2355), photographs and outline drawings of the ischia: (A) left ischium in lateral view; (B) ischial pair in ventral view; (C) ischial pair in dorsal view; (D) reconstructed ischial pair in dorsal view. Abbreviations: $\mathrm{am}=$ acetabular margin; fto =origin of $\mathrm{m}$. flexor tibialis; ila=iliac articulation; ilg=ischiadic longitudinal groove; ip=iliac pedicel; $\mathrm{obt}=\mathrm{obturator}$ plate; $\mathrm{sr}=$ symphysial ridge. Broken areas highlighted in grey; dotted lines represent reconstructed parts.

of the bones form a kind of 'apron', as typical of basal sauropodomorphs (Yates 2003a). In addition, although the specimens do not have well preserved distal pubes, neither of them shows evidence of the dorsoventral bulging typical of basal saurischians (Langer \& Benton 2006).

2.3.3. Ischium. Both ischia of the holotype are only partially preserved, while the incompletely exposed pair of UFRGS PV0725T has its proximal portion concealed below the ilia, and the ventral margin of the bones embedded in matrix. Nonetheless, their length can be estimated as about $90 \%$ of the respective pubes. The deep proximal body of the best preserved left ischium of the holotype has strongly abraded proximal margins. Yet, it is still possible to recognise the acetabular margin, which apparently lacks a medial wall, and a short iliac articulation. Proximal to the symphysis, the ischium is sigmoidal in dorsal and ventral views; laterally convex and medially concave at the body, but laterally concave and medially convex more distally, at the point where the shafts converge medially. The obturator plate is not complete in any available specimen, but seems restricted to a faint lamina that does not extend onto the elongated symphysis. The latter is formed by the rod-like distal portion of the shafts, corresponding to more than $60 \%$ of the length of the ischium.
The proximal portion of the body of the ischium bears a blunt ridge ('iliac pedicel' of Bonaparte et al. 1999) that extends obliquely along its lateral surface and is continuous to the dorsolateral corner of the shaft. Along most of its length, the shaft has a sub-triangular cross-section, with flat medial (articular), lateroventral, and dorsal surfaces. The latter bears a longitudinal groove ('ilg' in Fig. 10), which is more pronounced in UFRGS PV0725T, and possibly related to the origin of M. ischiofemoralis (Langer 2003). This groove separates the somewhat upturned laterodorsal corner of the shaft from a sharp medial ridge, which starts at the caudal margin of the iliac articulation. It extends along the mediodorsal corner of the proximal half of the shaft, at a point where the longitudinal groove gets broader and shallower. The ridge ('symphyseal ridge' of Bonaparte et al. 1999) forms the dorsal margin of the ischial symphysis, but is more pronounced proximal to that. The paired ischia are lateromedially constricted at their distal quarters, and also dorsally expanded, in a fashion similar to that seen in Saturnalia tupiniquim (Langer 2003). This is coupled with the dorsomedial displacement of the laterodorsal corner of the shafts, which meets its counterpart at the distal end of the bone. As a consequence, the flat dorsal surface of the proximal part of the shaft is hidden, giving place to a single 

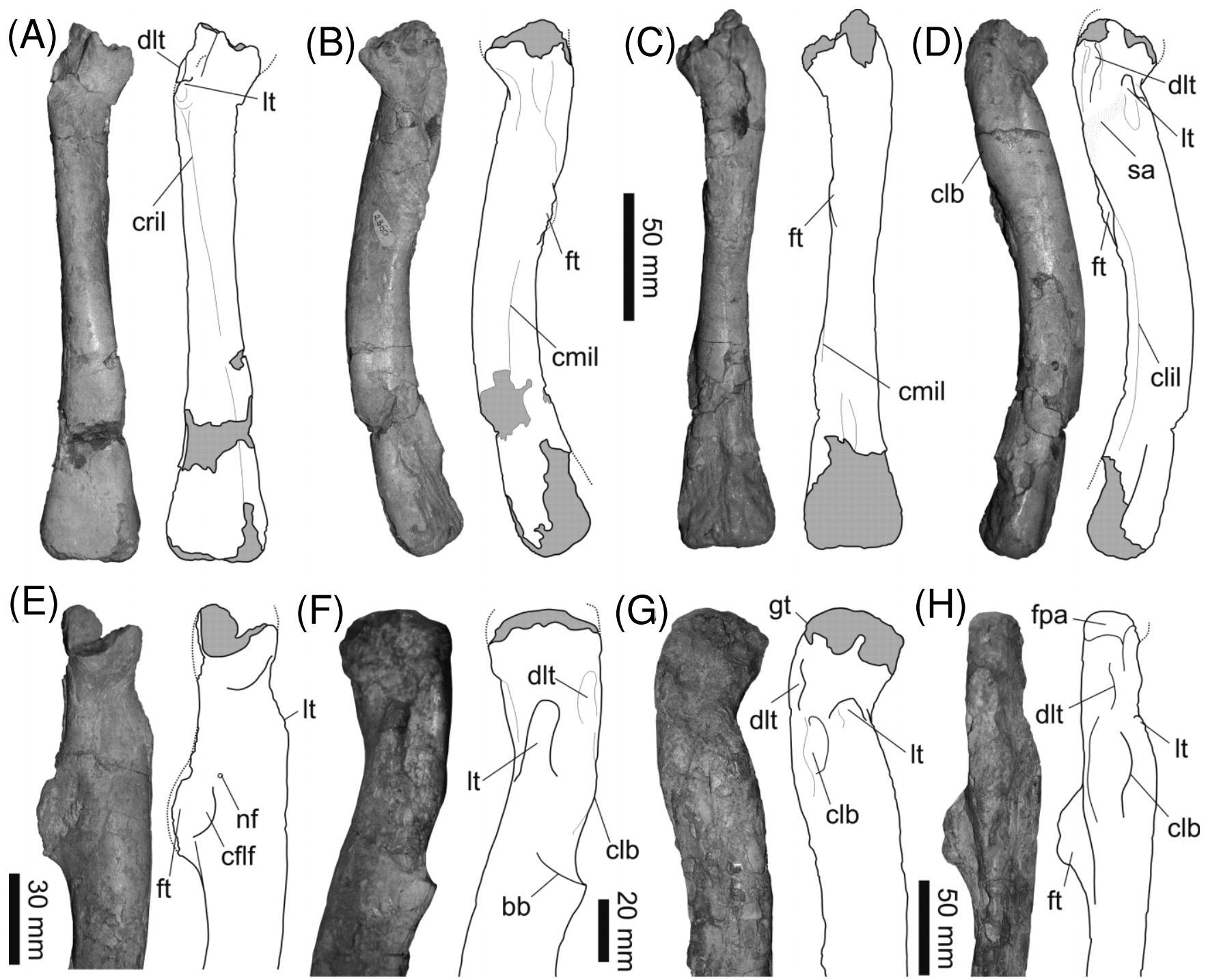

(G)
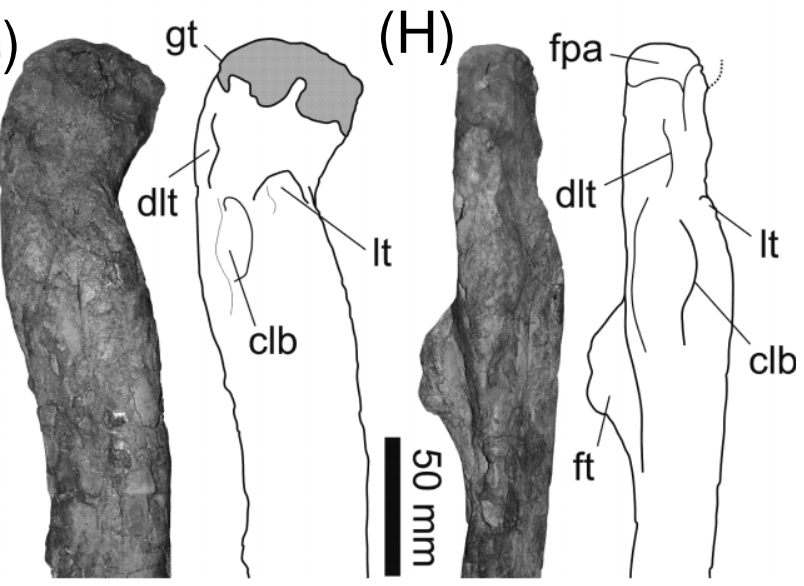

Figure 11 Guaibasaurus candelariensis, photographs and outline drawings of the femora: (A-D) right femur of MCN PV2355: (A) cranial view; (B) medial view; (C) caudal view; (D) lateral view; (E) proximal left femur of MCN PV2355 in medial view; (F) proximal left femur of UFRGS PV0725T in medial view; $(\mathrm{G}-\mathrm{H})$ proximal right femur of UFRGS PV0725T: $(\mathrm{G})$ cranial view; $(\mathrm{H})$ lateral view. Abbreviations: $\mathrm{bb}=$ bone breakage; $\mathrm{cff}=$ caudofemoralis longus fossa; $\mathrm{clb}=$ caudolateral bulge; clil=caudolateral intermuscular line; cmil=caudomedial intermuscular line; cril=cranial intermuscular line; $\mathrm{dlt}=$ dorsolateral trochanter; $\mathrm{fpa}=$ femoral proximal articulation; $\mathrm{ft}=$ fourth trochanter; $\mathrm{gt}=$ 'greater trochanter'; $\mathrm{lt}=$ lesser trochanter; $\mathrm{nf}=$ nutrient foramen; $\mathrm{sa}=$ scarred area. Broken areas highlighted in grey; dotted lines represent reconstructed parts.

dorsal crest. At this point, the paired ischia have an ovoid cross section, each bone bearing flat medial and rounded lateral surfaces. The latter bears rugosities and striations, which might be related to the origins of the caudal branch of M. flexor tibialis internus (Langer 2003). The distal margin of the ischium is not entirely preserved in any specimen, so that its shape is unknown.

2.3.4. Femur. The general preservation of the holotypic femora is better than that of UFRGS PV0725T. The latter specimen was taphonomically affected, resulting in the craniocaudal and lateromedial compression of the left and right bones, respectively. Except for its proximal fifth, which corresponds to the head, the right holotypic femur is cranially and also slightly medially arched. This configuration, along with the inturned head, gives the bone a subtle sigmoidal outline, both craniocaudally and lateromedially (Fig. 11A-D). Because of their fragmentation or concealment within the acetabulum, no femur referred to $G$. candelariensis allows a compressive view of its proximal articulation. Hence, the dimensions of the head given by Bonaparte at al. (1999, p. 100) are not reliable. Yet, based on what is preserved on the right side of the holotype (and on the left side of UFRGS PV0725T), it is possible to infer an angle slightly over $40^{\circ}$ between the long axis of the head and the intercondylar line. The compressed right femur of UFRGS PV0725T does not allow a safe estimation of the inturning of the head, but it is possible to infer that it was not well offset from the shaft. In that specimen (Fig. 11G), the 'greater trochanter' approaches the angular condition, i.e. a nearly straight angle between the proximal articulation and the long axis of the shaft.

G. candelariensis is unique among Triassic dinosaurs in the distribution of trochanters and other muscle attachment areas on the lateral side of the femoral head. The more proximal structure is the 'dorsolateral trochanter' named by Bonaparte et al. (1999), and later recognised in a series of other basal dinosaurs/dinosauromorphs (Langer \& Benton 2006; Ferigolo \& Langer 2007; Nesbitt et al. 2007; Barrett et al. 2008; Bittencourt \& Kellner 2009). It forms a cranially convex, crescent-shaped structure, with a steep proximal margin, on the laterocaudal surface of the bone, as also seen in $S$. tupiniquim (Langer 2003, contra Bonaparte et al. 2007). Craniodistal to that, the lesser trochanter is located at the 
laterocranial margin of the bone. In the holotype, it corresponds to a small proximodistally elongated crest, the distal margin of which merges smoothly onto the femoral shaft. The proximal margin, however, forms a steeper angle, but a cleft is not present. This configuration is also seen in the left femur of UFRGS PV0725T, but the trochanter seems laterocaudally displaced due to the compression of the bone. The lesser trochanter of the right femur (Fig. 11G) is less conspicuous, probably due to the poor preservation of the corresponding part of the bone.

Bonaparte et al. (2007, fig. 8) described a structure extending caudodistally from the lesser trochanter ('bb' in Fig. 11F) in the left femur of UFRGS PV0725T as a trochanteric shelf. Yet, this actually corresponds to an artefact of preservation (breakage), derived from the craniocaudal compression of the bone. The right femur of UFRGS PV0725T, as well as both holotypic elements, completely lack a similar 'structure'. In addition, the better preservation of the bone surface in the holotype allows the recognition of a faintly scarred ('sa' in Fig. 11D) area that extends caudodistally from the lesser trochanter along lateral surface of the femur, reaching its laterocaudal margin. It leads to an inconspicuous bulge of that corner ('clb' in Fig. 11), which is more prominent in UFRGS PV0725T. The whole structure is considered a homologue of the trochanteric shelf.

The fourth trochanter occupies the caudomedial corner of the femur. Measured from its middle portion, the structure is placed $141 \mathrm{~mm}$ from the distal edge of the right holotypic femur (172 $\mathrm{mm}$ in the left femur of UFRGS PV0725T). The element appears symmetrical (Langer \& Benton 2006, p. 341) in the right femur of the holotype (see Bonaparte et al. 1999, fig. 8), but it is incomplete along all its margins. Although also incomplete, the fourth trochanter is better preserved in the left femur, forming a steeper distal angle to the shaft if compared to that of its proximal margin (Fig. 11E). In UFRGS PV0725T, the fourth trochanters of both femora show a sub-trapezoidal profile, with proximal and distal margins forming steep angles to the shaft (Fig. 11H). Yet, the distal corner is more caudally expanded, so that the trochanter can be said to have an asymmetrical (semi-pendant) shape. Both specimens bear the typical depression for the caudofemoral musculature medial to the fourth trochanter. A nutrient foramen (Madsen \& Welles 2000, pl. 21) is seen between the lesser and the fourth trochanter, in the left femur of the holotype (Fig. 11E).

The shafts of both holotypic femora are broader craniocaudally than mediolaterally. The opposite condition measured in the left femur of UFRGS PV0725T is probably due to its craniocaudal compression. The cranial intermuscular line (Langer 2003) starts distal to the lesser trochanter (at the craniolateral margin of the bone) extending transversely along the mid-shaft ('DR' in Bonaparte et al. 1999, fig. 8), and is somewhat continuous to the sharp craniomedial corner of the distal third of the bone, which may represent the medial margin of the origin of $\mathrm{M}$. femorotibialis externus (Hutchinson 2001b; but see Langer 2003). The broken distal edge of the left holotypic femur, which has a transverse breadth of $28 \mathrm{~mm}$, exposes a rather thin cortex (c. $2 \mathrm{~mm}$ ). The distal ends of the femora in all available specimens are badly preserved, and almost no surface details can be observed. The fibular condyle may be slightly more expanded than the medial condyle, but the importance of this character to differentiate basal saurischians seems overestimated by Bonaparte et al. (1999). The distal margin of the femur is relatively broader in UFRGS PV0725T (left side) than in the holotype (right side), but this may be due to the craniocaudal compression of the former element.
2.3.5. Pelvic epipodium. Based on the best preserved bones (from the right side of the holotype and the left side of UFRGS PV0725T) the tibia of G. candelariensis (Figs. 12-14) corresponds to about $85-90 \%$ of the femoral length (Table S7). No articulated proximal end of the tibia is entirely preserved, but an isolated fragment (Fig. 13E-F), lacking the proximal (articular) surface and tentatively associated to the paratype, allows a better understanding of this part of the bone. The cnemial crest is well projected cranially, and accounts for more than $50 \%$ of the maximum transverse breadth of the proximal tibia (20 out of $36 \mathrm{~mm}$ ). It is caudally bound by marked grooves that extend distally along the lateral and medial surfaces of the shaft, the lateral of which is particularly excavated. This produces a proximal outline in which the crest curves laterally. Fibular and internal condyles are equally projected caudally, and separated by a shallow groove, but the fibular condyle is significantly larger. This set of features is roughly replicated in the proximal ends of the tibiae of the holotype (Fig. 12E-F), the cnemial crest of which seems broader (Bonaparte et al. 1999), less pronounced, and bound by subtler longitudinal grooves. Yet, these traits may be enhanced by the incomplete preservation of the condyle area. In the left side, both lateral and medial longitudinal grooves extend for about one fourth of the bone. No detail can be seen of the proximal ends of the tibiae of UFRGS PV0725T.

The tibial shaft of G. candelariensis is nearly straight, and tapers craniocaudally towards its distal end, but the distal end of the tibia is not well preserved enough in any specimen for a detailed inspection of its morphology. These are either partially incomplete, or concealed by the articulations with the fibula and astragalus, but match one another in most recognisable features. The descending process (outer malleolus) is the main attribute of the distal end of the tibia, expanding laterally and distally from the caudal margin of the bone. The proximal edge of the descending process does not merge smoothly into the shaft, but abruptly expands laterally from the caudolateral corner of the distal tibia (Fig. 12C). Cranial to that, the lateral surface of the tibia, facing towards the distal part of the fibula, is slightly concave.

As better seen in the left side of the paratype, the distal end of the tibia is transversally elongated, with nearly straight cranial and caudal margins. The medial margin is also flat, but extends more medially on its cranial portion, and is obliquely oriented. The slightly concave lateral margin is disrupted only on its caudal end by the projection of the descending process. The distal articular surface bears a transverse groove, which separates the descending process from a distally projecting craniomedial corner ('dcc' in Figs 12-13). Accordingly, the flat inclined platform that extends cranially from the descending process in various basal dinosaurs (Novas 1996; Langer 2003) is not present. The distal transverse groove excavates the entire laterodistal corner of the tibia, cranial to the descending process, but tapers medially, excavating the mediodistal corner of the bone only at its caudal portion. This excavation enters the medial surface of the bone forming a notch ('dln' in Figs 12-13), which is comparable to that of various theropods (e.g. Currie \& Zhao 1993; Ezcurra \& Novas 2007). In UFRGS PV0725T, the angle between the medial and caudal surfaces of the distal end of the tibia seems less acute than in the paratype, but this may be due to its compression.

Although present, the fibulae are incomplete in all specimens of $G$. candelariensis. This is especially the case of the proximal and distal ends of the bone, which are either fragmentary or concealed by other skeletal elements. The proximal end is only partially seen in the right side of the holotype, where it shows the typical transverse compression, flat medially, and laterally convex. This compression extends long the 


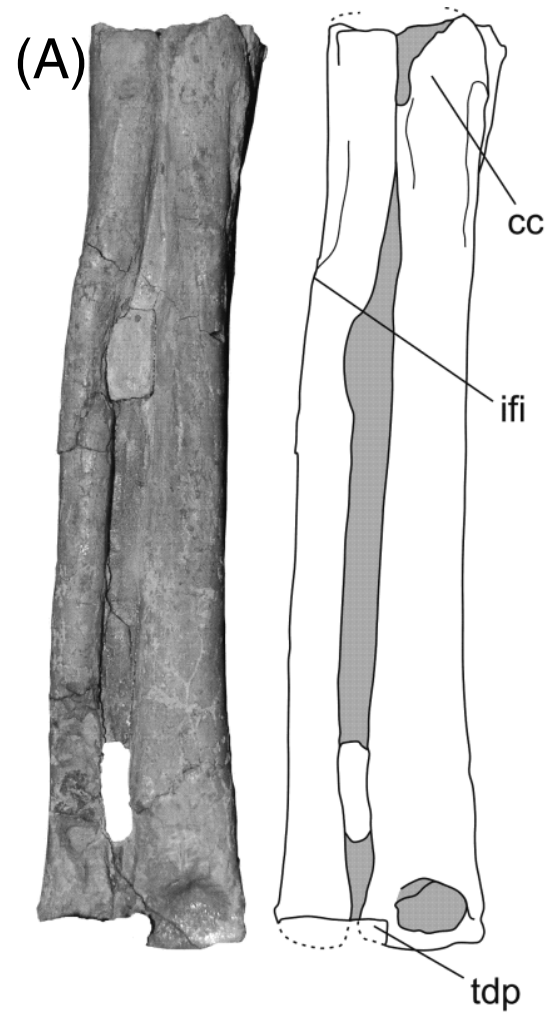

(B)

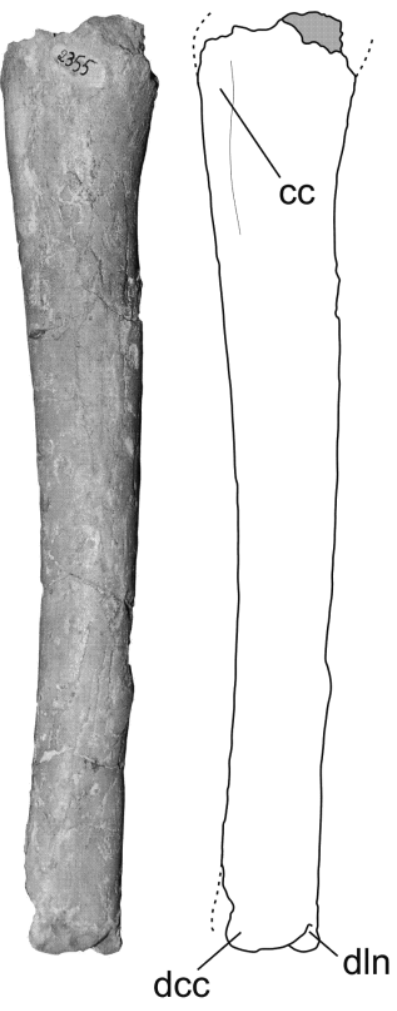

(C)

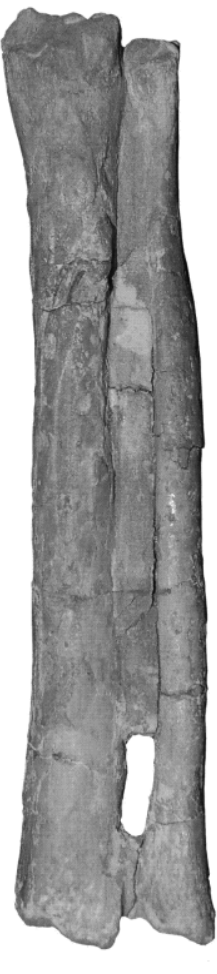

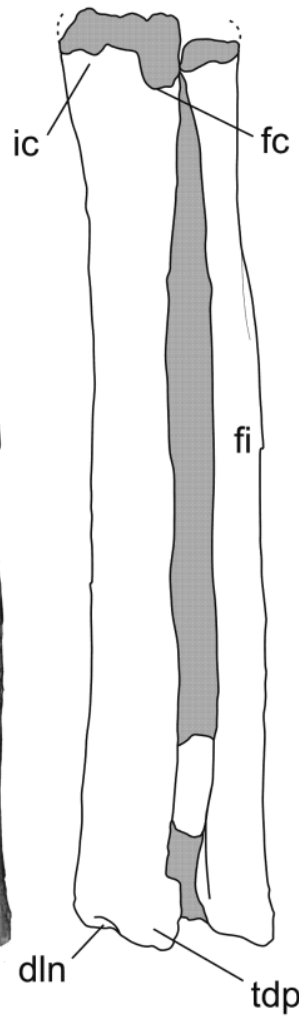

(D)

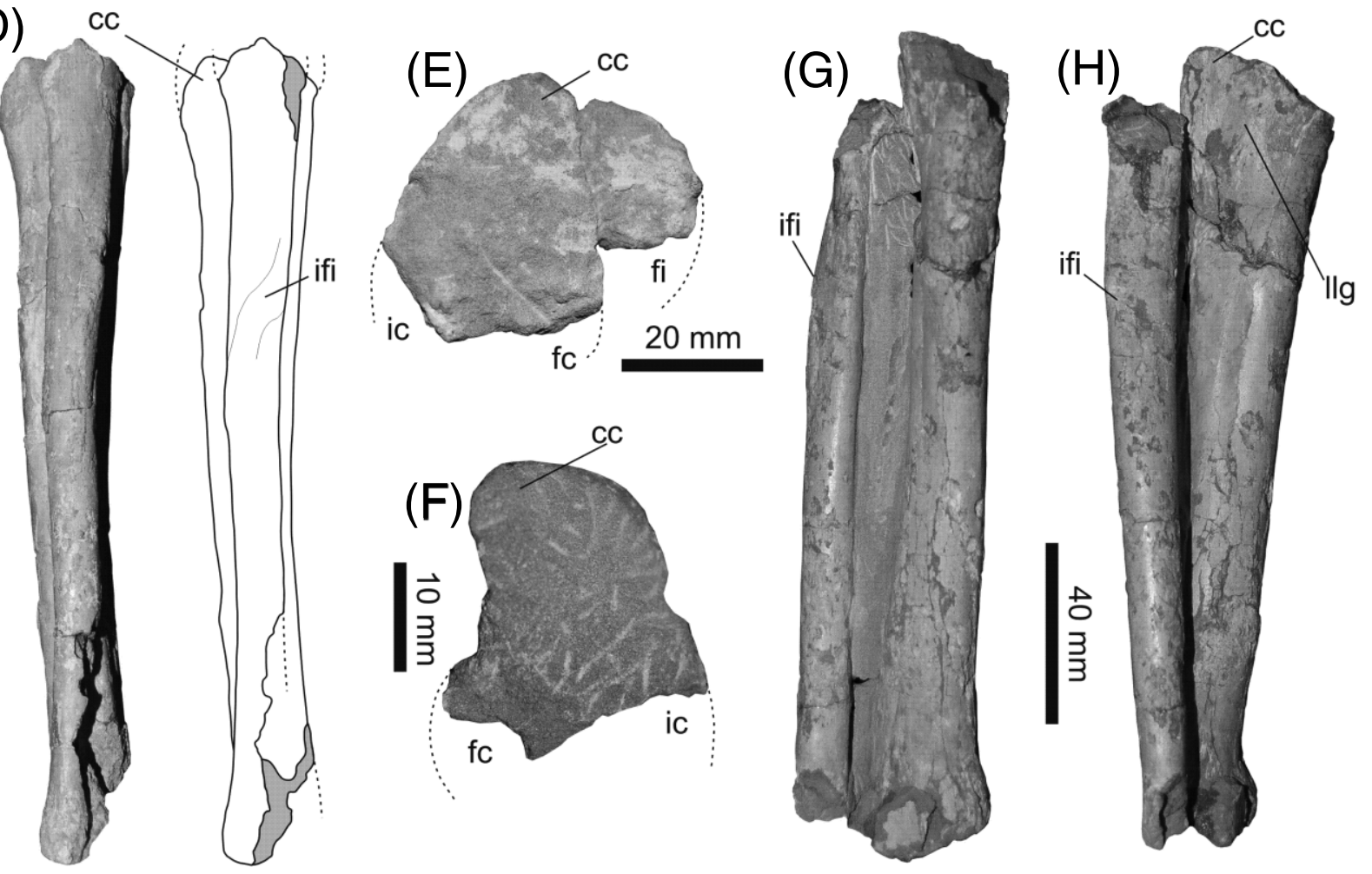

Figure 12 Guaibasaurus candelariensis (MCN PV2355), photographs and outline drawings of the epipodium: (A-E) right epipodium: (A) cranial view; (B) medial view; (C) caudal view; (D) lateral view; (E) proximal view; (F) left tibia in proximal view; $(\mathrm{G}-\mathrm{H})$ left epipodium: $(\mathrm{G})$ caudal view; $(\mathrm{H})$ lateral view. Abbreviations: $\mathrm{cc}=$ cnemial crest; $\mathrm{dcc}=$ distal craniomedial corner; $\mathrm{dln}=$ laterodistal notch; $\mathrm{fc}=$ fibular condyle; $\mathrm{f}=$ fibula; ic=internal condyle; ifi=insertion of $\mathrm{m}$. iliofibularis; $1 \mathrm{lg}=$ lateral longitudinal groove; $\mathrm{tdp}=$ tibial descending process. Broken areas highlighted in grey; dotted lines represent reconstructed parts.

proximal half of the shaft, as also seen in other specimens. At this point the fibula bears its more conspicuous feature, a lateral kink of the shaft accompanied by a faint ridge ('ifi' in Figs 12-13). This is more marked on the cranial margin of the bone, but extends distally along its lateral surface as a subtle border, and cranially bounds a flat caudolaterally facing area. This corresponds to the insertion area of $\mathrm{m}$. iliotibialis, as described for many dinosaurs (Welles 1984; Novas 1993, Carrano \& Hutchinson 2002; Langer 2003; Carrano 2007). The distal end of the fibula is broader craniocaudally, flat medially and convex laterally, but no further detail is noticeable.

2.3.6. Tarsus. The tarsus of $G$. candelariensis is better preserved in the paratype, and rather incomplete in the other specimens. The proximal series is nearly complete in the 


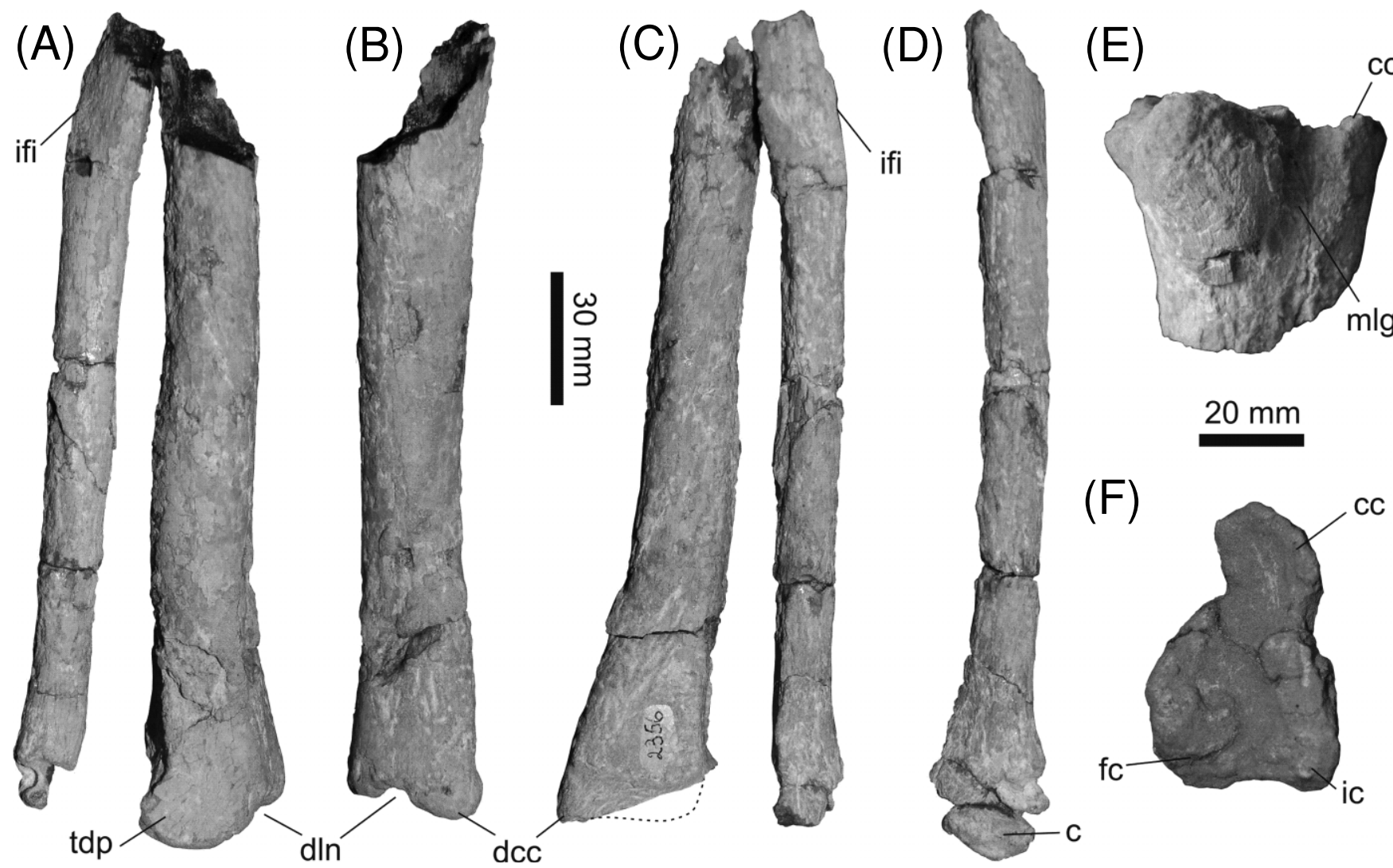

Figure 13 Guaibasaurus candelariensis (MCN PV2356), photographs of the left epipodium and calcaneum: (A-D) Articulated distal 2/3 of epipodium and calcaneum: (A) tibia and fibula in caudal view; (B) tibia in medial view; (C) tibia and fibula in cranial view; (D) fibula and calcaneum in lateral view; (E-F) Proximal portion of tibia: (E) medial view; (F) proximal view. Abbreviations: $\mathrm{c}=$ calcaneum; $\mathrm{cc}=$ cnemial crest; $\mathrm{dcc}=$ distal craniomedial corner; $\mathrm{dln}=$ laterodistal notch; $\mathrm{fc}=$ fibular condyle; ic=internal condyle; ifi=insertion of $\mathrm{m}$. iliofibularis; $\mathrm{mlg}=$ medial longitudinal groove; $\mathrm{tdp}=$ tibial descending process. Dotted lines in $(\mathrm{C})$ represent the reconstructed descending process of the tibia, which is hidden behind the tarsal bones.

paratype (which serves as the base for this description), badly preserved and partially covered by matrix and other bones in both sides of UFRGS PV0725T, and fragmented beyond proper recognition in the right side of the holotype. The pair of distal tarsals is available in the paratype, while a bone element cranial to the left calcaneum of UFRGS PV0725T may represent the lateral distal tarsal.

The main astragalar body is proximodistally flattened and transversally elongated, while a well developed ascending process emanates proximally form its craniolateral portion. The distal corners of the bone are rounded, while those from its proximal surface form more acute angles, which surround the articular facets for the epipodium. The astragalus of the paratype is somewhat deformed by pressure inflicted towards the craniodistal surface of the bone. Nonetheless, it is possible to see that the distal surface of the bone ('ads' in Fig. 14B) has a reduced craniocaudal expression, so that the cranial and caudal surfaces ('acrs' and 'acs' in Fig. 14B) are somewhat distally directed, and the bone is 'cuneiform' in lateral and medial profiles. This set of unique features is also present in the left ankle of UFRGS PV0725T. The medial astragalar margin of the paratype is missing (particularly the caudal corner), possibly due to over preparation. This margin is also poorly preserved in left tarsus of UFRGS PV0725T (Fig. 14H), but it is craniocaudally broader than the lateral margin, and forms a typical acute angle to the cranial margin. In addition, the astragalus of $G$. candelariensis is concave, both cranially and distally.

As seen in the paratype, the proximal surface of the astragalus is composed by the ascending process, as well as by a smaller lateral and a larger medial articular basins, which are separated by a crest ('cr' in Fig 14C) extending caudomedially from the ascending process. The former receives the tibial outer malleolus (descending process), which caudally overlaps the astragalar ascending process, while most of the distal tibia articulates to the larger medial basin. The fibular articulation is restricted to the lateral surface of the ascending process (' $\mathrm{fa}$ ' in Fig. 14D) and to a proximally facing facet lateral to that (' $\mathrm{fa}$ ' in Fig. 14C, E), which corresponds to the proximal surface of the laterocranial process of the astragalus. The ascending process is not bound by a well developed cranial platform ('acrp' in Langer 2003, fig. 6A), but bears a clear furrow on that surface. The broken ascending process of the right astragalus of UFRGS PV0725T reveals its pyramidal shape and sub-triangular base, with lateral, craniomedial and caudomedial corners. These define a free craniolateral surface, and medial and caudolateral surfaces, which respectively bound the 'large basin' for the articulation of the medial portion of the distal end of the tibia and the fibular plus the outer malleolus articular surfaces (Figs 14E, G). In the paratype, it is possible to see that the apex of the ascending process is lateromedially compressed and clockwise rotated (as seen in proximal view) relative to its basis. Hence, it bears a small free cranial surface, and larger lateral and caudomedial surfaces, which receive the fibula and tibia, respectively.

The astragalus has a well expanded laterocranial process, the distal surface of which bears a crescent-shaped depression for the articulation of the calcaneum. This is caudally bound by another depression ('alvd' in Langer 2003, fig. 6), which is better seen as a transverse groove at the caudal surface of the 
bone ('cg' in Fig. 14H-I). The caudal surface is proximodistally broader at the medial part of the bone, while the lateral portion is depressed for the articulation of the descending process of the tibia. More medially the astragalar caudoproximal corner bears a proximal expansion ('acc' in Fig. 14A, I; 'tg' in Nesbitt \& Chatterjee 2008, fig. 8) at its mid-length (seen both in the paratype and the left side of UFRGS PV0725T) and a proximally expanded medial corner ('cmb' in Fig. 14I), which fits to a corresponding slot ('dln' in Figs 12-14) at the distal surface of the tibia (preserved only in UFRGS PV0725T). The former ('acc') differs from the 'posterior ascending process' of lagerpetids (Sereno \& Arcucci 1993; Nesbitt et al. 2009c), which is much more elongated and positioned near the lateral margin of the astragalus.

As seen in the paratype, the calcaneum of G. candelariensis has a sub-triangular distal profile, with two well developed medial processes, and the calcaneal tuber. Despite the lateral projection of the latter structure, the entire bone is broader craniocaudally than mediolaterally. The astragalar articulation is restricted to the concave medial surface of the calcaneum formed by the two medial processes. This facet is somewhat proximally oriented, with the processes expanding slightly below the astragalus. The caudal of these has a concave proximal surface, which receives the lateral tip of the tibial descending process ('dpa' Fig. 14E). Craniolateral to that, the remaining proximal surface of the calcaneum forms a caudolaterally to craniomedially elongated fibular articulation, which is convex along its laterocranial margin (Fig. 13D). The corresponding (laterocranial) surface of the bone is especially deep caudally, near the calcaneal tuber, and bears a transverse groove ('lg' in Fig. 14F). The proximal surface of the right calcaneum of UFRGS PV0725T is exposed on its caudal portion (Fig. 14G). This reveals the inferred tibial articulation facet on the caudomedial corner of the bone, and a fibular articulation extending cranial to that.

The paratype has the medial distal tarsal in its original position, capping the proximal articulation of metatarsals II and III. Yet, given the poor preservation of bone surfaces, the trapezoidal outline depicted in Figure $15 \mathrm{~F}$ does not represent an accurate estimate of its overall shape. Its articulation to the lateral distal tarsal is nearly flat, but oblique, so that the latter expands caudal to, and slightly below (especially on the caudal portion of the joint) the former. As in other saurischians (Novas 1993; Langer 2003; Plateosaurus, GPIT 'skelett 2'), the lateral distal tarsal of $G$. candelariensis has a sub-triangular outline, with a concave surface lateral to a pointed cranial projection and a slightly convex caudal margin. The bone is proximally flat, but has a more rounded distal surface. Its craniodistal portion receives the proximal margin of metatarsal $\mathrm{IV}$, while metatarsal $\mathrm{V}$ fits to an axially elongated depression ('ldtg' in Fig. 15A) on the caudal surface of the bone. The lateral distal tarsal also touches metatarsal III via its medial corner, right below the articulation for the medial distal tarsal. The proximodistal expression of the lateral distal tarsal is not even throughout its extension. The bone is thinner on its free lateral margin, but its mediocaudal corner retains the distally expanding heel ('ldth' in Fig. 15A, E) of basal dinosauromorphs (Novas 1996) medial to the articulation for metatarsal V.

2.3.7. Pes. As preserved in the paratype (Fig. 16A-B), metatarsal I is significantly shorter than the three central metatarsals. The bone was preserved displaced from its original position, and it is unclear if it reached the level of the tarsus, as inferred based on the other specimens of G. candelariensis. Its proximal portion is lateromedially compressed (Table S9), indicating that it was apressed towards the flat medial surface of metatarsal II. This is also seen in the holotype (Fig. 15B-D), whereas the proximal part of the bone seems to overlap metatarsal II cranially in the left side of UFRGS PV0725T. In the paratype, the distal end of metatarsal I lacks the medial condyle, hampering its comparison to the preserved lateral condyle, but these seem of similar size, with the medial slightly more projected distally in the holotype. The paratype preserves a shallow extensor pit, and a well developed collateral pit in the lateral condyle. As also seen in the paratype, contra Bonaparte et al. (2007), metatarsal II is the shortest of the three central elements, a length relation that can not be safely established based on the holotype. The three weight-bearing metatarsals show a pattern of partial overlap of their proximal portions (Figs 15D, 16B, D). Metatarsal III covers metatarsal IV cranially, and metatarsal II overlaps the central element.

The proximal portion of metatarsal II is incomplete in the paratype, but its flattened, slightly excavated, cranial margin gives that part of the bone a sub-quadrangular cross section. The distal part of the bone is slightly curved medially, and the medial condyle is larger and more distally projected than the lateral. This seems to be also the case in the rather fragmentary right foot of the holotype, but both condyles are equally developed in its left side. Shallow extensor and deeper collateral (Fig. 16B) pits are present. Metatarsal III of the paratype is incomplete both proximally and distally, so that its total length cannot be established. Yet, the distal end is preserved as an isolated piece, showing equally developed medial and lateral condyles, the medial collateral pit, and an inconspicuous extensor pit. On the contrary, the right side of the holotype shows metatarsal III with a slightly more distally expanded medial condyle.

Metatarsal IV has a cranially flat proximal portion (Figs 15, $16 \mathrm{~B})$. In the paratype, it is possible to recognise a craniomedial to caudolateral compression and an excavation on the latter surface for reception of metatarsal V. The distal part of the bone is well preserved, both in the paratype and in the right side of the holotype. It is laterally curved, and its articulation is clearly asymmetrical, with a larger medial condyle. This produces a sub-triangular distal outline, with flattened medial, plantar and laterodorsal surfaces, and a reduced dorsal margin. Collateral and extensor pits are not evident, partially due to the poor preservation of the bone surfaces. The much reduced metatarsal $\mathrm{V}$ fits caudolateral to metatarsal IV. Its long axis is slightly curved (cranially concave and caudally convex) and bears a longitudinal groove on its lateral surface. Although laterally incomplete, the proximal portion of metatarsal V is better seen in the paratype. It is clearly expanded, especially on its caudomedial portion (Fig. 15E), which is bound laterally (on the caudal surface of the bone) by a longitudinal groove ('lgr' Fig. 15E). The bone tapers lateromedially towards its distal end, terminating on a slightly craniocaudally elongated tip. The caudolateral corner of the proximal portion is continuous to a longitudinal ridge that extends distally and traverses the caudal surface of the bone, reaching the caudomedial corner of the distal tip.

The paratype preserves (including unguals) two phalanges in digit I, three in digit II, four in digit III and five in digit IV. There is no evidence of a different phalangeal formula, either in the holotype or in UFRGS PV0725T. No vestige of phalanges was preserved in the fifth digit of either the paratype or the right foot of the holotype, which is still imbedded in the bearing rock. Hence, G. candelariensis is assumed to lack those elements. The first phalanx is always the longest non-ungual element of each digit, but their length in relation to the unguals is difficult to establish, due to the incomplete preservation of the latter elements. These are slightly curved, and reconstructed as non-raptorial (Fig. 17). Collateral and shallow extensor pits are inferred to occur in all non-ungual phalanges 
(A)

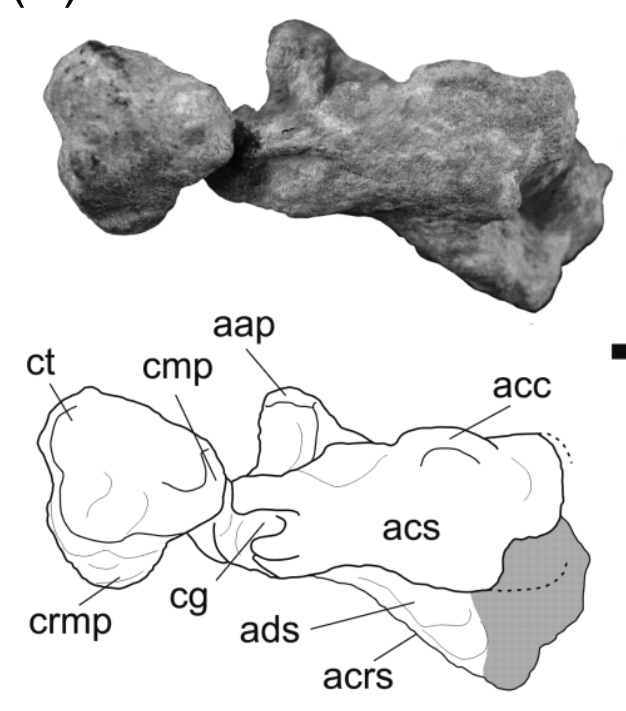

(D)
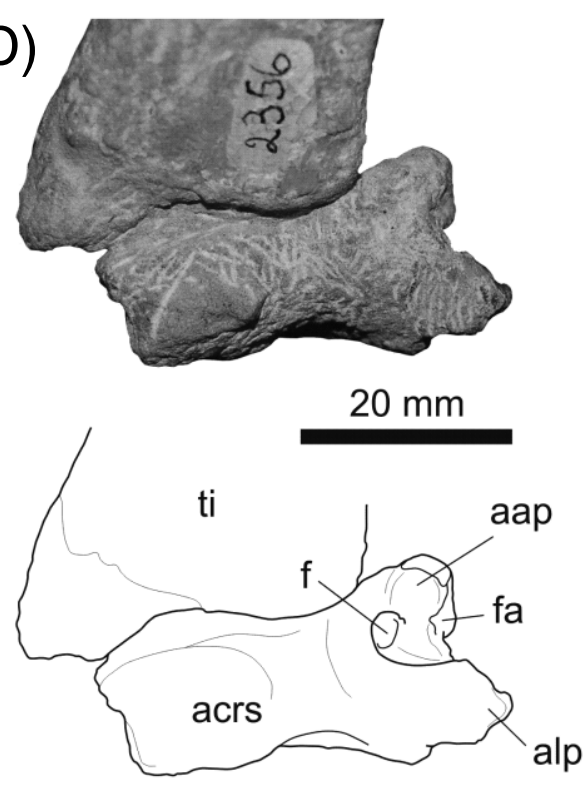

(G)

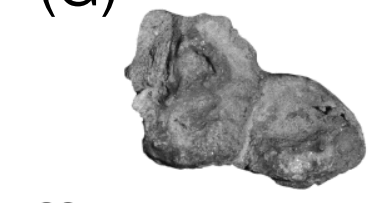

$30 \mathrm{~mm}$

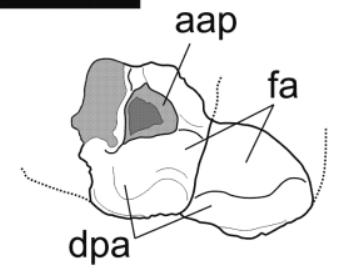

(H)
(B)

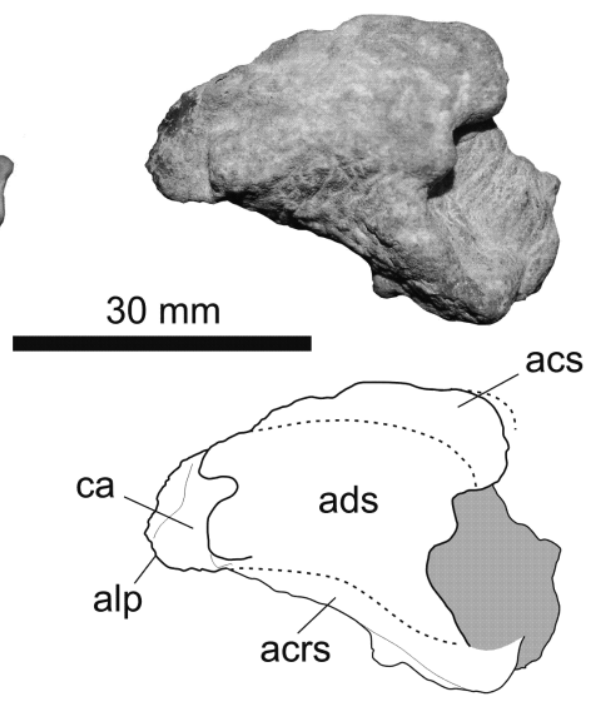

(E)
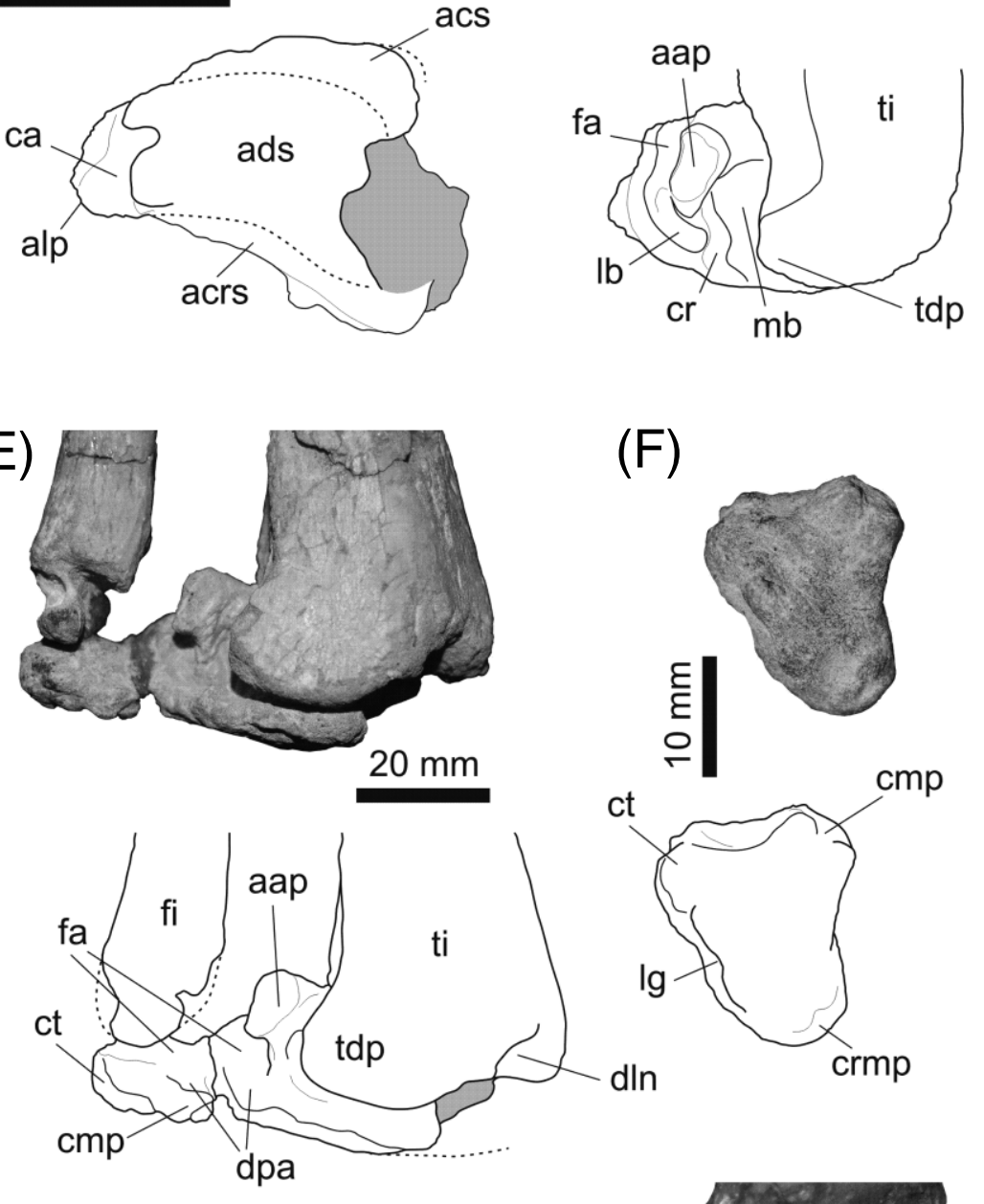

(F)

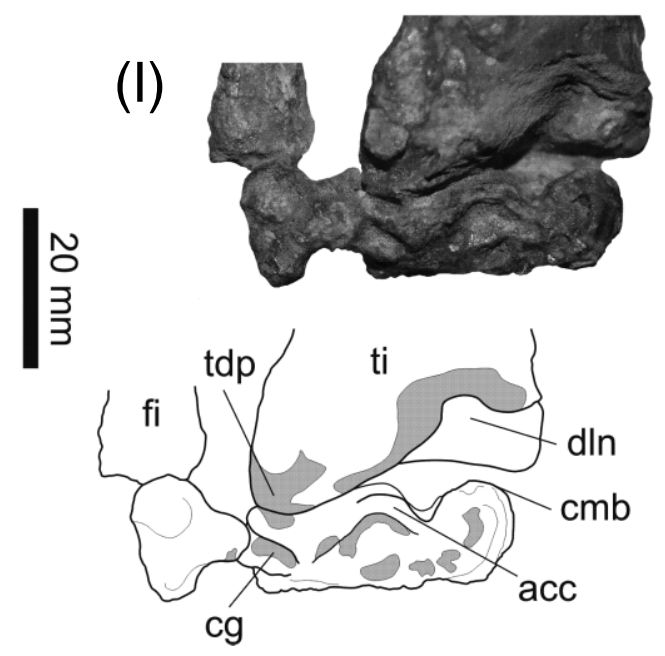

(C)
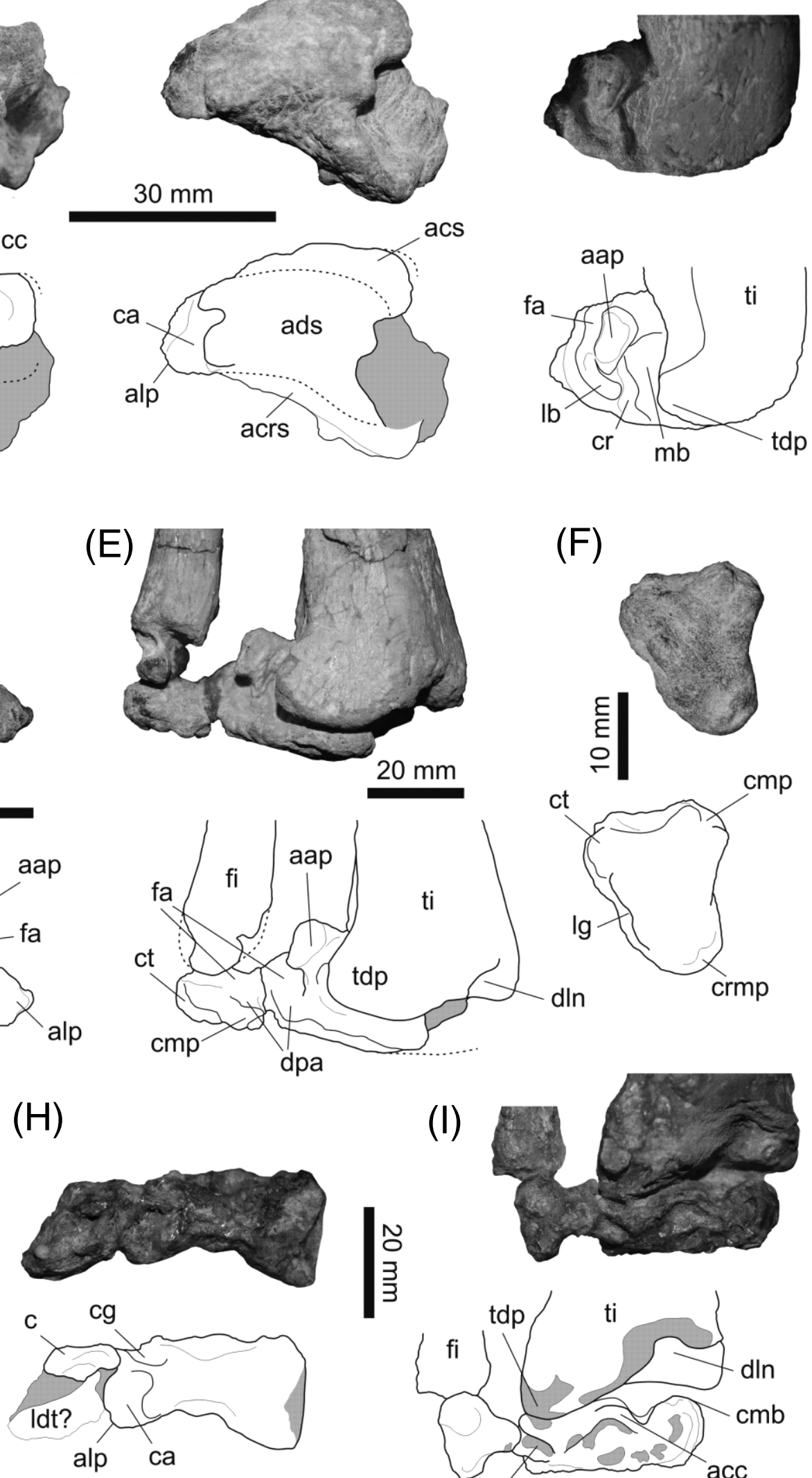

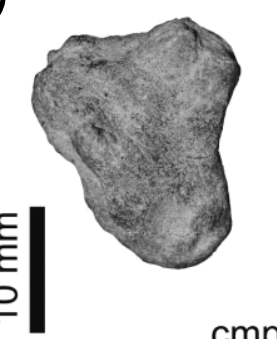

ct

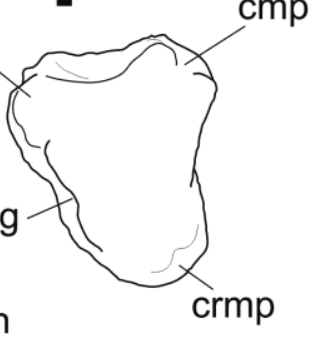

$\mathrm{cg}$ 


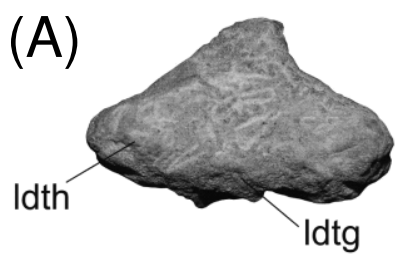

(B)

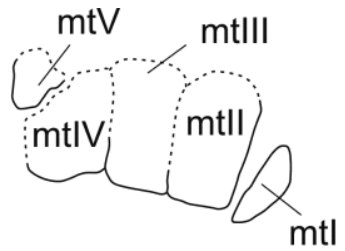

(D)

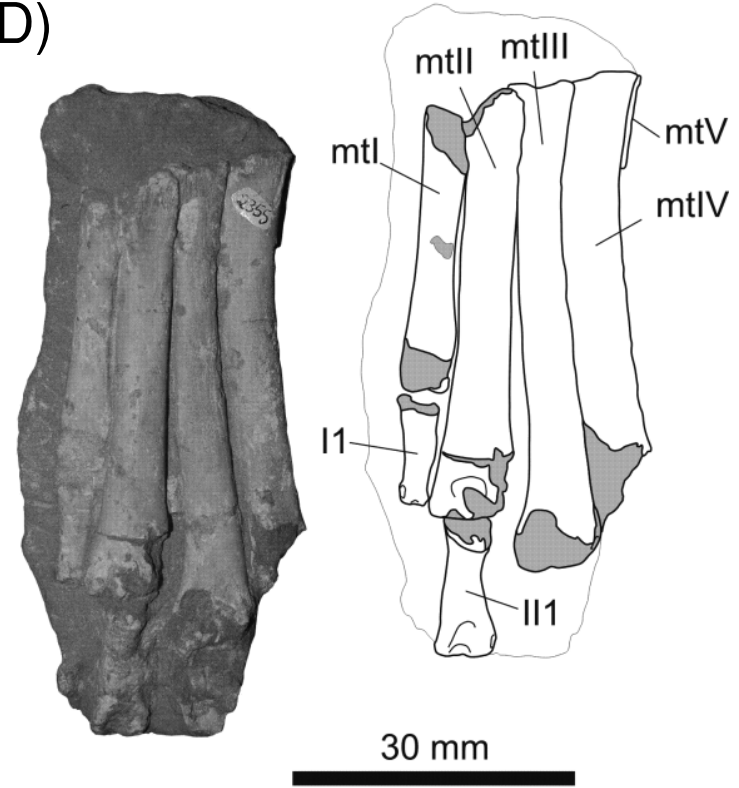

mtIV

(C)
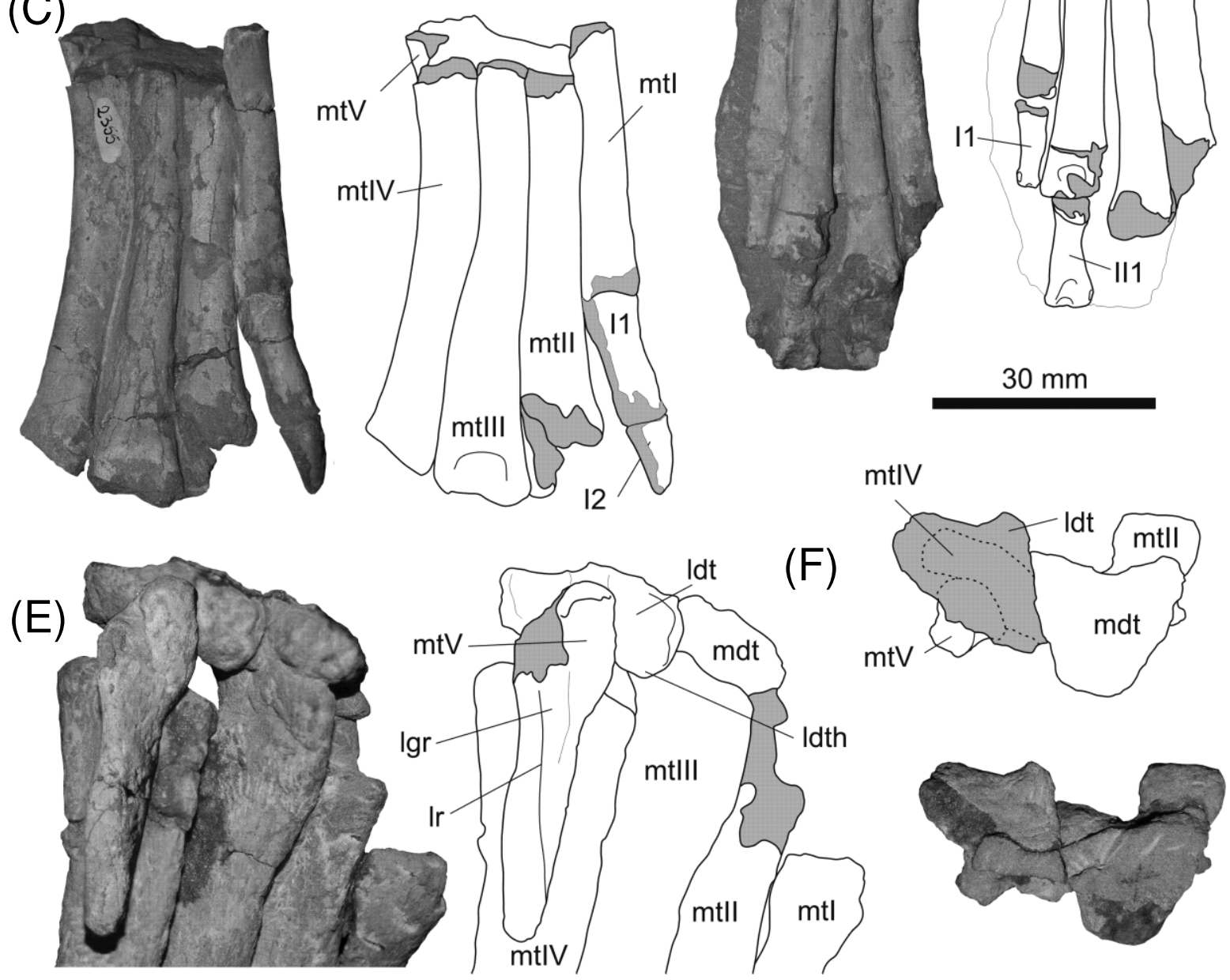

Figure 15 Guaibasaurus candelariensis, photographs and outline drawings of distal tarsals and feet: (A) left lateral distal tarsal of MCN PV2356 in distal view; (B-D) MCN PV2355: (B) right metatarsals in proximal view; (C) articulated right foot in cranial/dorsal view; (D) articulated left foot in cranial/dorsal view; (E-F) MCN PV2356: (E) distal tarsals and proximal portion of metatarsals in oblique (caudolateral) view; (F) distal tarsals and metatarsals in proximal view. Abbreviations: I1-2=phalanges $1-2$ of digit I; III = phalanx 1 of digit II; ldt=lateral distal tarsal; ldtg=caudal groove on lateral distal tarsal; ldth=mediocaudal heel on lateral distal tarsal; lgr=longitudinal groove; $1 \mathrm{r}=$ longitudinal ridge; $\mathrm{mdt}=$ medial distal tarsal; $\mathrm{mt} \mathrm{I}-\mathrm{V}=$ metatarsals $\mathrm{I}-\mathrm{V}$. Matrix and broken areas highlighted in grey; dotted lines represent reconstructed parts. In (F), the lateral distal tarsal is highlighted in grey and the proximal outline of metatarsals IV-V in dotted lines.

(including that of digit I), but these are variously incomplete and/or concealed by sediments. Non-ungual phalanges are usually broader than deep at their mid-length, and bear symmetrical ginglymi. That of digit I of the paratype is, however, slightly twisted along its longitudinal axis, with the medial collateral pit facing somewhat dorsally. As seen in UFRGS PV0725T, the ungual of that digit is also somewhat more curved than those of more lateral elements.

Figure 14 Guaibasaurus candelariensis, photographs and outline drawings of the tarsus and distal epipodium: (A-F) MCN PV2356: (A) astragalus in caudal view and displaced (oblique view) calcaneum; (B) astragalus in distal view; (C) lateral portion of astragalus in proximal view and part of the distal end of the tibia; (D) astragalus and distal end of the tibia in cranial view; (E) caudal view of proximal tarsals and distal epipodium as preserved; (F) calcaneum in proximal view; $(\mathrm{G}-\mathrm{I}) \mathrm{MCN}$ PV2356: $(\mathrm{G})$ caudolateral corner of right proximal tarsals in proximal view; $(\mathrm{H})$ left proximal tarsals as preserved in distal view; (I) caudal view of left proximal tarsals and distal epipodium as preserved. Abbreviations: aap=astragalar ascending process; acc $=$ astragalar caudal crest; acs = caudal surface of astragalus; acrs=cranial surface of astragalus; ads=distal surface of astragalus; alp= astragalar laterocranial process; $\mathrm{c}=$ calcaneum; $\mathrm{ca}=$ articular surface for the calcaneum; $\mathrm{cg}=$ astragalar caudal groove; $\mathrm{cmb}=$ astragalar caudomedial bump; $\mathrm{cmp}=$ caudomedial process of calcaneum; $\mathrm{cr}=$ proximal crest of the astragalus; $\mathrm{crmp}=$ craniomedial process of calcaneum; $\mathrm{ct}=$ calcaneal tuber; $\mathrm{dln}=$ laterodistal notch; $\mathrm{dpa}=$ articulation for the tibial descending process; $\mathrm{f}=$ ascending process furrow; $\mathrm{fa}=$ fibular articulation; $\mathrm{fi}=\mathrm{fibula} ; \mathrm{l}=$ lateral basin; ldt=lateral distal tarsal; $\lg =$ calcaneal lateral groove; $\mathrm{mb}=$ medial basin; $\mathrm{td} \mathrm{p}=$ tibial descending process; ti=tibia. Matrix and broken areas highlighted in grey; dotted lines represent reconstructed parts. 
(A)

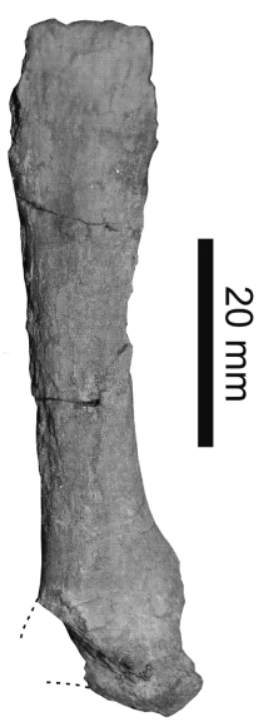

(C)

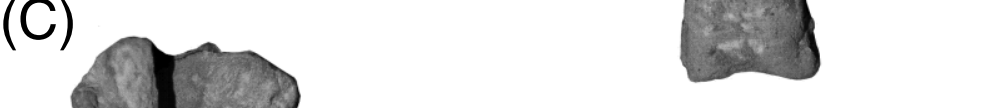

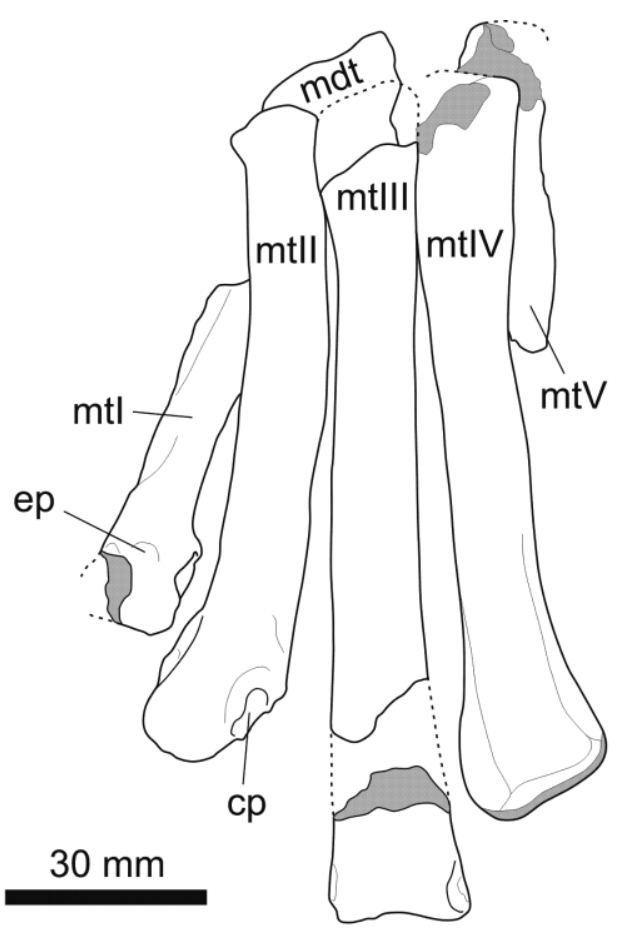

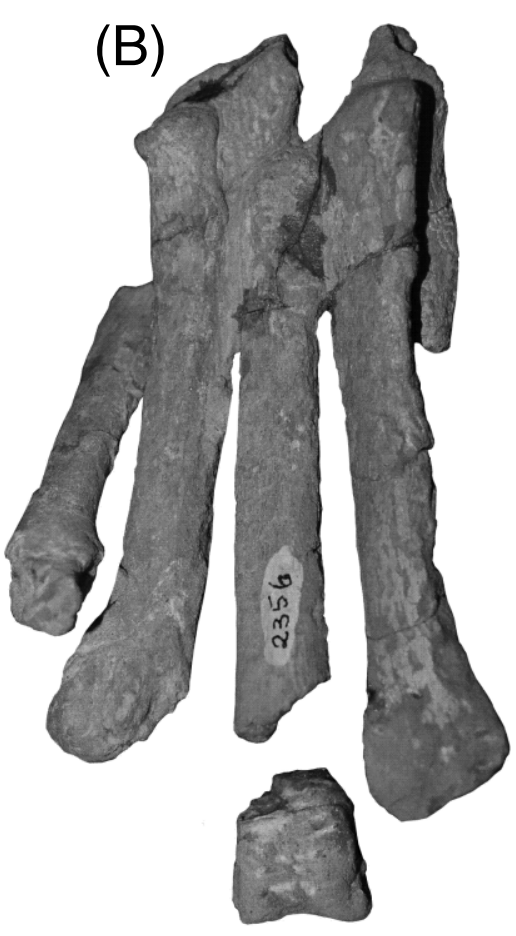

ep
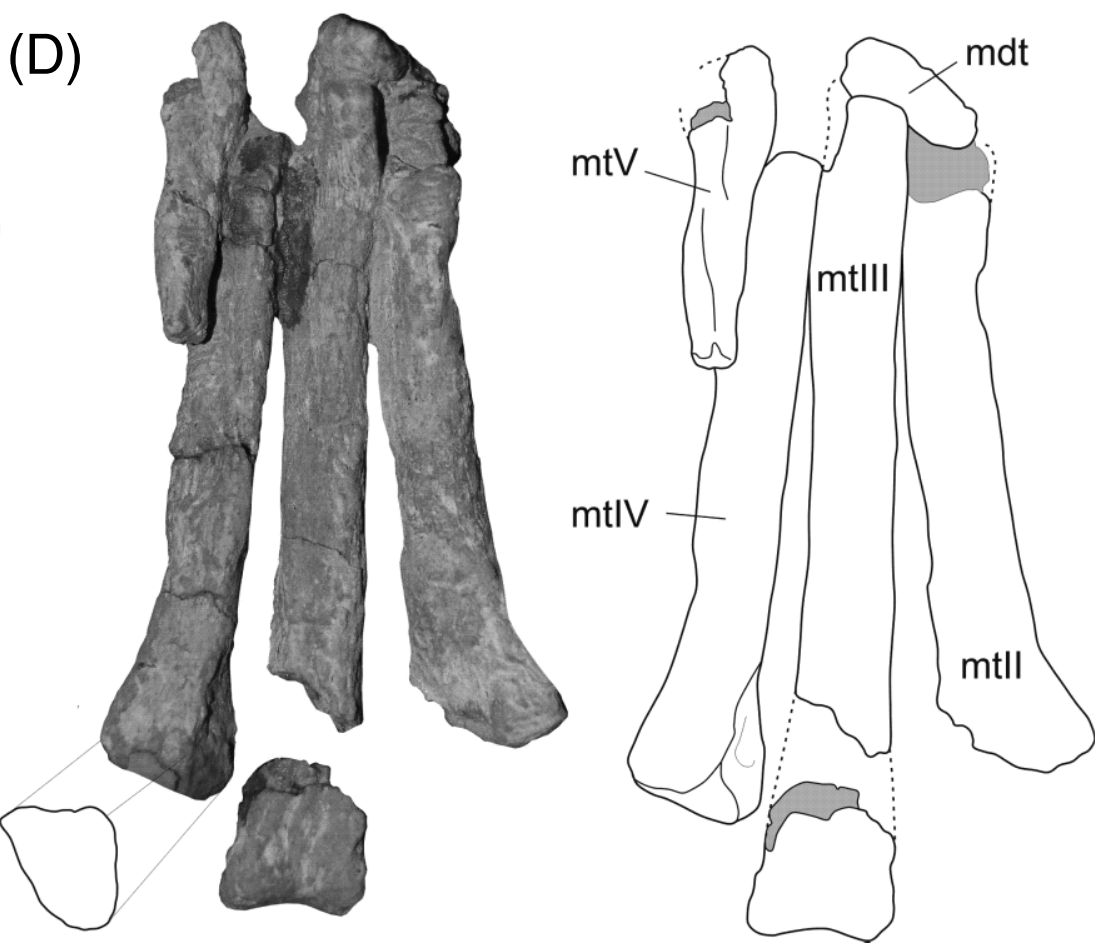

Figure 16 Guaibasaurus candelariensis (MCN PV2356) photographs and outline drawings of left distal tarsals and metatarsals: (A) Metatarsal I in lateral view; (B-D) medial distal tarsal and metatarsals: (B) cranial/dorsal view; (C) lateral view; (D) caudal/plantar view, with distal outline of Metatarsal IV. Abbreviations: $\mathrm{cp}=$ collateral pit; $\mathrm{ep}=$ extensor pit; $\mathrm{mdt}=$ medial distal tarsal; $\mathrm{mtI}-\mathrm{V}=$ metatarsals $\mathrm{I}-\mathrm{V}$; Matrix and broken areas highlighted in grey; dotted lines represent reconstructed parts.

\section{Discussion}

\subsection{Theropod/sauropodomorph traits of $G$.} candelariensis

As previously mentioned, phylogenetic studies have placed Guaibasaurus candelariensis as a eusaurischian closer to either the theropod (Langer 2004; Langer \& Benton 2006; Langer et al. 2007a; Yates 2007a, b) or the sauropodomorph (Ezcurra 2008; Ezcurra \& Novas 2009) clades. In this section, the anatomical features used in support of these hypotheses are accessed (and numbered sequentially), in an attempt to incorporate them (see section 3.2) into a comprehensive, recently presented study of early dinosaur relationships (Nesbitt et al. 2009b).

Langer \& Benton (2006) mentioned two putative theropod traits of G. candelariensis: (\#1) distal end of pubis significantly narrower than the proximal part of the shaft, and (\#2) symmetrical fourth trochanter. In fact, as discussed by Sereno (2007), character \#1 is poorly defined in Langer \& Benton 
(A)
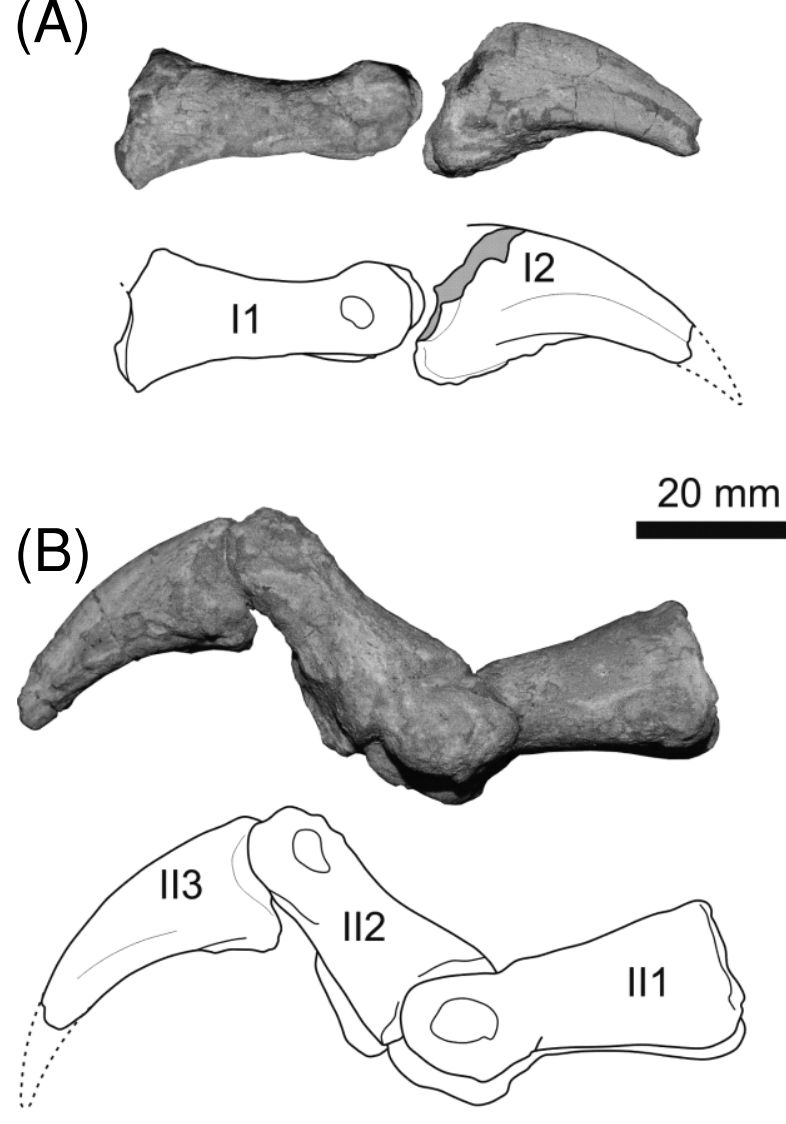

(C)
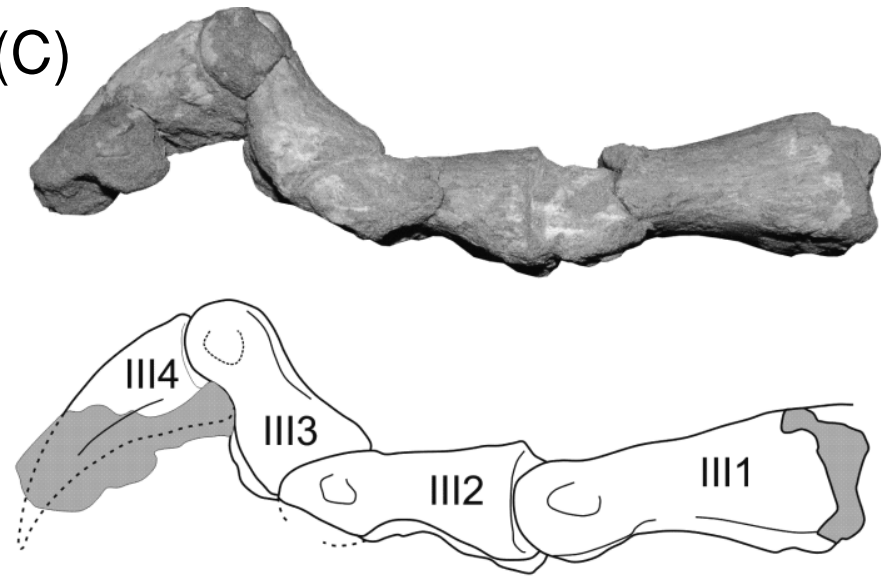

(D)
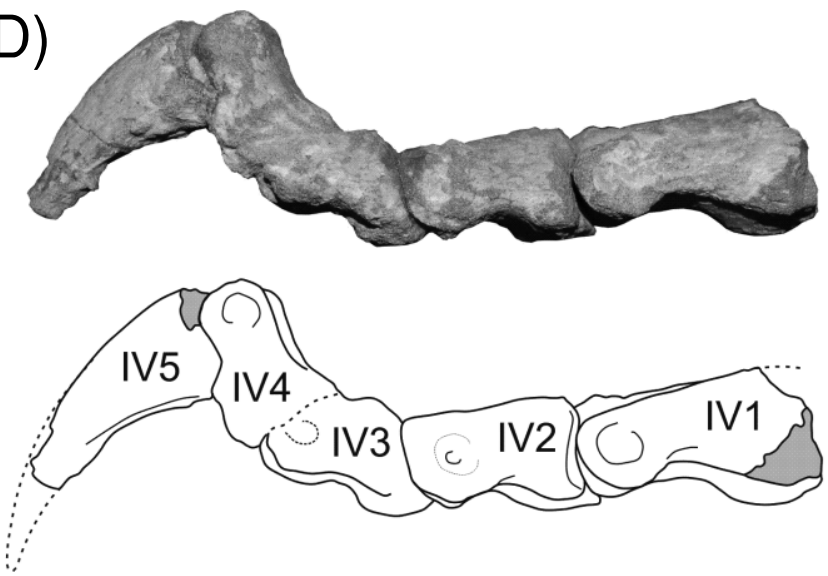

Figure 17 Guaibasaurus candelariensis (MCN PV2356) photographs and outline drawings of left pedal phalanges: (A) phalanges of digit I in medial view; (B) phalanges of digit II in lateral view; (C) phalanges of digit III in lateral view; (D) phalanges of digit IV in lateral view. Abbreviations: I1-2=phalanges 1-2 of digit I; II1-3 = phalanges $1-3$ of digit II; III $1-4=$ phalanges $1-4$ of digit III; IV1-5=phalanges $1-5$ of digit IV. Sediment cover and broken areas highlighted in grey; dotted lines represent reconstructed parts. Matrix and broken areas highlighted in grey; dotted lines represent reconstructed parts.

(2006), and the condition of G. candelariensis was coded as ambiguous. Indeed, while the holotype has the apomorphic (theropod) condition of 'Character 5' (pubic blade, distal width $65 \%$ or less than proximal width) in Sereno (2007, table IV), UFRGS PV0725T shows the plesiomorphic trait (shared with sauropodomorphs). This corresponds to Character 213 of Nesbitt et al. (2009b; Pubis, mediolateral width of distal portion: nearly as broad as proximal width; significantly narrower than proximal width; or mediolaterally compressed and not broader than anteroposteriorly deep), which is coded as variable for $G$. candelariensis (Table 1). Regarding character \#2 (contra Langer \& Benton 2006), the newly discovered UFRGS PV0725T clearly revealed that the fourth trochanter of $G$. candelariensis is asymmetrical, and was scored as such for Character 238 of Nesbitt et al. (2009b; Table 1). Therefore, neither of the two characters presented by Langer \& Benton (2006) unambiguously supports the theropod affinity of $G$. candelariensis.

In two successive numerical studies, Yates $(2007 \mathrm{a}, \mathrm{b})$ suggested the nesting of $G$. candelariensis within Theropoda, based on some synapomorphies: (\#3) postacetabular process longer than $100 \%$ of the distance between the pubic and ischial peduncles; (\#4) descending process of the tibia flaring laterally and backing the fibula; (\#5) pyramidal process on the posteromedial corner of the astragalus. Indeed, G. candelariensis shares a long postacetabular ala with most basal eusaurischians, and a proximal bump on the caudomedial corner of the astragalus with Neotheropoda, but also with some ornithischi- ans and sauropodomorphs. Neither of these characters was employed by Nesbitt et al. (2009b). Therefore, modifications of characters 70 of Langer \& Benton (2006) and 313 of Yates (2007a) were scored as Characters \#3 and \#5 in Tables 2-3, and incorporated into the data matrix modified from Nesbitt et al. (2009b). On the contrary, although somewhat expanded laterally, the descending process of the tibia of $G$. candelariensis does not back the fibula to the extent seen in ornithischians and neotheropods. This variation is well expressed by Character 254 of Nesbitt et al. (2009b), which was coded accordingly for $G$. candelariensis in Table 1 .

More recently, Ezcurra (2008) and Ezcurra \& Novas (2009) listed a series of putative sauropodomorph traits of $G$. candelariensis: (\#6) proximal caudal vertebrae with the base of the neural spine anteroposteriorly longer than half the length of the neural arch; (\#7) ilium with elongated pubic peduncle; (\#8) ilium with strongly laterally curved lamina; (\#9) supraacetabular crest contacting the distal end of pubic peduncle as a well developed crest; (\#10) ischial shaft triangular-shaped in cross-section; (\#11) proximal tibia with lateral condyle anterior to the lateral $[s i c]$ one. Indeed, as mentioned in the description, the iliac lamina of $G$. candelariensis is laterally concave. Yet, this condition is not unique to sauropodomorphs among basal dinosaurs, but also seen in ornithischians (Butler 2005, fig. 13; Scelidosaurus, NMHUK 6704), basal saurischians (Herrerasaurus, PVL 2566; Staurikosaurus, MCZ 1669), and theropods (Dilophosaurus, UCMP 72270; Liliensternus, HMN MB.R. 2175). On the other hand, the fibular 

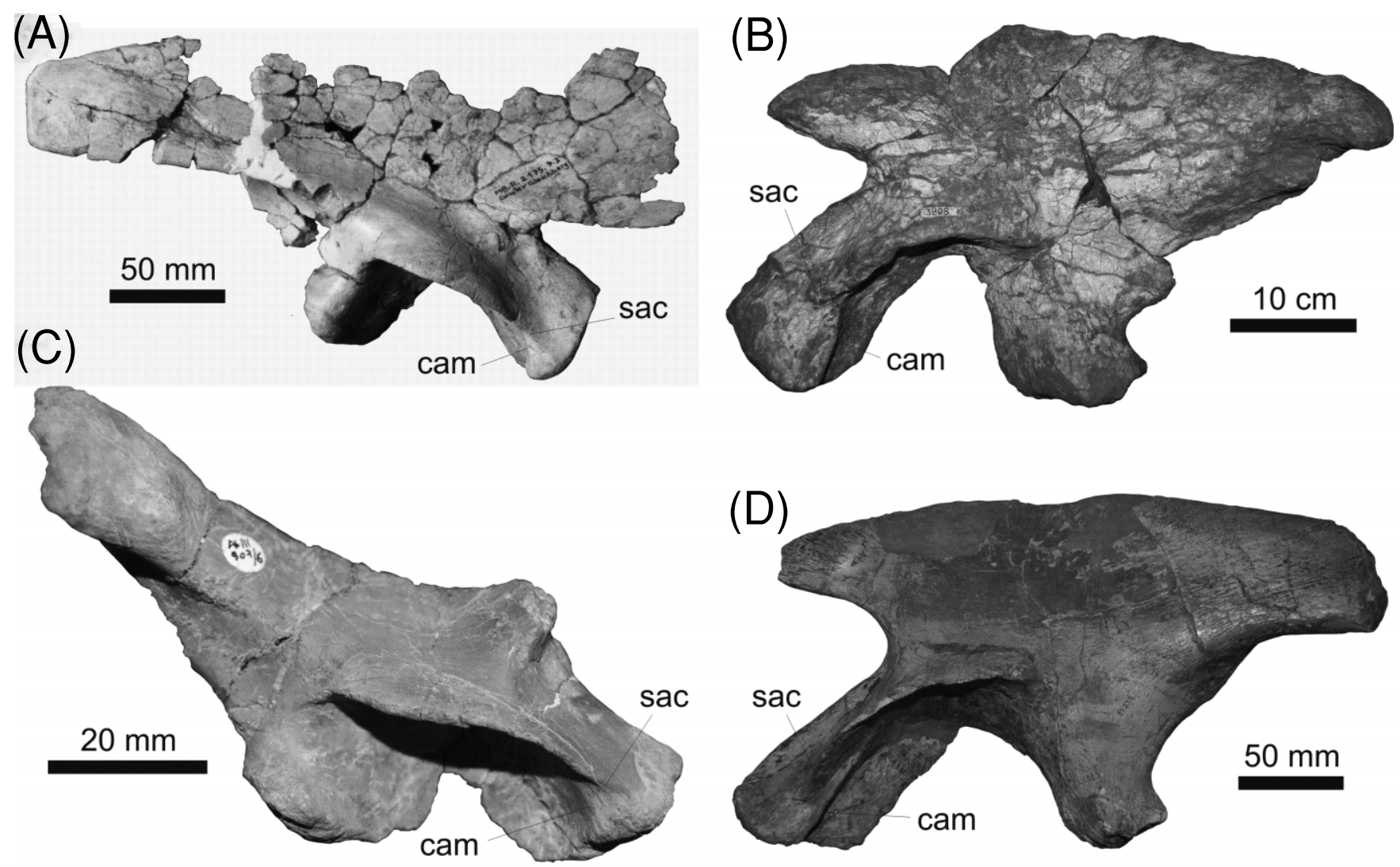

Figure 18 Ilia of selected dinosauromorphs in lateral view: (A) Liliensternus; HMN MB.R. 2175; (B) Riojasaurus, PVL 3808; (C) Silesaurus, ZPAL AbIII 907/6; (D) Efraasia, SMNS 12354. Abbreviations: $\mathrm{cam}=$ cranial margin of the acetabulum; sac $=$ supracetabular crest.

and medial condyles are equally projected caudally in the proximal tibia referred to UFRGS PV0725T. Accordingly, neither characters \#8 nor \#11 are considered to support the affinity of $G$. candelariensis to sauropodomorphs, and are not discussed further.

Character \#6 was first employed by Gauthier (1986; see also Yates 2003b) in order to diagnose the so-called 'broad-footed sauropodomorphs', which have neural spines with a longer base on their craniocaudally compressed proximal tail vertebrae. There seem to be polarisation problems with this character, since basal ('narrow-footed') sauropodomorphs are alternatively considered as possessing short (Yates \& Kitching 2003; Upchurch et al. 2007) or long (Yates 2007a, b) neural spine bases. In any case, the condition in G. candelariensis is hard to establish, particularly considering the ambiguity in defining the proximal extent of the base of the neural spine, and the limits of the neural arch. Accordingly, a modified character (\#6) was scored in Tables $2-3$, coded as uncertain for $G$. candelariensis, and incorporated into the data matrix modified from Nesbitt et al. (2009b). As mentioned above, the ischial shaft of $G$. candelariensis has a sub-triangular cross section along most of its length, but not at the more distal portion. Yet, for scoring purposes (Table 1), it will be considered as sharing the derived condition ' 2 ' of character 215 (Nesbitt et al. 2009b) with Herrerasaurus ischigualastensis, Saturnalia tupiniquim and various sauropodomorphs.

The shape of the pubic peduncle of the ilium is rather variable among basal dinosaurs. A slenderer condition can be achieved both by a reduction of its craniocaudal breadth, as typical of ornithischians (e.g. Butler 2005, fig. 24), or by the elongation of the structure, as more common within saurischians (Langer 2001, p. 195). Sereno (1999; see also Galton 1976) considered a peduncle that is more than twice as long as distally wide as apomorphic for sauropodomorphs. Defined as such, G. candelariensis would possess the apomorphic trait, because the distal width of the peduncle corresponds to $30 \%$ of its total length in UFRGS PV0725T (right side), and approximately $50 \%$ in the holotype (left side), although this relationship doubles in the former if the acetabular wall is also taken into account. In any case, a modified version of character 1-81 of Sereno (1999) was scored as Character \#7 in Tables 2-3, and incorporated into the data matrix modified from Nesbitt et al. (2009b).

Ezcurra (2008) considered a supra-acetabular crest that reaches the distal end of the pubic peduncle as a well developed crest to be apomorphic for Sauropodomorpha, including $G$. candelariensis. However, as clearly seen in some well preserved specimens (Fig. 18), the supra-acetabular crest of basal sauropodomorphs does not reach the distal margin of the pubic peduncle. Instead, it terminates at the middle of its distal half, at a point where the limit of the acetabular wall is marked by an additional ridge that extends below the supra-acetabular crest, reaching the distal margin of the peduncle. These two elements are also evident in forms such as Herrerasaurus (PVL 2566; PVSJ 461) Silesaurus, and Liliensternus (Fig. 18). The cranial border of their acetabulum is not as marked as that of basal sauropodomorphs, but the supra-acetabular crest equally does not reach the distal margin of the pubic peduncle. In the highly modified peduncle of basal ornithischians (Butler 2005 , figs 13,24$)$, the supra-acetabular crest is continuous to a sharp ridge that sets the cranial limits of the acetabulum and reaches the distal margin of the pubic peduncle. The condition in G. candelariensis and S. tupiniquim (MCP 3844-PV, 3846PV) superficially resembles that of ornithischians, because the two crests are not clearly set apart, causing the impression of a distally extensive supra-acetabular crest. Yet, that part of the ilium is not well preserved enough in $G$. candelariensis to differentiate the conditions described above, and character 
\#9 is not considered to unambiguously support its affinity to sauropodomorphs.

Langer et al. (2007a) listed additional putative theropod features of $G$. candelariensis: (\#12) marked longitudinal groove on the lateral surface of the cnemial crest and (\#13) tibiaastragalus $[s i c]$ articulation. In fact, a tibia-calcaneum contact is seen in $G$. candelariensis as well as in many basal theropods (Tykoski 2005) and ornithischians (Butler et al. 2008, 2009; Scutelosaurus, MNA V1752), although apparently not in Pisanosaurus mertii (PVL 2577). Character \#12 is more precisely defined and incorporated into the data matrix modified from Nesbitt et al. (2009b), along with a modified version of character 208 of Butler et al. (2008), scored as character \#13 (Tables 2-3).

Finally, Ezcurra (2008) and Ezcurra \& Novas (2009) listed some traits that potentially combine $G$. candelariensis and $S$. tupiniquim into a monophyletic Guaibasauridae: (\#3) ilium with elongated postacetabular process; (\#14) ilium with incipiently open acetabulum; (\#15) femur with proximal anterior trochanter at level with femoral head; (\#16) tibial distal end with concave posterolateral corner. The first character was already discussed in the context of Character \#3, while Character \#14 is represented by Character 198 of Nesbitt et al. (2009b), which was coded for $G$. candelariensis (Table 1). Regarding character \#16, the caudolateral corner of the distal tibia bears the typical descending process in both $G$. candelariensis and $S$. tupiniquim. Accordingly, it is not concave either distally or caudolaterally. The caudal margin of the distal tibia is slightly concave in the latter form, as in other basal dinosaurs (Langer and Benton 2006, fig. 13), but not in G. candelariensis (MCN PV2356). Therefore, character \#16 is not considered to support the affinity of those two taxa.

Characters related to the position/proximal projection of the lesser trochanter along the femoral shaft are well investigated in phylogenetic studies of all dinosaur lineages (Gauthier 1986; Gauffre 1996; Butler et al. 2008). Yet, among basal members of the group, variations in the relative position of the proximal tip of the trochanter and the distal margin of the femoral head are subtle. Theropods tend to retain a plesiomorphic trochanter, the proximal tip of which is at the level of, or slightly proximal to, the distal margin of the head (Raath 1990; Tykoski 2005; Liliensternus, HMN MB.R. 2175). This is also seen in basal dinosauromorphs (Ezcurra 2006), and more markedly among ornithischians (Santa Luca 1980; Butler et al. 2008; Scutelosaurus, MNA V175). Yet, in most basal dinosaurs (Eoraptor, PVSJ 512; Herrerasaurus, PVL 2566), including G. candelariensis, S. tupiniquim (MCP 3845-PV, 3846-PV), and various sauropodomorphs (Galton 2007; Efraasia, SMNS 12354), the lesser trochanter does not reach the femoral head. Therefore, character \#15 is also not considered to support the affinity of $G$. candelariensis to $S$. tupiniquim.

\subsection{Phylogenetic analyses and implications}

In order to understand the phylogenetic position of G. candelariensis among basal dinosaurs, a series of phylogenetic analyses based on the data-set provided by Nesbitt et al. (2009b) were performed. First, G. candelariensis was simply scored for the 315 characters of that study (Table 1), and the parsimony search was conducted with the same software and parameters employed by those authors. The analysis resulted in 18 MPTs of 883 steps, the strict consensus of which (Fig. 19A) shows $G$. candelariensis in a polytomy with herrerasaurs (Staurikosaurus, Herrerasaurus and Chindesaurus) and the clade formed by Eoraptor plus Tawa + Neotheropoda.

Attempting to further clarify the position of G. candelariensis within the polytomy mentioned above, six of the characters discussed in the previous section were added (Tables 2-3) into 
(A)

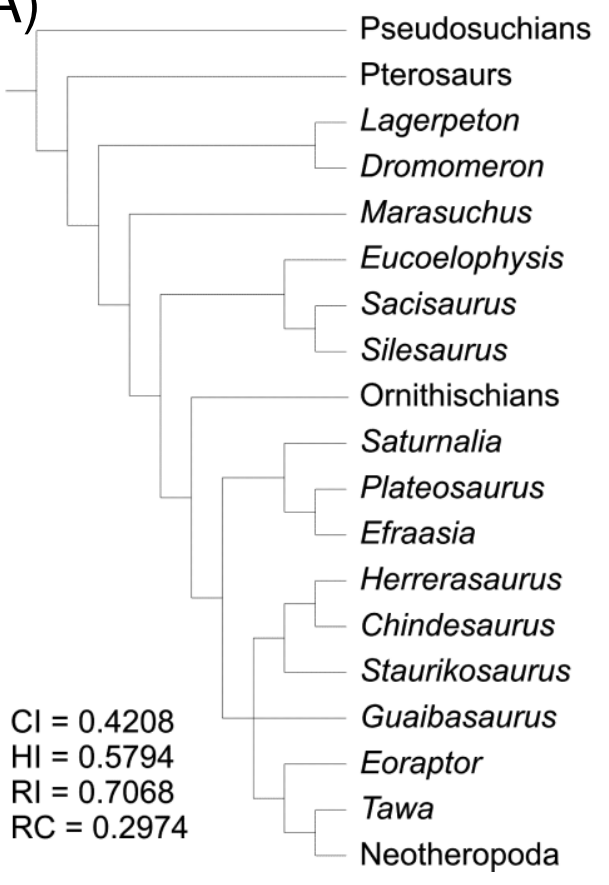

(B)

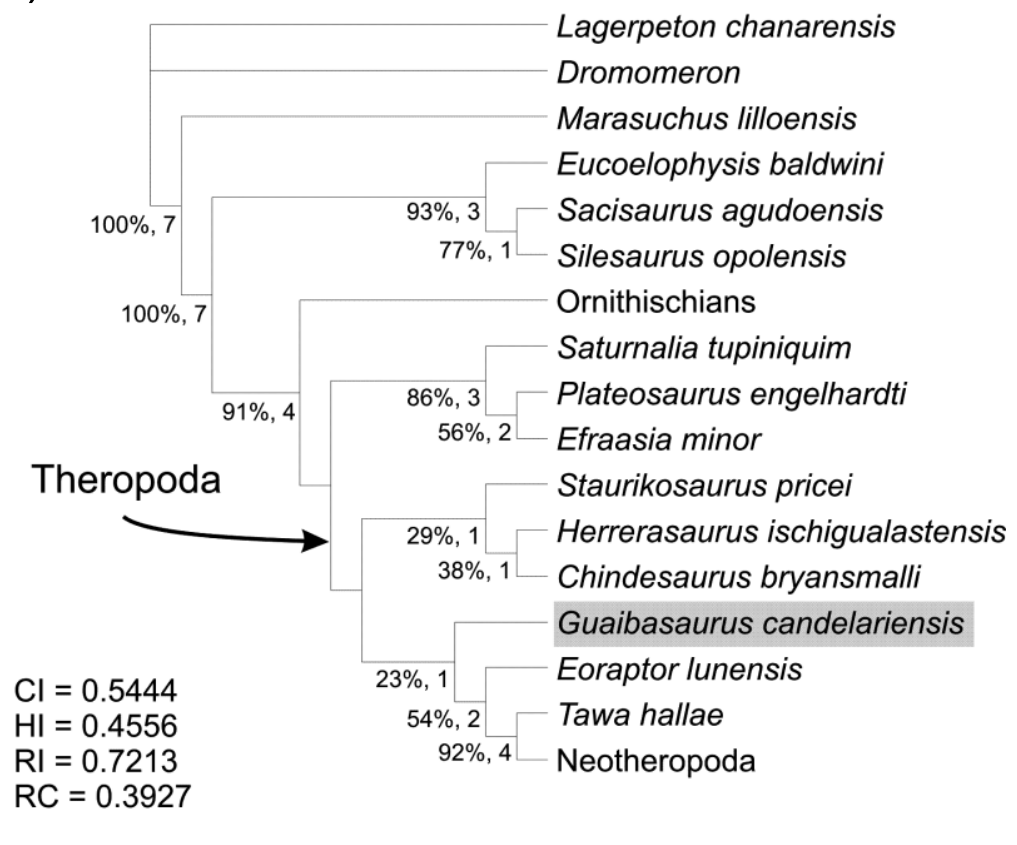

Figure 19 Strict consensus trees depicting the relationships of Guaibasaurus candelariensis within archosaurs: (A) simplified outcome of the inclusion of G. candelariensis in the data-set of Nesbitt et al. (2009b); (B) outcome of the analysis of the data-set modified from Nesbitt et al. (2009b); bootstrap (100 replicates) and bremer support' values are indicated for each clade. Abbreviations: $\mathrm{CI}=$ consistency index (excluding uninformative characters); $\mathrm{HI}=$ homoplasy index (excluding uninformative characters); $\mathrm{RC}=$ rescaled consistency index; $\mathrm{RI}=$ retention index.

Table 2 Definition of six characters added into a modified version of the data-matrix presented by Nesbitt et al. (2009b). Subequal values refer to variations of less than 5\%.

\begin{tabular}{|c|c|}
\hline Character \#3: & $\begin{array}{l}\text { Ilium, maximum length of the postacetabular ala: shorter than, subequal to }(0) \text {, or } \\
\text { longer than (1) the space between the preacetabular and postacetabular embayments } \\
\text { of the bone. }\end{array}$ \\
\hline Character \#5: & Astragalus, proximal expansion on the caudomedial corner: absent (0), or present (1) \\
\hline Character \#6: & $\begin{array}{l}\text { Proximal (1-4) caudal vertebrae, mid-length breadth (craniocaudal) of the neural } \\
\text { spines: broader than, subequal to (0), or narrower than (1) } 50 \% \text { of the respective } \\
\text { centrum length. }\end{array}$ \\
\hline Character \#7: & $\begin{array}{l}\text { Ilium, distal width (craniocaudal) of the pubic peduncle (not considering the } \\
\text { acetabular wall): more than }(0) \text {, subequal to, or less than (1) half the total length of } \\
\text { the peduncle. }\end{array}$ \\
\hline Character \#12: & $\begin{array}{l}\text { Tibia, proximal surface, depth of the lateral excavation (caudal to the cnemial crest): } \\
\text { less than }(0) \text {, subequal to, or more than (1) } 10 \% \text { of the craniocaudal length of the } \\
\text { articulation. }\end{array}$ \\
\hline Character \#13: & Calcaneum, tibial articulation: absent (0); present (1). \\
\hline
\end{tabular}

a modified version of the data-matrix of Nesbitt et al. (2009b), excluding non-dinosauromorph archosaurs and the much derived theropod Velociraptor mongoliensis. A preliminary analysis of the original data-set pruned of those terminals revealed the same arrangement of the remaining taxa suggested by Nesbitt et al. (2009b). With the addition of the extra characters, an heuristic search resulted in 6 MPTs of 495 steps, the strict consensus of which (Fig. 19B) shows the higher nesting of $G$. candelariensis, relative to herrerasaurs, in the theropod phylogenetic tree. The basal polytomy including Lagerpeton, Dromomeron and Dinosaurifomes is just the result of including lagerpetids as outgroups under the 'polytomy outroot' option of PAUP. The support for the more controversial clades is rather weak (Fig. 19B), and the theropod affinity of both $G$. candelariensis and herrerasaurs must be taken with caution. Otherwise, the affinity of $G$. candelariensis to sauropodomorphs, and especially the nesting of Saturnalia tupiniquim within a Guaibasauridae clade, is more consistently ruled out.
The recovery of that arrangement in previous studies is probably due to the sharing of generalised basal eusaurischian symplesiomorphies among those taxa. Constrained analyses were performed, showing that five additional steps are required to enforce a sister-taxon relationship between Saturnalia and Guaibasaurus, and seven additional steps to enforce a Eusaurischia exclusive of herrerasaurs.

Even if weakly supported by numerical data, the theropod affinity of $G$. candelariensis is further suggested by various anatomical traits it shares with all/some members of the group. Those derived from the analysed data-matrices, include $(*=$ theropod synapomorphies; $\dagger=$ synapomorphies of the clade including Guaibasaurus, Eoraptor, Tawa and Neotheropoda): sacral ribs shared between two sacral vertebrae; *humerus shorter than 0.6 of the length of the femur; *proximal ends of metacarpals abut one another without overlapping; *manus longer than 0.4 of the total length of humerus plus radius; *shaft of metacarpal IV significantly narrower than that of 
Table 3 Codification (and respective sources) of the six characters in Table 2 for the archosaur taxa selected by Nesbitt et al. (2009b), exclusive of non-dinosauromorphs and Velociraptor mongoliensis. ?= missing data; $v=$ polymorphic characters.

\begin{tabular}{|c|c|c|c|c|c|c|c|}
\hline Taxon & $\# 3$ & $\# 5$ & $\# 6$ & $\# 7$ & $\# 12$ & $\# 13$ & Source \\
\hline Lagerpeton chanarensis & 1 & 0 & $?$ & 1 & 0 & 0 & PLV 4619, PULR 06 \\
\hline Dromomeron romeri & $?$ & 0 & $?$ & $?$ & 0 & 0 & Nesbitt et al. (2009c) \\
\hline Dromomeron gregorii & $?$ & $?$ & $?$ & $?$ & 0 & $?$ & Nesbitt et al. (2009c) \\
\hline Marasuchus lilloensis & 1 & 1 & 1 & 1 & 0 & 0 & PVL 3870, 3871 \\
\hline Eucoelophysis baldwini & $?$ & $?$ & $?$ & $?$ & $?$ & $?$ & NMNNH P-22298 \\
\hline Sacisaurus agudoensis & $?$ & $?$ & $?$ & $?$ & 0 & $?$ & MCN PV10020 \\
\hline Silesaurus opolensis & 1 & 0 & 0 & $\mathrm{v}$ & 0 & 0 & ZPAL 361/20, 907/6, AbIII 361, 415 \\
\hline Eocursor parvus & $?$ & 0 & $?$ & 1 & 0 & 0 & Butler et al. (2007); Butler (2010) \\
\hline Pisanosaurus mertii & $?$ & 0 & $?$ & 1 & 0 & 0 & PVL 2577 \\
\hline Heterodontosaurus tucki & 0 & $?$ & 1 & $?$ & $?$ & $?$ & SAM-K1332 (photographs) \\
\hline Lesothosaurus diagnosticus & 0 & $?$ & $?$ & 1 & 0 & $?$ & NHMUK RUB-17 \\
\hline Scutellosaurus lawleri & $?$ & 0 & $?$ & $?$ & 0 & 1 & MNA V175, V1752 \\
\hline Saturnalia tupiniquim & 1 & 0 & $?$ & 1 & 0 & 0 & MCP 3844-PV, 3845-PV, 3846-PV \\
\hline Plateosaurus engelhardti & 1 & 0 & 0 & 1 & 0 & 0 & GPIT (mounted skeletons) \\
\hline Efraasia minor & 0 & $?$ & 0 & 1 & $?$ & $?$ & SMNS 12354 \\
\hline Herrerasaurus ischigualastensis & 0 & 0 & 0 & 1 & 0 & 0 & PVL 2566; PVSJ 373 \\
\hline Staurikosaurus pricei & 0 & $?$ & 0 & 1 & 0 & $?$ & MCZ 1669 \\
\hline Chindesaurus bryansmalli & $?$ & 0 & $?$ & 1 & 0 & $?$ & PEFO 33982 \\
\hline Eoraptor lunensis & 0 & $?$ & 0 & 0 & 0 & 0 & PVSJ 512 \\
\hline Tawa hallae & $?$ & $?$ & $?$ & 0 & $?$ & $?$ & Nesbitt et al. (2009b) \\
\hline Coelophysis bauri & 1 & 1 & 0 & 0 & 1 & 0 & $\begin{array}{l}\text { AMNH FR } 7224 \text { (cast), NMNNH (C-8-82 block); } \\
\text { Tykoski (2005) }\end{array}$ \\
\hline Syntarsus kayentakatae & 1 & 1 & $?$ & 0 & $?$ & 1 & Rowe (1989); Tykoski (2005) \\
\hline Liliensternus liliensterni & 1 & 1 & 0 & 0 & 0 & 0 & HMN MB.R. 2175 \\
\hline Zupaysaurus rougieri & $?$ & 1 & $?$ & $?$ & $?$ & 0 & PULR 076 \\
\hline Dilophosaurus wetherelli & 1 & 1 & 0 & 0 & 0 & 1 & UCMP 37302,77270 \\
\hline Cryolophosaurus ellioti & $?$ & 1 & $?$ & $?$ & $?$ & 1 & Smith et al. (2007) \\
\hline Ceratosaurus nasicornis & 1 & 1 & 0 & $?$ & $?$ & 1 & Madsen \& Welles (2000); Tykoski (2005) \\
\hline Piatnitzkysaurus floresi & 0 & $?$ & 0 & 0 & 0 & $?$ & PVL 4073 \\
\hline Allosaurus fragilis & 0 & 1 & 0 & 0 & 1 & 1 & Madsen (1976) \\
\hline Guaibasaurus candelariensis & 1 & 1 & $?$ & 1 & 1 & 1 & This work \\
\hline
\end{tabular}

metacarpals I-III; caudal margin of the postacetabular ala of the ilium notched or indented in lateral view; *femur with bone wall thickness less than $0 \cdot 3$ the shaft diameter at mid-length; * fibular condyle level with the medial condyle at the caudal border of the proximal tibia; †proximal expansion on the caudomedial corner of the astragalus; tastragalar proximal surface lacking a marked rimmed and elliptical fossa caudal to the ascending process; †metatarsal $\mathrm{V}$ without phalanges and tapering to a point. It is important to note that some of these traits may have a broader distribution among basal dinosaurs, but are hitherto unrecognised, given the poor preservation/ description of specimens.

Besides the above mentioned traits, other features of $G$. candelariensis may support its affinity to theropods. A narrow metacarpal III, with mid-shaft breadth less than $70 \%$ that of metacarpal II, has been variously regarded as a theropod feature (Rauhut 2003; Ezcurra 2006; Smith et al. 2007), although a similar condition has also been recorded in a number of basal sauropodomorphs (Galton 2007; Efraasia, SMNS 12667). This relation is about $65 \%$ in G. candelariensis, suggesting its nesting within Theropoda, or minimally within Eusaurischia. Likewise, the presence of deep extensor pits on metacarpals I-III was used by Sereno et al. (1993; see also Langer \& Benton 2006) as a typical theropod trait, but later recognised also in ornithischians (Butler et al. 2007, 2008). In the badly preserved left manus of UFRGS PV0725T, a very deep extensor pit is seen in metacarpal II, but not in the adjacent elements. Accordingly, further preparation and/or discoveries are needed to evaluate the significance of this feature for the classification of $G$. candelariensis.

At its distal third, the femur of $G$. candelariensis has a moderately sharp craniomedial corner (Fig. 11A). Although much less conspicuous, this is interpreted as homologous to the craniomedial distal crest (Hutchinson 2001b), recognised, and frequently hypertrophied, in theropods as the 'medial epicondylar crest' (Carrano et al. 2002; Carrano \& Hutchinson 2002; Tykoski 2005; Ezcurra 2006). Yet, a condition comparable that of $G$. candelariensis is also present in other dinosauromorphs (Herrerasaurus, PVL 2566; Saturnalia, MCP 3846-PV; Smith \& Pol 2007; Nesbitt et al. 2009c), hinting at a broader distribution of the feature among these archosaurs. Likewise, the deeply excavated cranial margin of the astragalus of $G$. candelariensis approaches the condition of many theropods (Dilophosaurus, UCMP 37302; Liliensternus, HMN MB.R. 2175; 'Syntarsus', QVM QG-CT-6; Tykoski 2005), while a less marked excavation is typical of other basal saurischians (Novas 1989; Langer 2003; Langer \& Benton 2006). Yet, a similarly concave astragalus also occurs in other dinosauromorphs (Scutellosaurus, MNA V175; Nesbitt et al. 2009c).

In addition, G. candelariensis and Chindesaurus bryansmalli (PEFO 10395) share intriguing anatomical traits not seen in typical herrerasaurs: Herrerasaurus, Staurikosaurus, TTU-P 10082 (Nesbitt \& Chatterjee 2008). This include a well developed brevis shelf; a transversely compressed, but not caudally folded, distal pubis (Langer \& Benton 2006; not seen in UFRGS PV0725T); a caudomedially notched (partially 
overprepared in PEFO 10395) distal end of the tibia, with a moderately expanded outer malleolus; and a cranially concave astragalus, with a furrow cranial to the ascending process (also seen in some specimens of Herrerasaurus; PVSJ 373) and a proximal expansion at the mid-length of the caudoproximal corner. These traits may emphasise the theropod, although not necessarily herrerasaurid, affinities of Chindesaurus bryansmalli.

Except for the controversial Staurikosauris pricei (Bittencourt \& Kellner, 2009), G. candelariensis is the only putative theropod recorded in the Santa Maria beds. This includes two successive stratigraphic units, the Santa Maria Formation, of Carnian age, which yielded Staurikosaurus, Saturnalia and Teyuwasu, and the Caturrita Formation, where Unaysaurus, Sacisaurus and Guaibasaurus were collected. The former unit represents a window into the first radiation of dinosaurs, while the Caturrita Formation is coeval to other Norian beds in which dinosaurs are already abundant, in the form of basal ornithischians (Butler et al. 2007), and a well established fauna of sauropodomorphs and neotheropods (Langer et al. 2010). The record of a plesiomorphic form such as G. candelariensis emphasises that, even after the establishment of those three main dinosaur clades, more basal dinosauromorphs continue to flourish until the end of the Triassic, as represented by non-dinosaurian taxa (Irmis et al. 2007) and basal saurischians (Nesbitt et al. 2007; Kutty et al. 2007; Nesbitt \& Chatterjee 2008).

\section{Acknowledgements}

We thank the following curators and researchers who granted access to comparative material: Angela Milner and Sandra Chapman (NHMUK); Michael Maisch and Alexander Hohloch (GPIT); Maria Claudia Malabarba (MCP); David and Janet Gillette (MNA); Bill Parker (PEFO); Spencer Lucas and Larry Rinehart (NMMNH); EmilioVaccari (PULR); Jaime Powell and Judith Babot (PVL); Rainer Schoch and Rupert Wild (SMNS); Pat Holroyd and Randy Irmis (UCMP); Ricardo Martinez and Oscar Alcober (UNSJ); Jerzy Dzik, Grzegorz Niedźwiedzki and Tomasz Sulej (ZPAL); Dave Unwin (HMN); and especially Ana Maria Ribeiro and Jorge Ferigolo $(\mathrm{MCN})$. Claudia Marsicano kindly provided photographs of Heterodontosaurus. We are indebted to Jaime Powel, Jerzy Dzik, Oliver Rauhut and Rainer Schoch for allowing us to figure specimens under their care. Thanks also to Jaime A. Headden for his skeletal reconstruction of Guaibasaurus. Financial support for international travel to study comparative specimens was provided by the Brazilian agency FAPESP (to MCL), Programa de Pós-Graduação em Biologia Comparada, FFCLRP-USP, and Santander Bank (to JSB). Other aspects of this work were funded by grants from the Brazilian agencies CNPq, FAPESP (to MCL), and CAPES (to JSB). This is contribution No. 19 of Laboratório de Paleontologia, FFCLRP-USP.

\section{Supplementary material}

Tables S1-S9 are published as Supplementary Material with the on-line version of this paper. This is hosted by the Cambridge Journals Online service and can be viewed at http://journals.cambridge.org/tre

\section{Note added in proof}

After the submission of this manuscript, M. D. Ezcurra published the description of Chromogisaurus novasi, along with a phylogenetic hypothesis that nests Guaibasaurus within
Sauropodomorpha, forming Guaibasauridae with Chromogisaurus, Saturnalia, Panphagia and Agnosphitys. Most of the characters employed in that study have already been discussed in the present paper, based on their first poposition in Ezcurra (2008) and Ezcurra \& Novas (2009). Accordingly, we endorse the theropod affinity as the most likely for Guaibasaurus within Saurischia.

Ezcurra, M. D. 2010. A new early dinosaur (Saurischia: Sauropodomorpha) from the Late Triassic of Argentina: a reassessment of dinosaur origin and phylogeny. Journal of Systematic Palaeontology 8, 371-425.

\section{References}

Andreis, R. R., Bossi, G. E. \& Montardo, D. K. 1980. O Grupo Rosário do Sul (Triássico) no Rio Grande do Sul. In Anais do XXXI Congresso Brasileiro de Geologia (Camboriú) 2, 659-73.

Barrett, P. M., Butler, R. J., Novas, F. E., Moore-Fay, S. C., Moody, J. M., Clark, J. M. \& Sánchez-Villagra, M. R. 2008. Dinosaur remains from the La Quinta Formation (Lower or Middle Jurassic) of the Venezuelan Andes. Paläontologische Zeitschrift 82, 163-77.

Baumel, J. J. 1993. (ed.) Handbook of Avian Anatomy: Nomina Anatomica Avium (2nd edn). Publications of the Nuttall Ornithological Club 23. Cambridge, Masachussetts: Harvard University. $779 \mathrm{pp}$.

Bittencourt, J. S. \& Kellner, A. W. A. 2009. The anatomy and phylogenetic position of the Triassic dinosaur Staurikosaurus pricei Colbert, 1970. Zootaxa 2079, 1-56.

Bonaparte, J. F. 1984. Locomotion in rauisuchid thecodonts. Journal of Vertebrate Paleontology 3, 210-18.

Bonaparte, J. F., Ferigolo, J. \& Ribeiro, A. M. 1999. A new Early Late Triassic saurischian dinosaur from Rio Grande do Sul State, Brazil. In Tomida, Y., Rich, T. H. \& Vickers-Rich, P. (eds) Proceedings of the Second Gondwanan Dinosaur Symposium. National Science Museum Monographs 15, 89-109. Tokyo: National Science Museum.

Bonaparte J. F., Brea G., Schultz C. L. \& Martinelli A. G. 2007. A new specimen of Guaibasaurus candelariensis (basal Saurischia) from the Late Triassic Caturrita Formation of southern Brazil. Historical Biology 19, 73-82.

Bonaparte, J. F. \& Ferigolo, J. 1998. A new and primitive saurischian dinosaur, Guiabasaurus dandelariai, gen and sp. nov., from the late Triassic Caturrita Formation of southern Brazil. In Tomida, Y., Rich, T. H. \& Vickers-Rich, P. (eds) Second Gondwanan Dinosaur Symposium. Abstracts with Program, 11. Tokyo: National Science Museum.

Butler, R. J. 2005. The 'fabrosaurid' ornithischian dinosaurs of the Upper Elliot Formation (Lower Jurassic) of South Africa and Lesotho. Zoological Journal of the Linnean Society 145, 175-218.

Butler, R. J. 2010. The anatomy of the basal ornithischian dinosaur Eocursor parvus from the lower Elliot Formation (Late Triassic) of South Africa. Zoological Journal of the Linnean Society 160, 648-84.

Butler, R. J., Smith, R. M. H. \& Norman, D. B. 2007. A primitive ornithischian dinosaur from the Late Triassic of South Africa, and the early evolution and diversification of Ornithischia. Proceedings of the Royal Society B 274, 2041-46.

Butler, R., Upchurch, P. \& Norman, D. B. 2008. The phylogeny of the ornithischian dinosaurs. Journal of Systematic Palaeontology $\mathbf{6}$, $1-40$.

Butler, R. J., Galton, P. M., Porro, L. B., Chiappe, L. M., Henderson, D. M. \& Erickson, G. M. 2009. Lower limits of ornithischian dinosaur body size inferred from a new Upper Jurassic heterodontosaurid from North America. Proceedings of the Royal Society B 277, 375-81.

Carpenter, K., Miles, C., Ostrom, J. H. \& Cloward, K. 2005. Redescription of the small maniraptoran theropods Ornitholestes and Coelurus from the Upper Jurassic Morrison Formation of Wyoming. In Carpenter, K. (ed.) The Carnivorous Dinosaurs, 49-71. Bloomington: Indiana University Press.

Carrano, M. T. 2007. The appendicular skeleton of Majungasaurus crenatissimus (Theropoda: Abelisauridae) from the Late Cretaceous of Madagascar. Journal of Vertebrate Paleontology 27 (Supplement to Number 2: Society of Vertebrate Paleontology Memoir 8), 163-79.

Carrano, M. T., Sampson, S. D. \& Forster, C. A. 2002. The osteology of Masiakasaurus knopfleri, a small abelisauroid (Dinosauria: 
Theropoda) from the Late Cretaceous of Madagascar. Journal of Vertebrate Paleontology 22, 510-34.

Carrano, M. T. \& Hutchinson, J. R. 2002. The pelvic and hind limb musculature of Tyrannosaurus rex (Dinosauria: Theropoda). Journal of Morphology 253, 207-28.

Claessens, L. P. A. M. 2004. Dinosaur gastralia: origin, morphology, and function. Journal of Vertebrate Paleontology 24, 89-106.

Colbert, E. H. 1989. The Triassic dinosaur Coelophysis. Bulletin of the Museum of Northern Arizona 57, 1-160. Flagstaff: Museum of Northern Arizona Press.

Currie, P. J. \& Zhao, X.-J. 1993. A new carnosaur (Dinosauria, Theropoda) from the Jurassic of Xinjiang, People's Republic of China. Canadian Journal of Earth Sciences 30, 2037-81.

Da Rosa, A. A. S. 2005. Paleoalterações de depósitos sedimentares de planícies aluviais do Triássico médio a superior do sul do Brasil: caracterização, análise estratigráfica e preservação fossilifera. $\mathrm{PhD}$ Dissertation, Unisinos, São Leopoldo, Brazil.

Ewer, R. F. 1965. The anatomy of the thecodont reptile Euparkeria capensis Broom. Philosophical Transactions of the Royal Society B 248, 379-435.

Ezcurra, M. D. 2006. A review of the systematic position of the dinosauriform archosaur Eucoelophysis baldwini from the Upper Triassic of New Mexico, USA. Geodiversitas 28, 649-84.

Ezcurra, M. D. 2008. A new early dinosaur from the Carnian Ischigualasto Formation (NW Argentina) and the origin of dinosaurs. In Calvo, J. O., Valieri, R. J., Porfiri, J. D. \& dos Santos, D. (eds) Libro de Resúmenes, III Congreso Latinoamericano de Paleontologia de Vertebrados, 87. Neuquen: Universidade Nacional del Comahue.

Ezcurra, D. M. \& Novas, F. E. 2007. Phylogenetic relationships of the Triassic theropod Zupaysaurus rougieri from NW Argentina. Historical Biology 19, 35-72.

Ezcurra, D. M. \& Novas, F. E. 2009. Guaibasauridae, a new clade of triassic basal sauropodomorphs. Journal of Vertebrate Paleontology 29 (Supplement to Number 3), 92A.

Faccini, U. F. 1989. O Permo-Triássico do Rio Grande do Sul: uma análise sob o ponto de vista das seqüencias deposicionais. MSc Thesis, Universidade Federal do Rio Grande do Sul, Porto Alegre, Brazil. $212 \mathrm{pp}$

Ferigolo, J. \& Langer, M. C. 2007. A Late Triassic dinosauriform from south Brazil and the origin of the ornithischian predentary bone. Historical Biology 19, 23-33.

Galton, P. M. 1976. Prosauropod dinosaurs (Reptilia: Saurischia) of North America. Postilla 169, 1-98.

Galton, P. M. 2007. Notes on the remains of archosaurian reptiles, mostly basal sauropodomorph dinosaurs, from the 1834 fissure fill (Rhaetian, Upper Triassic) at Clifton in Bristol, southwest England. Revue de Paléobiologie 26, 505-91.

Gauffre, F.-X. 1996. Phylogénie des dinosaures prosauropodes et étude d'un prosauropode du Trias supérieur d'Afrique australe. $\mathrm{PhD}$ Dissertation, Muséum National d'Histoire Naturelle, Paris.

Gauthier, J. 1986. Saurischian monophyly and the origin of birds. In Padian, K. (ed.) The Origin of Birds and the Evolution of Flight. Memoirs of the California Academy of Sciences 8, 1-55. San Francisco: California Academy of Sciences.

Gower, D. J. \& Schoch, R. R. 2009. Postcranial anatomy of the rauisuchian archosaur Batrachotomus kupferzellensis. Journal of Vertebrate Paleontology 29, 103-22.

Holz, M. \& Schultz, C. L. 1998. Taphonomy of the south Brazilian Triassic paleoherpetofauna: fossilization mode and implications for morphological studies. Lethaia 31, 335-45.

Huene, F. von 1926. Vollständige Osteologie eines Plateosauriden aus dem schwäbischen Keuper. Geologie und Paläeontologie Abhandlungen (Neue Folge) 15, 139-79.

Huene, F. von 1942. Die fossilen Reptilien des Südamerikanischen Gondwanalandes. Munich: C. H. Becksche Verlag.

Hutchinson, J. R. 2001a. The evolution of the pelvic osteology and soft tissues on the line to extant birds (Neornithes). Zoological Journal of the Linnean Society 131, 123-68.

Hutchinson, J. R. 2001b. The evolution of the femoral osteology and soft tissues on the line to extant birds (Neornithes). Zoological Journal of the Linnean Society 131, 169-97.

Irmis, R. B., Nesbitt, S. J., Padian, K., Smith, N. D., Turner, A. H., Woody, D. \& Downs, A. 2007. A Late Triassic dinosauromorphs assemblage from New Mexico and the rise of dinosaurs. Science 317, 358-61.

Krebs, B. 1965. Ticinosuchus ferox nov. gen. nov. sp. Ein neuer Pseudosuchier aus der Trias des Monte San Giorgio. Neues Jahrbuch für Geologie und Paläontologie, Abhandlungen 81, 1-140.

Kutty, T. S., Chatterjee, S., Galton, P. M. \& Upchurch, P. 2007. Basal sauropodomorphs (Dinosauria: Saurischia) from the Lower
Jurassic of India: their anatomy and relationships. Journal of Paleontology 81, 1218-40.

Langer, M. C. 2001. Saturnalia tupiniquim and the early evolution of dinosaurs. PhD. Dissertation, University of Bristol, UK. 415 pp.

Langer, M. C. 2003. The sacral and pelvic anatomy of the stemsauropodomorph Saturnalia tupiniquim (Late Triassic, Brazil). Paleobios 23, 1-40.

Langer, M. C. 2004. Basal Saurischia. In Weishampel, D. B., Dodson, P. \& Osmólska, H, (eds) The Dinosauria (2nd edn), 25-46. Berkeley: University of California Press.

Langer, M. C., Abdala, F., Richter, M. \& Benton, M. J. 1999. A sauropodomorph dinosaur from the Upper Triassic (Carnian) of southern Brazil. Comptes Rendus de l'Académie des Sciences IIA 329, 511-17.

Langer, M. C., Bittencourt, J. S. \& Schultz, C. L. 2007a. The inclusivity and phylogenetic position of Guaibasaurus candelariensis: a basal dinosaur from the Late Triassic of Brazil. Journal of Vertebrate Paleontology 27 (3, suppl.), 103A-104A.

Langer, M. C., Ribeiro, A. M., Schultz, C. L. \& Ferigolo, J. 2007 b. The continental tetrapod-bearing Triassic of South Brazil. In Lucas, S. G. \& Spielmann, J. A. (eds) The Global Triassic. New Mexico Museum of Natural History and Science Bulletin 41, 201-18. Albuquerque: New Mexico Museum of Natural History and Science.

Langer, M. C., França, M. A. G. \& Gabriel, S. 2007c. The pectoral girdle and forelimb anatomy of the stem-sauropodomorph Saturnalia tupiniquim (Late Triassic, Brazil). In Barrett, P. M. \& Batten, D. J. (eds) Evolution and palaeobiology of early sauropodomorph dinosaurs. Special Papers in Palaeontology 77, 113-37. London: The Palaeontological Association.

Langer, M. C., Ezcurra, M., Bittencourt, J. S. \& Novas, F. 2010. The origin and early evolution of dinosaurs. Biological Reviews 85, 55-110.

Langer, M. C. \& Benton, M. J. 2006. Early dinosaurs: a phylogenetic study. Journal of Systematic Palaeontology 4, 309-58.

Long, R. A. \& Murry, P. A. 1995. Late Triassic (Carnian and Norian) tetrapods from the Southwestern United States. New Mexico Museum of Natural History and Science Bulletin 4, 1-254. Albuquerque: New Mexico Museum of Natural History and Science.

Madsen, J. H. 1976. Allosaurus fragilis: a revised osteology. Bulletin of the Utah Geology and Mineralogy Survey 109, 3-163.

Madsen, J. H. \& Welles, S. P. 2000. Ceratosaurus (Dinosauria, Theropoda); a revised osteology. Utah Geological Survey, Miscellaneous Publications 00-2, 1-80.

Marsh, O. C. 1881. Principal characters of American Jurassic dinosaurs. Part V. American Journal of Science Series 3 21, 417-23.

Martínez, R. N. 2009. Adeopapposaurus mognai, gen. et sp. nov (Dinosauria: Sauropodomorpha), with comments on adaptations of basal sauropodomorpha. Journal of Vertebrate Paleontology 29, 142-64.

Nesbitt, S. J., Irmis, R. B. \& Parker, W. G. 2007. A critical reevaluation of the Late Triassic dinosaur taxa of North America. Journal of Systematic Palaeontology 5, 209-43.

Nesbitt, S. J., Turner, A. H. Spaulding, M., Conrad, J. L. \& Norell, M. A. 2009a. The theropod furcula. Journal of Morphology 270, 856-79.

Nesbitt, S. J., Smith, N. D., Irmis, R. B., Turner, A. H., Downs, A. \& Norell, M. A. 2009b. A complete skeleton of a Late Triassic saurischian and the early evolution of dinosaurs. Science 326, 1530-33.

Nesbitt, S. J., Irmis, R. B., Parker, W. G., Smith, N. D., Turner, A. H. \& Rowe, T. 2009c. Hindlimb osteology and distribution of basal dinosauromorphs from the Late Triassic of North America. Journal of Vertebrate Palaeontology 29, 498-516.

Nesbitt, S. J. \& Chatterjee, S. 2008. Late Triassic dinosauriforms from the Post Quarry and surrounding areas, west Texas, U.S.A. Neues Jahrbuch für Geologie und Paläontologie Abhandlungen 249, 143-56.

Nichols, E. L. \& Russell, A. P. 1985. Structure and function of the pectoral girdle and forelimb of Struthiomimus altus (Theropoda: Ornithomimidae). Palaeontology 28, 643-77.

Novas, F. E. 1989. The tibia and tarsus in Herrerasauridae (Dinosauria, incertae sedis) and the origin and evolution of the dinosaurian tarsus. Journal of Paleontology 63, 677-90.

Novas, F. E. 1993. New information on the systematics and postcranial skeleton of Herrerasaurus ischigualastensis (Theropoda: Herrerasauridae) from the Ischigualasto Formation (Upper Triassic) of Argentina. Journal of Vertebrate Paleontology 13, $400-23$. 
Novas, F. E. 1996. Dinosaur monophyly. Journal of Vertebrate Paleontology 16, 723-41.

Owen, R. 1842. Report on British fossil reptiles. Part II. Reports of the British Association for the Advancement of Science 11, 60-204.

Padian, K., Hutchinson, J. R. \& Holtz, T. R. 1999. Phylogenetic definitions and nomenclature of the major taxonomic categories of the carnivorous Dinosauria (Theropoda). Journal of Vertebrate Paleontology 19, 69-80.

Raath, M. A. 1990. Morphological variation in small theropods and its meaning in systematics: evidence from Syntarsus rhodesiensis. In Carpenter, K. \& Currie, P. J. (eds) Dinosaur systematics. approaches and perspectives, 91-105. Cambridge, UK: Cambridge University Press.

Rauhut, O. W. M. 2003. The interrelationships and evolution of basal theropod dinosaurs. Special Papers in Palaeontology 69, 1-213. London: The Palaeontological Association.

Rowe, T. 1989. A new species of the theropod dinosaur Syntarsus from the Early Jurassic Kayenta Formation of Arizona. Journal of Vertebrate Paleontology 9, 125-36.

Rubert, R. R. \& Schultz, C. L. 2004, Um novo horizonte de correlação para o Triássico Superior do Rio Grande do Sul: Pesquisas 31, 71-88.

Santa Luca, A. P. 1980. The postcranial skeleton of Heterodontosaurus tucki (Reptilia, Ornithischia) from the Stormberg of South Africa. Annals of the South African Museum 79, 159-211.

Seeley, H. G. 1888. On the classification of the fossil animals commonly named Dinosauria. Proceedings of the Royal Society 43, 165-71.

Sereno, P. C. 1993. The pectoral girdle and forelimb of the basal theropod Herrerasaurus ischigualastensis. Journal of Vertebrate Paleontology 13, 425-50.

Sereno, P. C. 1999. The evolution of dinosaurs. Science 284, 2137-47.

Sereno, P. C. 2007. The phylogenetic relationships of early dinosaurs: a comparative report. Historical Biology 19, 145-55.

Sereno, P. C., Forster, C. A., Rogers, R. R. \& Monetta, A. M. 1993. Primitive dinosaur skeleton from Argentina and the early evolution of the Dinosauria. Nature 361, 64-66.

Sereno, P. C. \& Arcucci, A. B. 1993. Dinosaurian precursors from the Middle Triassic of Argentina: Lagerpeton chanarensis. Journal of Vertebrate Paleontology 13, 385-99.

Sereno, P. C. \& Arcucci, A. B. 1994. Dinosaurian precursors from the Middle Triassic of Argentina: Marasuchus lilloensis, gen. nov. Journal of Vertebrate Paleontology 14, 53-73.

Smith, N. D., Makovicky, P. J., Hammer, W. R. \& Currie, P. J. 2007. Osteology of Cryolophosaurus ellioti (Dinosauria: Theropoda) from the Early Jurassic of Antarctica and implications for early theropod evolution. Zoological Journal of the Linnean Society 151, 377-421.
Smith, N. D. \& Pol, D. 2007. Anatomy of a basal sauropodomorph dinosaur from the Early Jurassic Hanson Formation of Antarctica. Acta Palaeontologica Polonica 52, 657-74.

Tykoski, R. S. 2005. Anatomy, ontogeny, and phylogeny of coelophysoid theropods. PhD Dissertation, University of Texas at Austin, USA.

Upchurch, P., Barrett, P. M. \& Galton, P. M. 2007. A phylogenetic analysis of basal sauropodomorph relationships: implications for the origin of sauropod dinosaurs. In Barrett, P. M. \& Batten, D. J. (eds) Evolution and palaeobiology of early sauropodomorph dinosaurs. Special Papers in Palaeontology 77, 57-90. London: The Palaeontological Association.

Walker, A. D. 1961. Triassic reptiles from the Elgin area: Stagonolepis, Dasygnathus and their allies. Philosophical Transactions of the Royal Society B 244, 103-204.

Weishampel, D. B., Dodson, P. \& Osmólska, H. 2004. Introduction. In Weishampel, D. B., Dodson, P. \& Osmólska, H. (eds) The Dinosauria, second edition, 1-3. Berkeley: University of California Press.

Welles, S. P. 1984. Dilophosaurus wetherilli (Dinosauria, Theropoda): osteology and comparisons. Palaeontographica Abteilung A 185, 85-180.

Wilson, J. A. 1999. A nomenclature for vertebral laminae in sauropods and other saurischian dinosaurs. Journal of Vertebrate Paleontology 19, 639-53.

Yates, A. M. 2003a. The species taxonomy of the sauropodomorph dinosaurs from the Löwenstein Formation (Norian, Late Triassic) of Germany. Palaeontology 46, 317-37.

Yates, A. M. 2003b. A new species of the primitive dinosaur, Thecodontosaurus (Saurischia: Sauropodomorpha), and its implications for the systematics of early dinosaurs. Journal of Systematic Palaeontology 1, 1-42.

Yates, A. M. 2007a. Solving a dinosaurian puzzle: the identity of Aliwalia rex Galton. Historical Biology 19, 93-123.

Yates, A. M. 2007b. The first complete skull of the Triassic dinosaur Melanorosaurus Haughton (Sauropodomorpha: Anchisauria). In Barrett, P. M. \& Batten, D. J. (eds) Evolution and Palaeobiology of early sauromorph dinosaurs. Special Papers in Palaeontology 77, 9-55. London: The Palaeontological Association.

Yates, A. M. \& Kitching, J. W. 2003. The earliest known sauropod dinosaur and the first steps towards sauropod locomotion. Proceedings of the Royal Society B 270, 1753-58.

Yates, A. M. \& Vasconcelos, C. C. 2005. Furcula-like clavicles in the prosauropod dinosaur Massospondylus. Journal of Vertebrate Paleontology 25, 466-68.

Zerfass, H., Lavina, E. L., Schultz, C. L., Garcia, A. G. V., Faccini, U. F. \& Chemale Jr, F., 2003. Sequence stratigraphy of continental Triassic strata of southernmost Brazil: a contribution to Southwestern Gondwana palaeogeography and palaeoclimate. Sedimentary Geology 161, 85-105. 